Aproximação poligonal robusta de curvas implícitas Filipe de Carvalho Nascimento 

Data de Depósito:

Assinatura:

Filipe de Carvalho Nascimento

\title{
Aproximação poligonal robusta de curvas implícitas
}

\author{
Dissertação apresentada ao Instituto de Ciências \\ Matemáticas e de Computação - ICMC-USP, \\ como parte dos requisitos para obtenção do título \\ de Mestre em Ciências - Ciências de Computação e \\ Matemática Computacional. VERSÃO REVISADA \\ Área de Concentração: Ciências de Computação e \\ Matemática Computacional \\ Orientador: Prof. Dr. Afonso Paiva Neto
}


Ficha catalográfica elaborada pela Biblioteca Prof. Achille Bassi e Seção Técnica de Informática, ICMC/ USP, com os dados fornecidos pelo(a) autor(a)

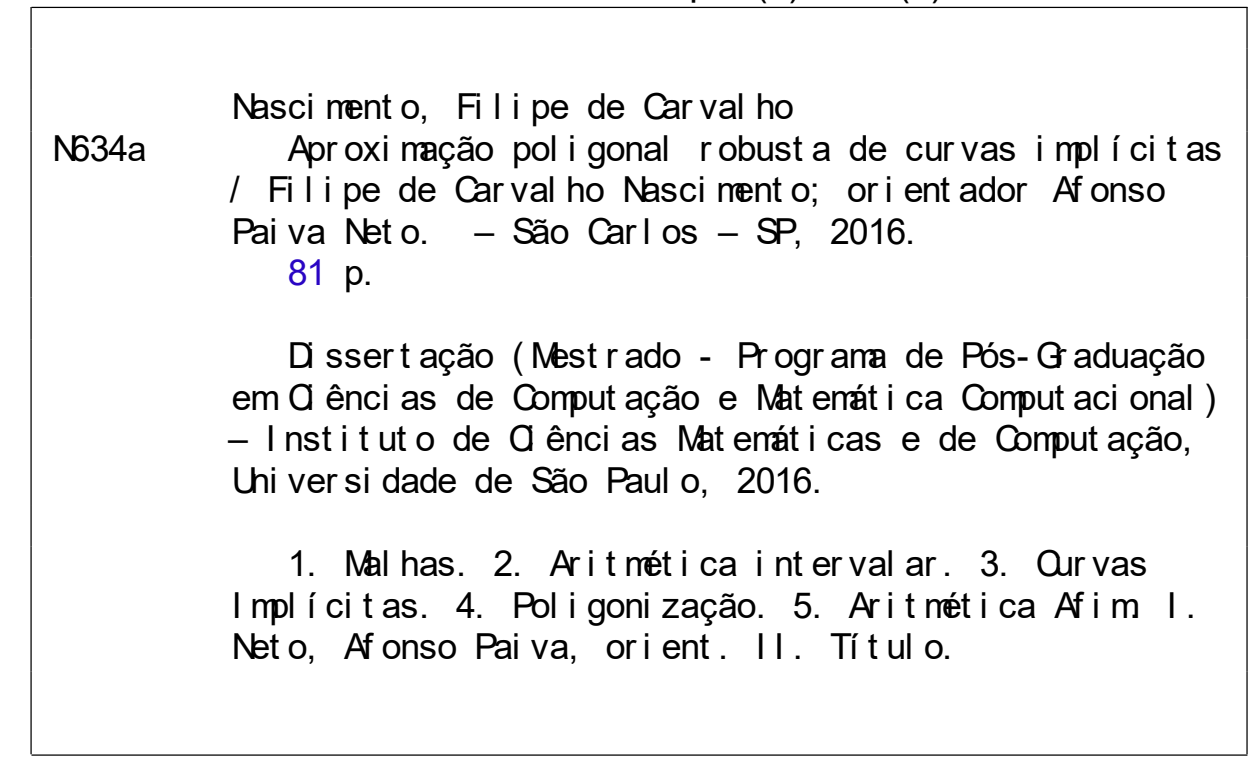


Filipe de Carvalho Nascimento

\section{Robust polygonal approximation of implicit curves}

Master dissertation submitted to the Instituto de Ciências Matemáticas e de Computação - ICMCUSP, in partial fulfillment of the requirements for the degree of the Master Program in Computer Science and Computational Mathematics. FINAL VERSION

Concentration Area: Computer Science and Computational Mathematics

Advisor: Prof. Dr. Afonso Paiva Neto

USP - São Carlos

July 2016 

Aos meus pais que sempre trabal haram duro para que eu pudesse aproveitar grandes oportunidades na vida, que ensi naram a enfrentar meus medos e nunca perder o animo. Também ao meu irmão que sempre me apoiou e esteve ao meu lado.

À minha namorada, que me deu forças e me fez sorrir nos momentos mais difíceis.

Ao meu orientador, professor Afonso Paiva, que desde o inicio me guiou com paciência e sabedoria pelo mundo da pesqui sa sendo o grande responsável por me abrir os ol hos sobre a Matemática na Computação Gráfica.

Ao grupo de Visualização e Processamento Geométrico do ICMC, por ter me dado a oportunidade de compartilhar das experiencias dos seus membros pesquisadores que tanto me ensinaram.

Ao Grupo de Estudos para Maratona de Programação (GEMA) por me manter sempre ativo nos estudos em computação testando ao extremo meus ânimos.

Aos funcionários e professores do ICMC-USP.

À FAPESP (Fundação de Amparo à Pesquisa do Estado de São Paulo) pelo apoio financeiro à real ização desse trabal ho. 

"A vida é bela."

(Joaquim Roque do Nascimento) 



\section{RESUMO}

NASCIMENTO, F. C.. Aproximação poligonal robusta de curvas implícitas. 2016. 81 f. Dissertação (Mestrado em Ciências - Ciências de Computação e Matemática Computacional ) Instituto de Ciências Matemáticas e de Computação (ICMC/USP), São Carlos - SP.

Modelagem geométrica envol vendo obj etos impl ícitos é um tema de intensa pesquisa em Computação Gráfica. Portanto, obter técnicas eficientes para representar esses objetos é de extrema importância. Dois grupos de objetos impl íci tos relevantes para Computação Gráfica são as curvas implícitas e superfícies impl ícitas. As técnicas tradicionais para se aproximar curvas e superfícies impl ícitas envol vem dividir o domínio e buscar em suas partições partes da curva ou da superfície. Neste projeto propomos um novo métodos de poligonização robusta de curvas implícitas usando uma ferramenta numérica auto-val idada chamada de Aritmética Afim. O método consiste na poligonização adaptativa de curvas implícitas em mal has triangulares tridimensionais.

Palavras-chave: Mal has, Aritmética intervalar, Curvas Implícitas, Poligonização, Aritmética Afim. 



\section{ABSTRACT}

NASCIMENTO, F. C.. Aproximação poligonal robusta de curvas implícitas. 2016. 81 f. Dissertação (Mestrado em Ciências - Ciências de Computação e Matemática Computacional ) Instituto de Ciências Matemáticas e de Computação (ICMC/USP), São Carlos - SP.

Geometric modeling involving implicit objects is a topic of intense research in Computer Graphics. Thus, obtain efficient techniques for representing these objects is of utmost importance. Two groups of relevant implicit objects for Computer Graphics are implicit curves and implicit surfaces. Traditional techniques for approximating implicit curves and surfaces involve splitting the domain and searching for parts of the curve or the surface. In this project we propose a new methods of robust polygonization of implicit curves using the self-validated numerical tool called Affine Arithmetic. The method consists in the adaptive polygonization of implicit curves in thre-dimensional triangular meshes.

Key-words: Meshes, Interval Arithmetic, Implicit Curves, Polygonization, Affine Arithmetic. 



\section{LISTA DE ILUSTRAÇÕES}

Figura 1 - Esquerda: umacurvaimplícita representada por um conjunto desegmentos de reta. Direita: uma superfície impl ícita representada por uma mal ha triangular (Figura retirada de (PAIVA et al., 2006)).

Figura 2 - Curva impl ícita em vermel ho e sua aproximação poligonal em verde. Note como al gumas características da curva não estão representadas. . . . . . . . 26

Figura 3 - Uma decomposição do domínio é defini da e o objeto implícito é amostrado. Os pontos são conectados formando uma aproximação poligonal do obj eto implícito.

Figura 4 - Dependência parcial entre duas quantidades na forma AA (região cinza escuro).(Imagem retirada de (FIGUEIREDO; STOLFI, 2003)) . . . . . . .

Figura 5 - Esquerda: Interpolação Linear. Direita: Método da Bisseção. Figuras retiradas de (PAIVA et al., 2012). . . . . . . . . . . . . . . . . . . . . 38

Figura 6 - Enumeração da curva dada implicitamente por $y^{2}-x^{3}+x=0$ no quadrado $\Omega=[-2[$ 國 $\times[-2$ 國. Figura retirada de (LOPES; OLIVEIRA; FIGUEIREDO, 2002a).

Figura 7 - Faixas afins cal culadas em cada envolvendo a curva em cada uma das células. Figura retirada de (PAIVA et al., 2012). . . . . . . . . . . . . . . . . . 42

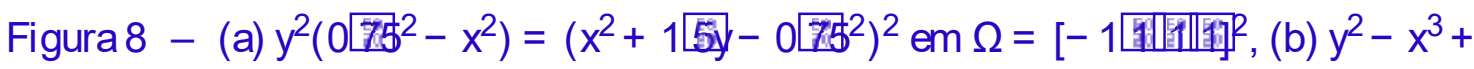
$\mathrm{x}=0\left[5 \mathrm{~lm} \Omega=\left[-5\left[21[\mathrm{~F} \mid \mathbf{2 1}]^{2}\right.\right.\right.$. As imagens de cima foram geradas com o Algoritmo 1 e as outras com o Al goritmo 2. Figuras retiradas de (PAIVA et al., 2012)

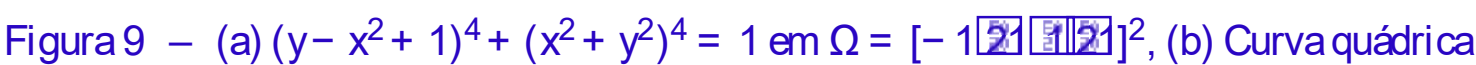

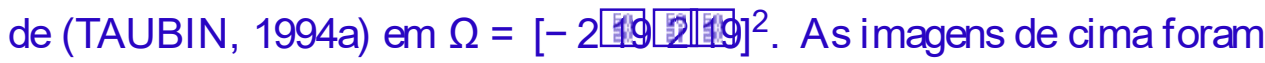
geradas com o Algoritmo 1 e as outras com o Algoritmo 2. Figuras retiradas de (PAIVA et al., 2012). . . . . . . . . . . . . . . . . . 44

Figura 10 - Simplexos de dimensões $0,1,2$ e $3 \ldots \ldots \ldots$. . . . . . . . . 46

Figura 11 - Exemplo de união de si mplexos de dimensão 2 constituindo um complexo simplicial. . . . . . . . . . . . . . . . . . . 46

Figura 12 - Incluindo o triângul o dentro de um paral elogramo. . . . . . . . . . . . . 48

Figura 13 - Decompondo o triângulo em paral elogramos. . . . . . . . . . . . . . . 48

Figura 14 - Efei tos das diferentes estratégias do uso de paral el ogramos para aproximar poligonal mente uma curva impl ícita em triângulos. 
Figura 15 - Exemplo de faixas afins (em cinza) cal culadas para cada um dos paral elogramos que compõem o triângulo. . . . . . . . . . . . . . . . . . . . 51

Figura 16 - Malha 4-8. Imagem retirada de (VELHO; ZORIN, 2001). . . . . . . . . . . 53

Figura 17 - Subdivisão MP. Triangulo é dividido em 4 novos triângul os através da conexão dos pontos médios de suas arestas. . . . . . . . . . . . . . . . . . . . . 54

Figura 18 - Janelas principais. . . . . . . . . . . . . . . . . . . . 55

Figura 19 - Janela AA. . . . . . . . . . . . . . . . . . . 55

Figura 20 - A proximação da curva por segmentos de reta em um triângul o. . . . . . . . . 56

Figura 21 - Curva implícita Taubin. Regiões de maior curvatura apresentam maior número de triângulos. . . . . . . . . . . . . . . . . . . . 57

Figura 22 - Método aplicado em uma (b)sopa de triângulos, e em uma (c)mal ha. . . . . 57

Figura 23 - Curva implícita dada por $y^{2}\left(a^{2}-x^{2}\right)-\left(x^{2}+2 a y-a\right)^{2}=0$ com a $=0$ 75s. $\quad 58$

Figura 24 - Curva implícita dada por $\left(y-x^{2}+1\right)^{4}+\left(x^{2}+y^{2}\right)^{4}-1=0 . \ldots . . . .58$

Figura 25 - Curva implícita dada por $y^{2}-x^{3}+x-05=0 \ldots \ldots$

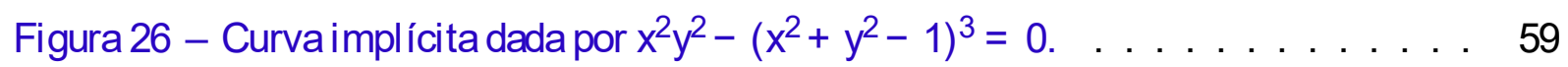

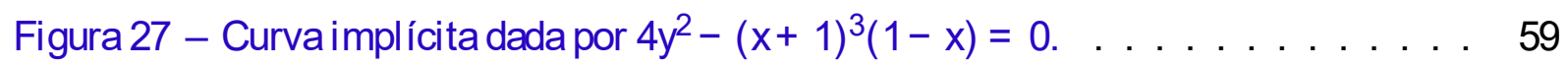

Figura 28 - Curvaimplícita dada por $(x y+\cos (x+y))(x y+\sin (x+y))=0 . \quad \ldots . . \quad 59$

Figura 29 - Curva implícita dada por $(x y+\cos (x+y))(x y+\sin (x+y))=0 . \quad \ldots . .60$

Figura 30 - Logotipo Pisces (http://www.geom.umn.edu/ fjw/pisces/). (a) O algoritmo de marching cubes gera uma curva com topologia errada na mal ha de 101 triangulos e (b) só produz um resul tado sati sfatório com a mal ha de 12928 triangulos. (c) utilizando adaptatividade obtem-se um bom resul tado com 2382 triangulos. . . . . . . . . . . . . . . . . . . . . 60 60

Figura 31 - Curva implícita dada por $y-3 \operatorname{sen} x=0 . \ldots \ldots$. . . . . . . . . 62

Figura 32 - Curva implícita dada por $\mathrm{y}^{2}(3+2 y)-\left(x^{2}-1\right)^{2}=0 . \ldots \ldots 2$

Figura 33 - Curva implícita dada por $(x y-2)\left(x^{2}+y^{2}-1\right)=0 . \ldots \ldots 63$

Figura 34 - Curva implícita dada por $x y^{2}\left(1-{ }^{p} \overline{x y^{2}}\right)-004=0 . \ldots 63$

Figura 35 - Intersecção da esfera com harmôni cos esféricos reais. . . . . . . . . . . . . . 64

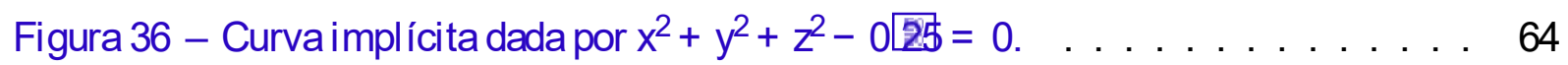

Figura 37 - Curvas implíci tas dadas pela Esfera $(x-a)^{2}+y^{2}-a^{2}=0$ com diferentes valores dea. . . . . . . . . . . . . . . . . 6 65

Figura 38 - Intersecção entre o hiperboloi de dado pela equação $x^{2}-y^{2}-z^{2}=1$ e a super-

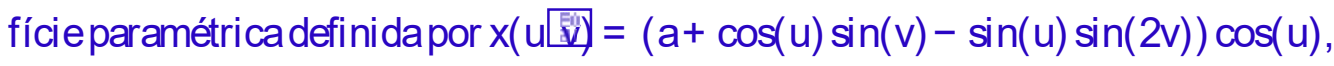
$y(u$ 国 $)=(a+\cos (u) \sin (v)-\sin (u) \sin (2 v)) \sin (u), z(u$ 河) $=\sin (u) \sin (v)+$

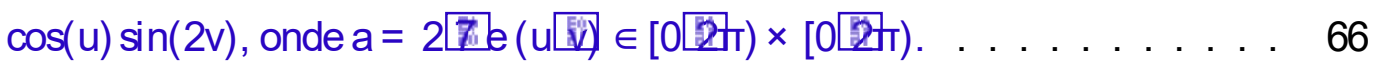

Figura 39 - Ponto de singularidade.

Figura 40 - Variação do comprimento da faixa afim para diferentes ângulos do vértice superior e diferentes funções para cada um dos paral elogramos que dividem o triângulo. 
Figura 41 - Exemplo de geração de imagem confiável de uma curva implícita fornecida pelo usuário. . . . . . . . . . . . . . . . . . . . . . . . . 70

Figura 42 - Exemplos de imagens bi nárias usadas para construção de conjuntos de pontos. 72

Figura 43 - O processo de construção de conjuntos de pontos a partir de imagens binarias: Primeiro, o contorno da curva é extraído pixel a pixel, onde cada pixel representa um vértice da curva e depois a curva pode ser simplificada diminuindo o número de vértices. Foi utilizado o código Deci mat e Pol ygon fornecido por (SEMECHKO, 2012). . . . . . . . . . . . . . . . . . . . . . . 72

Figura 44 - Circle Test: Teste utilizando pontos gerados pela equação paramétrica do circulo. . . . . . . . . . . . . . . . . . . . . . . . 73

Figura 45 - Hand Test: Teste usando os pontos extraídos da imagem binaria de uma mão. 73

Figura 46 - Arrow Test: Teste usando os pontos extraídos da imagem binaria de uma mão. Células descartadas pela ausência da curva estão pintadas de cinza. . . . . . 74

Figura 47 - Intersecção de um conjunto de pontos e uma mal ha triangular. Malha inicial (esquerda). Mal ha após 11 chamadas recursivas (direita). As normais dos pontos estao pintadas de vermel ho e a curva aproximada de verde. . . . . . 76 



\section{LISTA DE ALGORITMOS}

Algoritmo 1 - Explore $X \times Y \ldots \ldots$. . . . . . . . . . . . . . 39

Algoritmo 2 - Explore $X \times Y \ldots \ldots \ldots$. . . . . . . . . . . . 40

Algoritmo 3 - Explore $T \ldots \ldots \ldots \ldots$. . . . . . . . . . 47 



\section{LISTA DE TABELAS}

Tabela 1 - Exemplos de combinações de val ores extremos de $\varepsilon_{i}$. . . . . . . . . . . . 34

Tabela 2 - Performance e estatísticas entre os resultados obtidos com os Algoritmos $1 \mathrm{e}$ 2, respectivamente. A coluna AI indica a tolerancia do o gradiente escolhida para o Al goritmo 1 e a coluna AA a tol erância para a largura da faixa afim para o Algoritmo 2. As col unas restantes mostram os resultados para Al / AA. 43

Tabela 3 - Diferentes performances das diferentes estratégias para o uso de paral el ogramos em triângulos. . . . . . . . . . . . . . . . . . . . . . 49

Tabela 4 - Resultados produzi dos pelo algoritmo 2. . . . . . . . . . . . . . . 56

Tabela 5 - Resultados produzi dos pelo Algoritmo 2 para Mal has Triangulares 3D. . . . 61

Tabela 6 - Resultados com a região parcial mente negativa utilizando (GAY; COEURJOLLY; HURSTAND, 2006). . . . . . . . . . . . . . . . . . . . . . 74

Tabela 7 - Resultados com a região parcial mente negativa utilizando (IMS, 2010). . . . 75 



\title{
LISTA DE ABREVIATURAS E SIGLAS
}

\author{
AA ....... Aritmética Afim \\ Al ....... Aritmética Intervalar \\ MP ....... Mid-Point
}



INTRODUÇÃO . . . . . . . . . . . . . . . . . . . . . . . 25

$1.1 \quad$ Objetivos do Trabalho . . . . . . . . . . . . . . . 27

$1.2 \quad$ Trabalhos Relacionados . . . . . . . . . . . . . . . . 28

$1.3 \quad$ Contribuições do Trabalho . . . . . . . . . . . . . . . . . . . 30

$1.4 \quad$ Organização do Trabalho . . . . . . . . . . . . . . . . . . . 30

2 MÉTODOS INTERVALARES . . . . . . . . . . . . . . 31

$2.1 \quad$ Aritmética Intervalar $(\mathrm{Al}) \ldots \ldots \ldots \ldots \ldots \ldots$

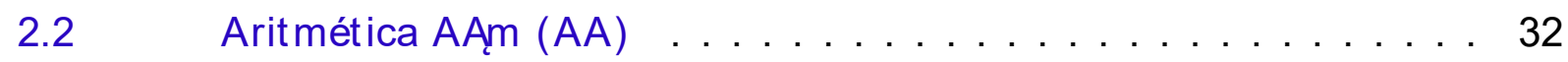

$2.3 \quad$ Bibliotecas . . . . . . . . . . . . . . . . 35

3 APROXIMAÇÃO POLIGONAL DE CURVAS IMPLÍCITAS . . . . . 37

$3.1 \quad$ Métodos de Aproximação . . . . . . . . . . . . . . 37

$3.2 \quad$ Aproximação de Curvas Implícitas com Al . . . . . . . . . . . . 38

3.3 Aproximação de Curvas Implícitas com AA . . . . . . . . . . . . . . 40

3.3.1 Estimativa de Curvatura com AA . . . . . . . . . . . . . . . . 41

$3.4 \quad$ Comparação ent re Al e AA . . . . . . . . . . . . . . . 42

4 CURVAS IM PLÍCITAS EM MALHAS TRIANGULARES . . . . . . 45

$4.1 \quad$ Malhas Triangulares . . . . . . . . . . . . . . 46

$4.2 \quad$ Aproximação em Malhas Triangulares . . . . . . . . . . . . . . 46

$4.3 \quad$ Detalhes de Implement ação . . . . . . . . . . . . . . . . 47

4.3.1 Aritmética Afim em Triângulos . . . . . . . . . . . . . . . . . . 48

4.3.2 Função de Inclusão . . . . . . . . . . . . . . . . . . . . . 50

4.3.3 Estimativa da Curvatura . . . . . . . . . . . . . . . . . 50

4.3.4 Estimativa de Curvatura em Triângulos 3D . . . . . . . . . . . . 52

4.3 .5 Subdivisão da Malha Triangular . . . . . . . . . . . . . . . . . 53

$4.4 \quad$ Visualização dos Resultados . . . . . . . . . . . . . . . . . . . . 54

$4.5 \quad$ Resultados . . . . . . . . . . . . . . . . . . 54

$4.6 \quad$ Resultados em Malhas Triangulares 3D $\ldots \ldots$. . . . . . . . . 61

$4.7 \quad$ Considerações Finais . . . . . . . . . . . . . . . . 63

5 TRABALHOS COM PLEMENTARES . . . . . . . . . . . . . . 69

$5.1 \quad$ Imagens ConAáveis de Curvas Implícitas . . . . . . . . . . . . 69 
$5.2 \quad$ Superfícies Implícitas de Conjuntos de Pontos . . . . . . . . . . 70

5.2.1 Implementação . . . . . . . . . . . . . . . . . . . 71

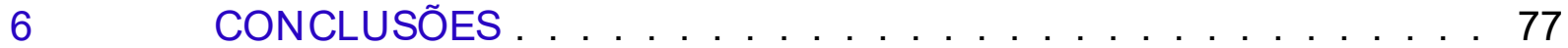

REFERÊNCIAS . . . . . . . . . . . . . . . . . . . . 79 
CAPÍTULO
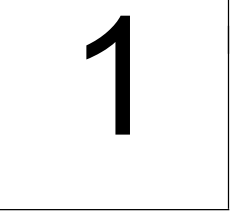

INTRODUÇÃO

Brevemente, um obj eto implícito é defini do como o conjunto de soluções de uma equação $f(p)=0$, onde $f: \Omega \subseteq R^{n} \rightarrow R$. Se $f$ é bem comportada, este conjunto se trata de uma superfície de dimensão $n-1$ em $R^{n}$. Para os casos de $n=2$ e $n=3$, os objetos impl ícitos recebem respectivamente os nomes de curvas implícitas e superfícies implícitas.

Objetos implícitos oferecem grandes vantagens na definição de modelos geométricos. Diferente de superfícies paramétricas por exemplo, superfícies impl ícitas conseguem representar facilmente formas geométricas compl exas e lidar natural mente com mudanças topol ógicas durante uma animação. Operações bool eanas entre model os geométricos - utilizadas em geometria sólida construtiva por exemplo - são triviais, dado que não necessitam de avaliações ponto a ponto.

Muitos problemas em Computação Gráfica e Engenharia são formulados a partir da mani pul ação e representação de objetos impl ícitos, tais como reconstrução de superfícies a partir de scanners 3D e superfícies livres em simul ação de escoamento de fluídos. Objetos implícitos são aproximados poligonal mente e representados no computador através de modelos geométricos (conjuntos de elementos geométricos). Por exemplo, curvas implícitas podem ser aproximadas por conjuntos de segmentos de reta e superfícies implícitas por mal has triangulares (Figura 1).
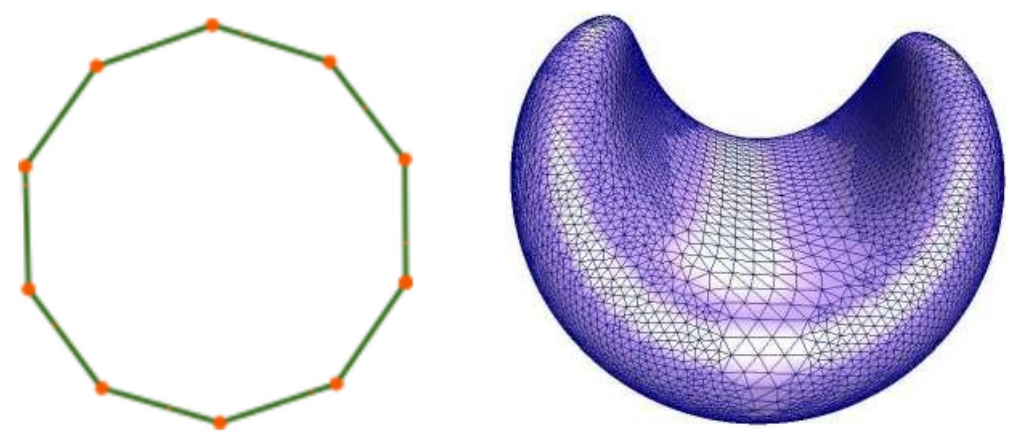

Figura 1 - Esquerda: uma curva impl ícita representada por um conjunto de segmentos de reta. Direita: uma superfície implícita representada por uma mal ha triangular (Figura retirada de (PAIVA et al., 2006)). 
Em contraste aos objetos paramétricos, cal cul ar aproximações poligonais de objetos implícitos é uma tarefa compl exa e desafiadora. É preciso encontrar as várias componentes do objeto impl ícito que se encontram no domínio e amostrálas para que o modelo geométrico seja construído. Técnicas tradi cionais baseadas em enumeração decompõem o domínio em porções menores (ex. triângulos, tetraedros, quadriláteros, etc.) e calculam a intersecção do objeto impl ícito com as arestas da decomposição, podendo sofrer da sub-divisão excessiva do domínio ou deixar de encontrar todas componentes. Técnicas de continuação geram a aproximação "caminhando" sobre o objeto implícito a partir de pontos pertencentes ao objeto implícito já conhecidos, exigindo portanto o conhecimento prévio da local ização de cada componente, o que não é uma tarefa trivial. Portanto é importante se desenvolver técnicas robustas e eficientes de aproximação poligonal de objetos implícitos.

Uma maneira de tornar o al goritmo de aproximação poligonal mais eficiente, é decompor o domínio de maneira adaptativa. Estruturas como a quadtree (espaços 2D) e a octree (espaços 3D), permitem que o domínio seja refinado apenas em regiões que contém componentes do objeto implícito, diminuindo significativamente o número de sub-regiões que precisam ser processadas.

Entende-se por robustez do al goritmo, neste contexto, a capacidade do al gorítimo de detectar as componentes do objeto implícito presentes no domínio de entrada. Um al goritmo é consi derado robusto se consegue, dentro de suas limitações, detectar todas componentes do objeto impl ícito contidas no domínio. Por exemplo, os pontos de uma curva impl ícita são amostrados sobre as arestas da mal ha que decompõe o domínio e depois são conectados para que formem os segmentos de reta que aproximam a curva implícita (Figura 2). Note que apenas as partes da curva impl ícita que intersectam as arestas são representadas, características e componentes da curva menores que se encontram completamente dentro de uma célula (ex: uma fol ha da quadtre).

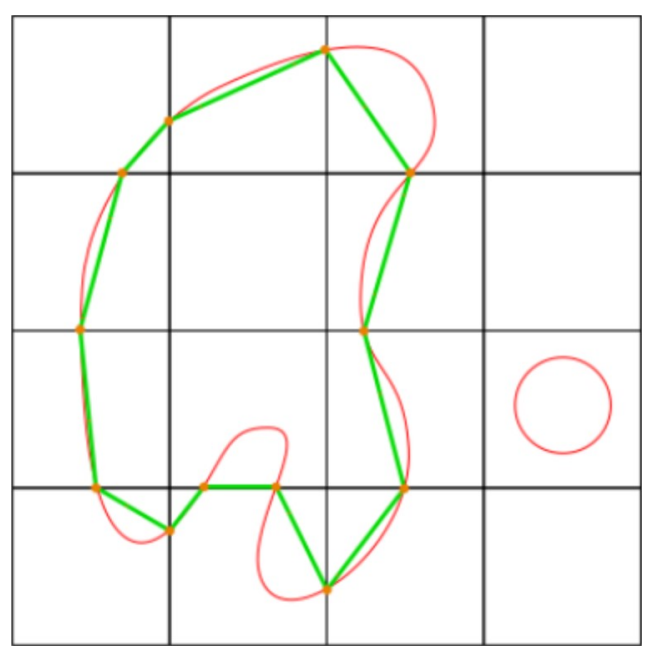

Figura 2 - Curva implícita em vermel ho e sua aproximação poligonal em verde. Note como al gumas características da curva não estão representadas. 
O uso de métodos numéricos intervalares permite que operações sejam feitas sobre regiões do domínio, excluindo as limitações impostas por técni cas que se baseiam intei ramente em pontos amostrados. Operações interval ares garantem robustez ao al goritmo, pois conseguem detectar até mesmo componentes da curva implícita menores que a resolução das células da quadtree (Figura 3a), fazendo com que estas células sejam subdivididas para se obter uma mel hor aproximação. Uma vez que a decomposi ção do domíni o é estabelecida, pontos do objeto implícito são cal culados e conectados formando a aproximação poligonal (Figura 3).

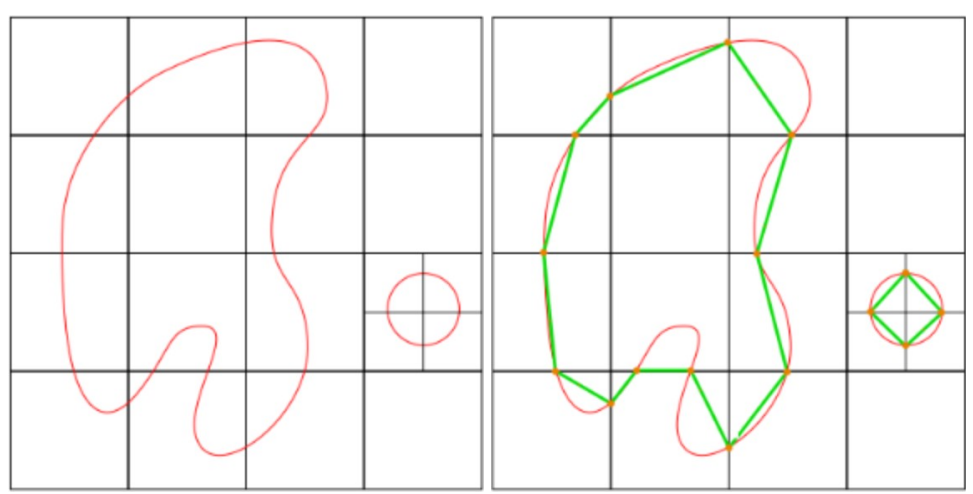

(a)

(b)

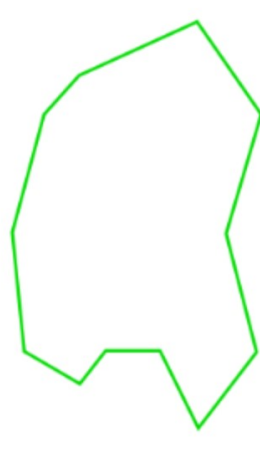

(c)

Figura 3 - Uma decomposição do domínio é definida e o objeto implícito é amostrado. Os pontos são conectados formando uma aproximação poligonal do objeto implícito.

\subsection{Objetivos do Trabalho}

Este trabal ho se concentra no problema de aproximar poligonal mente curvas impl ícitas e superfícies impl ícitas em diferentes tipos de domínios. É assumido que o objeto impl ícito é previamente defini do e pretende-se cal cular e representar sua aproximação poligonal através de um model o geométrico. No caso de curvas implícitas, o modelo é descrito por um conjunto de segmentos de reta.

O erro de precisão numérica cometido na representação de números em ponto-flutuante no computador deve ser levado em conta para que o modelo discreto respeite o modelo real do problema. Os mesmos métodos numéricos auto-val idados utilizados para garantir a robustez do al gorítimo, também garantem que o modelo discreto (computador) cuide dos erros de preci são das quanti dades envolvendo a correção no processo dos cál culos.

Várias maneiras de se encontrar aproximações de curvas implícitas em quadtrees e mal has triangulares foram propostas através dos anos (DOBKIN et al., 1990), (SUFFERN, 1990), (LOPES; OLIVEIRA; FIGUEIREDO, 2002a). Muitas destas técni cas utilizam métodos numéricos robustos a fim de tornar seus al goritmos mais eficientes e confiáveis.

Este trabal ho utiliza o mesmo espírito do trabal ho apresentado por (LOPES; OLIVEIRA; FIGUEIREDO, 2002a), que executa aproximação poligonal de curvas implícitas decompondo o 
domíni o através de quadtrees retangulares utilizando o método numérico auto-val idado chamado Aritmética Intervalar (FIGUEIREDO; STOLFI, 1997). Entretanto, este trabal ho tem por objetivo propor um método para aproximar poligonal mente curvas em mal has triangulares substituindo Aritmética Intervalar pela Aritmética Afim (FIGUEIREDO; STOLFI, 2003). Da mesma maneira, este trabal ho estende o método de aproximação de superfícies implícitas apresentado por (PAIVA et al., 2006).

Diferente da Aritmética Interval ar, a Aritmética Afim consegue cobrir, dentro de certas limitações, regiões não retangulares do domínio cometendo erros de menor magnitude. Isto signi fica que é capaz de concentrar os cál cul os do al goritmo de maneira mais precisa e se adapta melhor a domínios formados por triângul os.

Assim, este trabal ho também propõe um método robusto para aproximação de curvas impl ícitas sobre mal has triangulares e apresenta uma discussão sobre as diferenças entre o uso da Aritmética Interval ar e a Aritmética Afim.

\subsection{Trabalhos Relacionados}

Provavelmente, um dos métodos mais influentes na área de aproximação poligonal de superfícies impl ícitas é o al goritmo Marching Cubes (LORENSEN; CLINE, 1987). Neste método, valores da superfície impl ícita são amostrados em cada vértice de uma mal ha cúbica e as cé ul as que apresentam pelo menos uma aresta com vértices de val ores com si nais opostos são classificadas como células que intersectam a superfície. As combinações dos 8 si nais de cada cubo formam os índices de uma tabela que armazena as configurações de triângul os que devem ser geradas dentro de cada cubo. Assim, em cada uma das células que intersectam a superfície, triângulos são gerados formando uma aproximação poligonal da superfície implícita.

O algoritmo de Marching Tetrahedra (GUÉZIEC; HUMMEL, 1995) é baseado no al goritmo de Marching Cubes com a diferença nas subdivi sões do domínio. Ao invés de cubos, o domínio é subdividido em tetraedros. A grande vantagem é que a tabela de configurações de triângul os para as combinações de sinais em um tetraedro, além de menor, não apresenta ambigui dades, diferente da tabel a do Marching Cubes.

Anal ogamente, os al goritmos de Marching Cubes e Marching Tetrahedra são aplicados na aproximação poligonal de curvas implícitas. No lugar de cubos, quadrados são utilizados e no lugar de tetraedros o domínio é subdividido em triângulos.

A qual idade e confiabilidade das aproximações poligonais geradas pel os métodos descritos acima está di retamente ligada à resol ução da mal ha utilizada. Detal hes ou componentes da superfície implícita que tem tamanho menor que as célul as não são representados no resultado final. Para obter aproximações mais confiáveis é preciso utilizar mal has com maior resolução, significando um aumento no número de células, exigindo mais tempo de processamento do 
al goritmo.

Algoritmos como os descritos acima caracterizam técnicas de enumeração. A técnica de conti nuação por sua vez, apresenta uma abordagem diferente. Conhecido um ponto do objeto implícito, métodos numéri cos são utilizados para que novos pontos sejam descobertos. Desta forma, o al goritmo " caminha" sobre o objeto implícito armazenando todos pontos encontrados e gera uma aproximação poligonal do objeto implícito a partir destes pontos. A vantagem é que a descoberta de novos pontos não depende mais de uma subdivisão do espaço e sim do método numérico utilizado. Por outro lado, não é trivial o conhecimento prévio de pontos do objeto implícito. O trabal ho de (DOBKIN et al., 1990) apresenta um método de conti nuação para aproximação de curvas implíci tas em mal has triangulares regulares. A mal ha é utilizada para a determinação de pontos ini ciais do al goritmo, mas sendo uma mal ha regular, o método não é adaptativo e fica limi tado à resolução da mal ha.

O trabal ho de (PERSIANO; COMBA; BARBALHO, 1993) apresenta uma técnica adaptativa para refinamento de triangulações aplicada em aproximação de curvas implícitas em malhas triangulares. Porém, não é um al goritmo robusto já que a técnica é baseada em amostragem de pontos.

Técnicas robustas são apresentadas nos trabal hos de (SUFFERN; FACKERELL, 1991) e (MITCHELL, 1991), que se baseiam no uso de métodos interval ares para aproximar curvas implícitas adaptativamente através de quadtrees. O método descrito em (SNYDER, 1992b; SNYDER, 1992a) define estimativas interval ares para o gradiente da função que define a curva implícita e as incorpora no critério de adaptabilidade do al goritmo, porém a aproximação final não é expl i ci tamente adaptada à curvatura da curva.

O trabal ho de (LOPES; OLIVEIRA; FI GUEI REDO, 2002b) apresenta uma estimativa intervalar do gradiente para desenvolver um método intervalar adaptativo para aproximação poligonal de curvas implícitas com quadtrees retangulares no plano. O método é espacial e geometricamente adaptativo, gerando células mai ores onde a variação da curvatura da curva implíci ta é baixa. O trabal ho faz os cál culos limitando-se a diferenciação automática, que pode ser evitado com o uso da Aritmética Afim.

Comba e Stolfi (COMBA; STOLFI, 1993) introduziram Aritmética Afim e mostraram como pode ser utilizada para se obter melhores resultados do que a Aritmética Intervalar clássi ca na aproximação de curvas impl ícitas. Outros exempl os foram dados por (FIGUEIREDO; STOLFI, 1996), (FIGUEIREDO; STOLFI, 1996). Martin em (MARTIN et al ., 2002) compara as performances de vários métodos intervalares para o desenho de curvas al gébricas utilizando quadtrees, incluindo métodos baseados em Aritmética Afim.

Técni cas equival entes às descritas anteriormente podem ser aplicadas na aproximação de superfícies impl ícitas. O trabal ho de (JR.; FIGUEIREDO; GATTASS, 1999) desenha superfícies implícitas através de técnicas de traçamento de rai os enquanto (PAIVA et al ., 2006) aproxima 
superfícies impl ícitas de forma robusta utilizando Aritmética Interval ar e octrees.

\subsection{Contribuições do Trabalho}

Os estudos do tema se iniciaram no ano de 2012 dentro das disciplinas de graduação Projeto Supervisionado ou de Graduação I e II. Por fim, os projetos desenvolvidos nestas disciplinas se deram na mesma linha de pesquisa, este trabal ho se tornou uma extensão natural dos resul tados obtidos até então.

Ao decorrer do tempo, o trabal ho rendeu duas publicações:

- Publição no SIBGRAPI $2012^{1}$ com o artigo “ Approximating implicit curves on triangulations with affine arithmetic" (PAIVA et al., 2012).

- Uma extensão da publicação anterior foi publicada no Computer Graphics Journal 2014 com o artigo " Approximating im- plicit curves on plane and surface triangulations with affine arithmetic" (NASCIMENTO et al., 2014).

A combinação destas publicações e do restante do trabal ho compõem um estudo deta Ihado sobre o uso da Aritmética Afim em métodos de aproximação de objetos implícitos. Os al goritmos desenvolvidos são adaptativos e robustos, características fundamentais para eficiência e confiabilidade dos resultados.

Também foi criado um website para aproximação em tempo real de curvas implícitas diretamente do browser. O website <ht t p: / / f i I i pecn. gi t hub. i o/ hebG- Tool s/ 2Daur ves. ht $\mathrm{m}$ > (NASCIMENTO, 2015) permi te que o usuário escreva uma equação al gébrica qual quer (seguindo um conjunto regras) e visualize o desenho da curva aproximada. Detal hes sobre este projeto em específico são encontrados no Capítul o 5.

\subsection{Organização do Trabalho}

Este trabal ho está organizado da seguinte manei ra: O Capítul o 2 faz uma introdução aos dois métodos interval ares, Aritmética Intervalar eAritmética Afim. O Capítulo 3 trata do método de aproximação poligonal de curvas implícitas no plano e o Capítul o 4 descreve os detal hes do método proposto para aproximação poligonal de curvas implícitas em mal has triangulares. $O$ Capítulo 5 apresenta a apl icação desenvolvida para aproximação de curvas impl íci tas em tempo real . O Capítul o 6 discute trabal hos futuros e concl usões.

1 Qual is B1 em eventos no comitê de Ciências da Computação. 


\section{2}

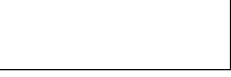

\section{MÉTODOS INTERVALARES}

Devida a natureza discreta da computação digital existe uma diferença entre o val or real de uma quantidade e o seu val or representado em um sistema computacional. Esta diferença representa o erro cometido ao se armazenar e processar uma quantidade dentro de um sistema computacional. No computador, números reais são armazenados em uma estrutura de números de ponto flutuante e dispõem apenas de um número finito de bits para sua representação. $A$ medi da que operações são feitas envolvendo números de ponto flutuante os resultados precisam ser arredondados para que possam ser armazenados nesta estrutura.

As sol uções de um problema encontradas por meio de al goritmos numéricos são aproximações da sol ução real do problema pois não fornecem os val ores reais das quantidades das soluções reais, e sim val ores próximos aos val ores reais. Esta proximidade da aproximação para a solução real, conhecida como erro da aproximação, é definida não só pelo al goritmo mas justamente pelas limitações do sistema computacional .

Métodos Numéricos auto-val i dados surgem para contornar os problemas causados pelo erro numérico. $\mathrm{O}$ uso de interval os para representar quanti dades permite que o erro cometido pelo armazenamento e por operações aritméticas seja levado em conta e o al goritmo passe a ter garantias sobre a faixa de val ores da qual o val or real pertence. Uma discussão detal hada sobre estes métodos pode ser encontrada em (FIGUEIREDO; STOLFI, 1997).

\subsection{Aritmética Intervalar $(\mathrm{Al})$}

A Aritmética Intervalar (AI) é o modelo mais eficiente e simples de todos modelos numéricos auto-val idados. Criada na década de 1960 por Ramon E. Moore, na Universi dade de Stanford, Al se baseia em interval os para cál culo numérico onde cada quantidade $x \in R$ é representada por um intervalo $\bar{x}$ de números com pontos flutuantes proporcionando cálculos confiáveis através de controles automáticos de erro. Em outra pal avas, cada quantidade x é 


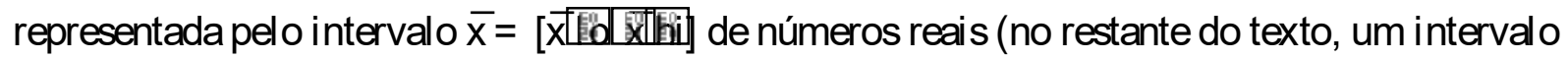
real de a ab, inclusive, será representada pela notação [a $[\vec{b}]$ ), significando que o verdadeiro val or de $x$ é conhecido por satisfazer $\bar{x}$ 區 $\leq x \leq \bar{x}$ 面

Além disso, Al proporcionaversões intervalares de todas as operações básicas aritméticas e funções científicas elementares, tais como:

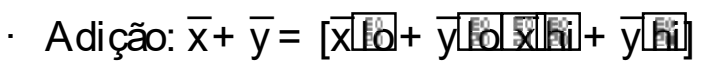

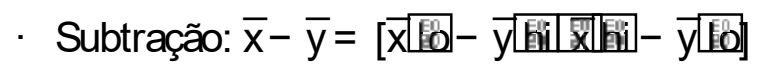

Pode-se pensar que $\bar{x}+\bar{y} e \bar{x}-\bar{y}$ representam os interval os que contém $x+y$ e $x-$ $y$, respectivamente, para todos possíveis pares $x \in \bar{x}$ e $y \in \bar{y}$. De maneiras análogas, outras operações como multi plicação e divisão podem ser defini das assim como todas outras operações matemáticas comuns. Portanto, Al se torna uma ferramenta natural para implementar funções de incl usão, pois consegue tratar de maneria robusta extensões interval ares de funções reais. Uma descrição mais detal hada de AI pode ser encontrada em (FIGUEIREDO; STOLFI, 1997).

\subsection{Aritmética AĄm (AA)}

A A ritmética Afim (AA) é si milar à aritmética interval ar no sentido de tratar erros de arredondamento e truncagem de forma automática. Em adição, AA mantém correlações entre as quantidades computadas. Uti lizando esta informação extra, a AA consegue obter interval os menores em seus cál cul os mostrando-se mais precisa que AI.

Na aritmética afim, as operações são feitas utilizando-se formas afins, que compõem um polinômio de primeiro grau:

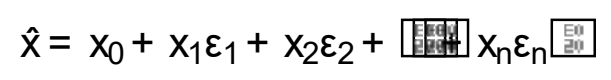

Os coeficientes $x_{i}$ são números de pontos flutuantes finitos enquanto $\varepsilon_{i}$ são variáveis reais simbólicas cujos val ores são desconhecidos, no intervalo $U=\left[-1\right.$ [ 1 1]. O número $x_{0}$ recebe o nome de valor central da forma afim $\hat{x}$, os coeficientes $x_{i}$ são as desvios parciais e $\varepsilon_{i}$ são os símbolos de ruído.

Cada símbolo de ruído $\varepsilon_{\mathrm{i}}$ representa uma componente da incerteza da quantidade $\mathrm{x}, \mathrm{o}$ coeficiente $x_{i}$ correspondenteàmagnitude desta componente. $O$ mesmo ruído pode contribuir para a incerteza de duas ou mais quantidades que compõem uma expressão. Este compartil hamento de um ruído entre duas formas afins $\hat{x}$ e ŷ, indica uma dependência parcial entre as duas quantidades. A magnitude e o sinal desta dependência é determinada através dos coeficientes correspondentes $x_{i}$ e $y_{i}$.

Dado um intervalo $\bar{x}=[a[\bar{b}]$ representando al guma quantidade $x$ em Al, a forma AA equival ente para a mesma quantidade é dada por $\hat{x}=x_{0}+x_{k} \varepsilon_{k}$, onde $x_{0}$ é o ponto médio do 
interval o e $x_{k}$ a metade de seu comprimento:

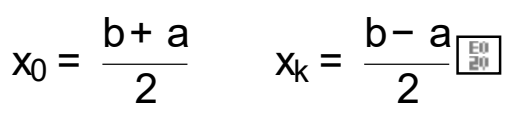

O símbolo de ruído $\varepsilon_{k}$ representa a incerteza no val or de $x$ que é implícita em seu intervalo representado por $\bar{x}$. Como o interval o não indica nenhuma correl ação entre o val or de $x$ e outras variáveis, $\varepsilon_{\mathrm{k}}$ deve ser diferente de todos os outros símbol os de ruído utilizados no mesmo cál culo.

Para que seja possível efetuar operações com AA, devem-se substituir as operações de

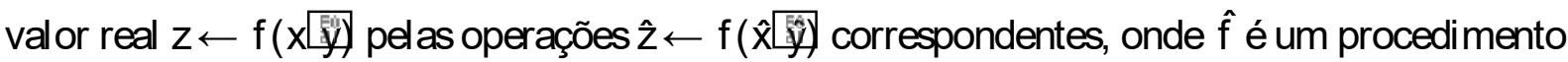
que cal cula uma forma afim para $z \leftarrow f(x$ 國) sendo consistente com $\hat{x}$ e ŷ. Por definição, $x$ e y são definidos como:

$$
\begin{aligned}
& \mathrm{x}=\mathrm{x}_{0}+\mathrm{x}_{1} \varepsilon_{1}+\text { 藏然 } \mathrm{x}_{\mathrm{n}} \varepsilon_{\mathrm{n}}
\end{aligned}
$$

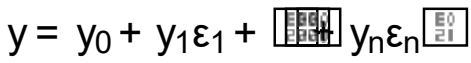

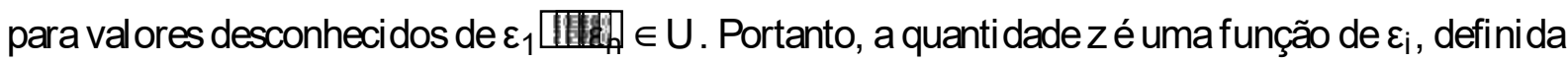

$$
\begin{aligned}
& z=f(x)
\end{aligned}
$$

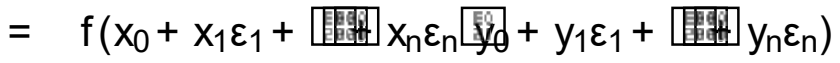

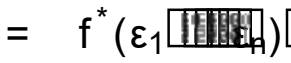

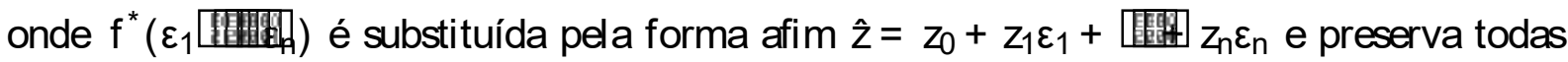
possiveis restrições entre $x$, y e $z$ Se $f$ é uma função afim de seus argumentos $x$ e y, então pode ser rearranjada em uma combinação afim dos símbol os de ruído $\varepsilon_{i}$. Neste caso, trata-se de uma operação afim e esta combi nação afim descreve toda a informação sobre as quantidades $x$, y e $z$ que pode ser deduzi da das formas afins $\hat{x}, \hat{y}$ e da operação $f$. Em particular, para qual quer $\alpha$, $\zeta \in R$,

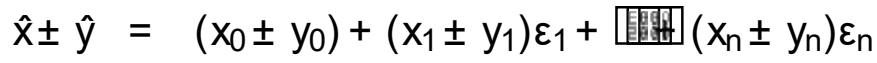

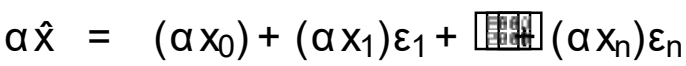

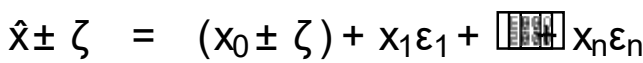

Note que, de acordo com as fórmulas acima, a diferença $\hat{x}-\hat{x}$ é zero. Este fato ocorre pois neste caso os dois operandos da subtração compartilham os mesmos símbolos de ruído caracterizando a mesma quanti dade e não duas quanti dades que por acaso apresentam a mesma faixa de val ores possíveis. O estudo do caso de f não ser uma operação afim pode ser encontrado em (FIGUEIREDO; STOLFI, 1997).

Por exemplo, suponhamos as quanti dades $x$ e y representadas pel as formas afins

$$
\hat{x}=20-4 \varepsilon_{1}+2 \varepsilon_{3}+3 \varepsilon_{4} \quad \hat{y}=10-2 \varepsilon_{1}+1 \varepsilon_{2}-1 \varepsilon_{4} \text { 監 }
$$

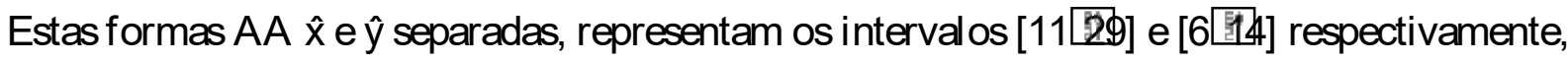
definindo a região cinza claro na Figura 4. Porém, como ambas contém $\varepsilon_{1}$ e $\varepsilon_{4}$ com coeficientes 


\begin{tabular}{|c|c|c|c|c|c|}
\hline$\varepsilon_{1}$ & $\varepsilon_{2}$ & $\varepsilon_{3}$ & $\varepsilon_{4}$ & $\hat{\mathrm{x}}$ & $\hat{\mathrm{y}}$ \\
\hline \hline- & - & - & - & 19 & 12 \\
+ & - & - & - & 11 & 8 \\
- & + & - & - & 19 & 14 \\
- & - & + & - & 23 & 12 \\
- & - & - & + & 25 & 10 \\
+ & + & - & - & 11 & 10 \\
\hline
\end{tabular}

Tabela 1 - Exemplos de combinações de val ores extremos de $\varepsilon_{i}$.

não nulos, elas não são inteiramente independentes entre si . Desta forma, anal isadas em conjunto, formam a faixa cinza escuro da Figura 4.

A faixa AA formada pelas formas x̂ ề em conjunto é cal culada montando-se o fecho convexo de todos pontos formados por todas combinações de val ores extremos de $\varepsilon_{i}$. Como $U=[-1[1]$, estas combinações podem ser representadas pelas combinações de sinais dos coeficientes $x_{i}$ e $y_{i}$. O zonotopo da Figura 4 pode ser obtido cal culando o fecho convexo dos pontos $(\hat{x}, \hat{y})$ da Tabela 1 . Note que como temos $1 \leq \mathrm{i} \leq 4$, existem $2^{4}$ combinações.

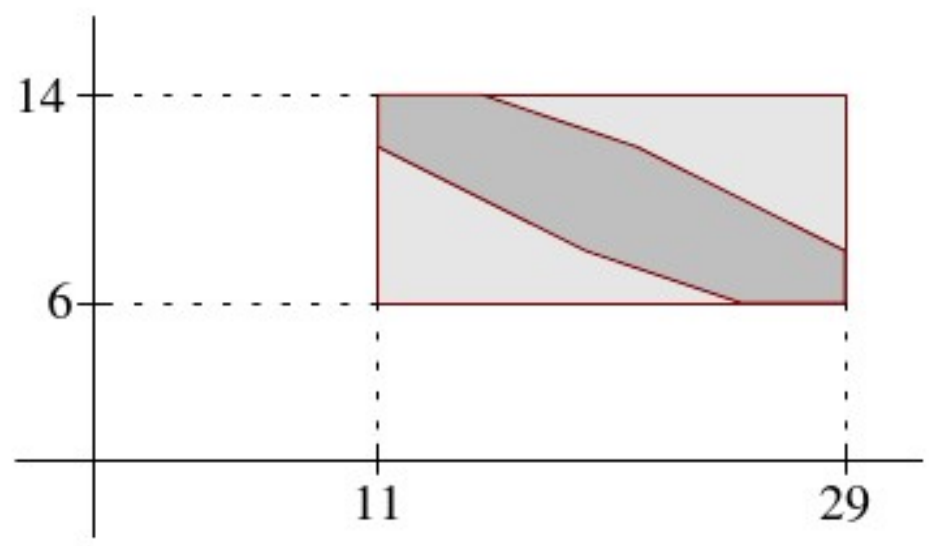

Figura 4 - Dependência parcial entre duas quantidades na forma AA (região cinza escuro).(Imagem retirada de (FIGUEIREDO; STOLFI, 2003))

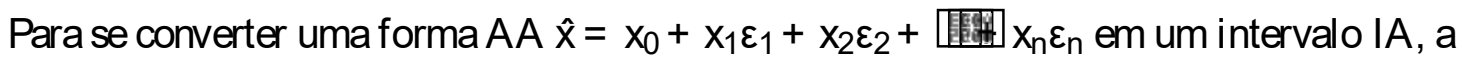
seguinte operação deve ser feita:

$$
[\hat{x}]=\left[x_{0}-\operatorname{rad}(\hat{x})\left[\log _{\theta}+\operatorname{rad}(\hat{x})\right][\underline{[-10}\right.
$$

onde $\operatorname{rad}(\hat{x})=\sum_{i=1}^{n}\left|x_{i}\right|$. Note que esta conversão remove a informação sobre os ruídos, não sendo mais possível cal cular al gum tipo de correlação entre quantidades. Em outras palavras, podemos pensar como a forma AI sendo representada pelo retângulo cinza claro na Figura 4 caso $\hat{x}$ e ŷ fossem convertidos para forma AI. Deste modo, podemos notar visual mente que a faixa que a Aritmética Afim produz é de fato mais estreita que a produzida pela AI. Uma comparacão entre Al e AA também pode ser encontrada em (MOCHIZUKI, 2004). 


\subsection{Bibliotecas}

Existem muitos pacotes que implementam aritmética afim disponíveis na internet, para este projeto foi escol hida a biblioteca I i baf $\mathrm{f}$ a (GAY; COEURJOLLY; HURSTAND, 2006). Esta bibli oteca of erece todas operações el ementares e suficientes para o desenvolvimento do projeto, assim como o tratamento de erros de arredondamento e outras características para lidar com a imprecisão computacional. 

CAPÍTULO
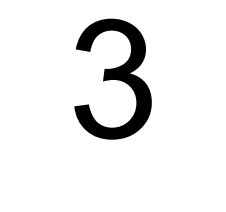

\section{APROXIMAÇÃO POLIGONAL DE CURVAS IMPLÍCITAS}

\subsection{Métodos de Aproximação}

Pode-se definir o problema de se encontrar uma curva implícita como o problema de calcular uma aproximação poligonal de uma curva $C$ dada implicitamente pela função $f: \Omega \subseteq R^{2} \rightarrow R$, tal que:

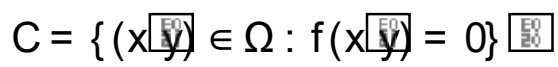

Testar todos val ores de pares (x $\mathrm{y}$ ) em $\Omega$ é impraticável. Como introduzido anteriormente no texto, existem formas mais eficientes de se encontrar pontos pertencentes a $\mathrm{C}$ como por exemplo, métodos de enumeração adaptativa. Enquanto a técnica de enumeração divide $\Omega$ igual mente em porções menores, a enumeração adaptativa propõe dividir o domínio iterativamente de maneira que regiões sem presença de $\mathrm{C}$ sejam descartadas antecipadamente e o al goritmo se concentre apenas em regiões de interesse. A preci são da aproximação está diretamente ligada ao refinamento do domínio, quanto menores as células mais características e componentes de C serão captadas.

A pós decompor $\Omega$ em regiões menores, o próximo passo é cal cular as intersecções de C com as arestas das células que compõe a decomposi ção. Toda aresta que apresenta val ores de $f$ de sinais opostos contem um ponto pertencente $\mathrm{a} C$ que pode ser cal culado facilmente via interpolação linear. Os pontos então, são conectados por segmentos de reta que por fim formam a aproximação poligonal da curva implícita.

Na enumeração adaptativa, a decomposição final do domíni o apresenta arestas de diversos tamanhos sendo possível porções de uma mesma aresta fazerem parte de várias células. O uso da interpolação linear neste caso pode causar descontinuidades na aproximação de $C$, dado que o cál culo de um mesmo ponto de $\mathrm{C}$ pode ser feito a partir de arestas de tamanhos diferentes. $\mathrm{O}$ uso 
do método da bisseção resolve este problema, como pode ser visto na Figura 5.
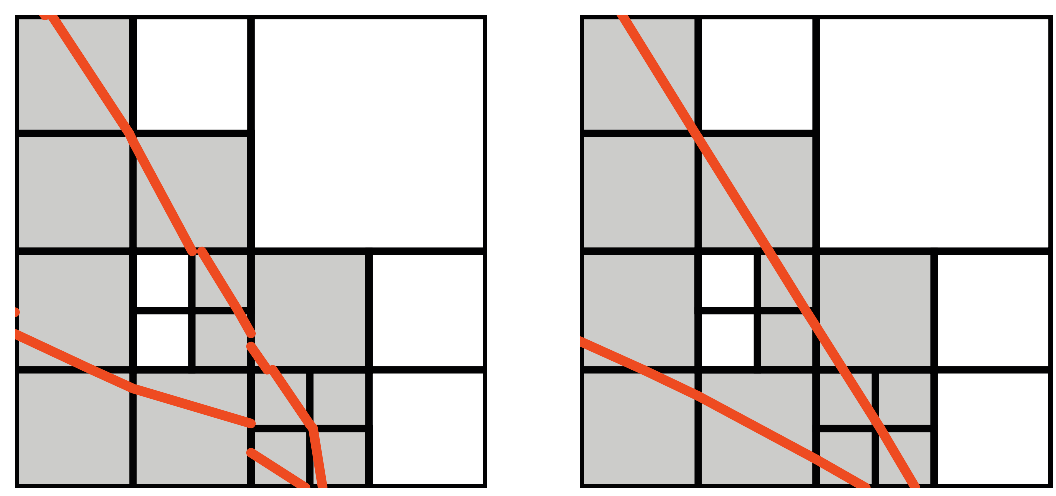

Figura 5 - Esquerda: Interpolação Linear. Direita: Método da Bisseção. Figuras retiradas de (PAIVA et al., 2012).

\subsection{Aproximação de Curvas Implícit as com Al}

O trabal ho apresentado em (LOPES; OLIVEIRA; FIGUEIREDO, 2002a) propõe um método eficiente e robusto que executa enumeração adaptativa, de forma que se obtenham célul as menores em regiões próximas à curva. A Al é utilizada para apontar a ausência de C dentro de uma célula de maneira confiável, possibilitando uma adaptatividade espacial (em relação à localização de $C$ em $\Omega$ ). Além disso, o método propõe uma adaptatividade geométrica, com base na variação da curvatura de $C$ dentro de cada célula.

A ausência de $C$ em cada célula é verificada através de uma função de inclusão para $f$. Essa função de inclusão é simplesmente a extensão intervalar $F$ da função $f$ defini da nos subconjuntos(célul as) $X \times Y$ de $\Omega$, onde $X$ eY são interval os reais. Além disso, afunção intervalar $\mathrm{F}$ possui a seguinte propriedade teórica:

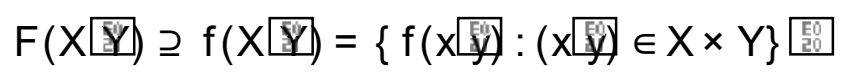

Note que $F(X)$ é uma estimativa para o conjunto formado por todos os val ores de $f$ em $X \times Y$, podendo ser estritamente maior do que $f(X)$. Desta maneira, é possível afirmar

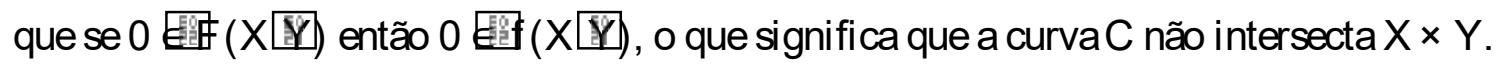

A característica da adaptatividade espacial é adqui ri da acrescentando-se ao critério de parada o teste da função de incl usão e uma tolerância $\varepsilon \geq 0$ dada pelo usuário. Essa tolerância define o tamanho míni mo que uma célula pode atingir.

A adaptatividade geométrica vem do uso da informação sobre a variação da curvatura de $C$ dentro de cada célula. Esta adaptatividade permite que regiões onde a curva apresenta baixa variação em sua curvatura apresentem célul as mai ores do que regiões com al ta variação na curvatura, isto significa que porções da curva podem ser aproximadas por segmentos de reta mais rapi damente sem que o algoritmo precise subdividir o domínio mais vezes. 
A estimativa da curvatura, ao invés de utilizar derivadas de segunda ordem de $f$, utiliza a extensão intervalar $G$ do gradiente normal izado de $f$, isto é, da normal no ponto $(X, Y)$. $A$ extensão interval ar do gradiente $G$ sati sfaz a seguinte propriedade:

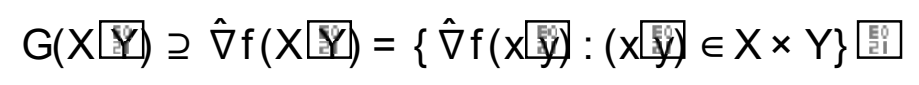

onde $\hat{\nabla} f$ é o gradiente normalizado. Geometricamente, o gradiente intervalar $\mathrm{G}$ representa uma caixa (retângulo) determinada pela extensão intervalar das derivadas parciais de $f$, isto

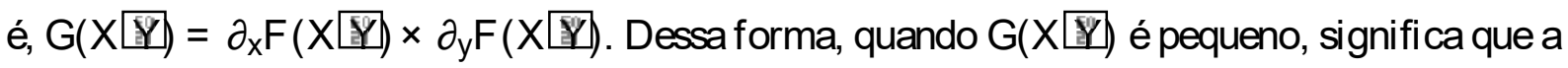
normal de $C$ não está sofrendo muita variação em $X \times Y$, e por isso $C$ está numa região de baixa curvatura, logo pode ser aproximada por um segmento de reta em $\mathrm{X} \times \mathrm{Y}$. A magnitude máxima de $G(X[Y)$ é defini da pelo usuário por uma tolerância $\delta$.

Da união das adaptatividades espacial e geométrica, tem-se um algoritmo recursivo (Algoritmo 1) para se obter uma aproximação poligonal de C. Para cada célula processada pelo al goritmo, primei ramente é fei to o teste da ausência da curva pel a função de inclusão. Quando a função de inclusão acusa ausência da curva, a célul a é descartada e o al goritmo termina. Quando o teste fal ha, as di mensões da célul a são verificadas para que não se gerem células menores do que o tamanho defi ni do pelo usuário. Também é apl icado o teste sobre a variação de curvatura para garantir a adaptatividade geométrica. Para ambas verificações, a função diam() é utilizada. Esta função tem como entrada dois interval os e retorna a extensão do mai or intervalo. Se todos os testes fal ham, então a célula é subdividida e o al goritmo é chamado recursivamente para cada subdivisão.

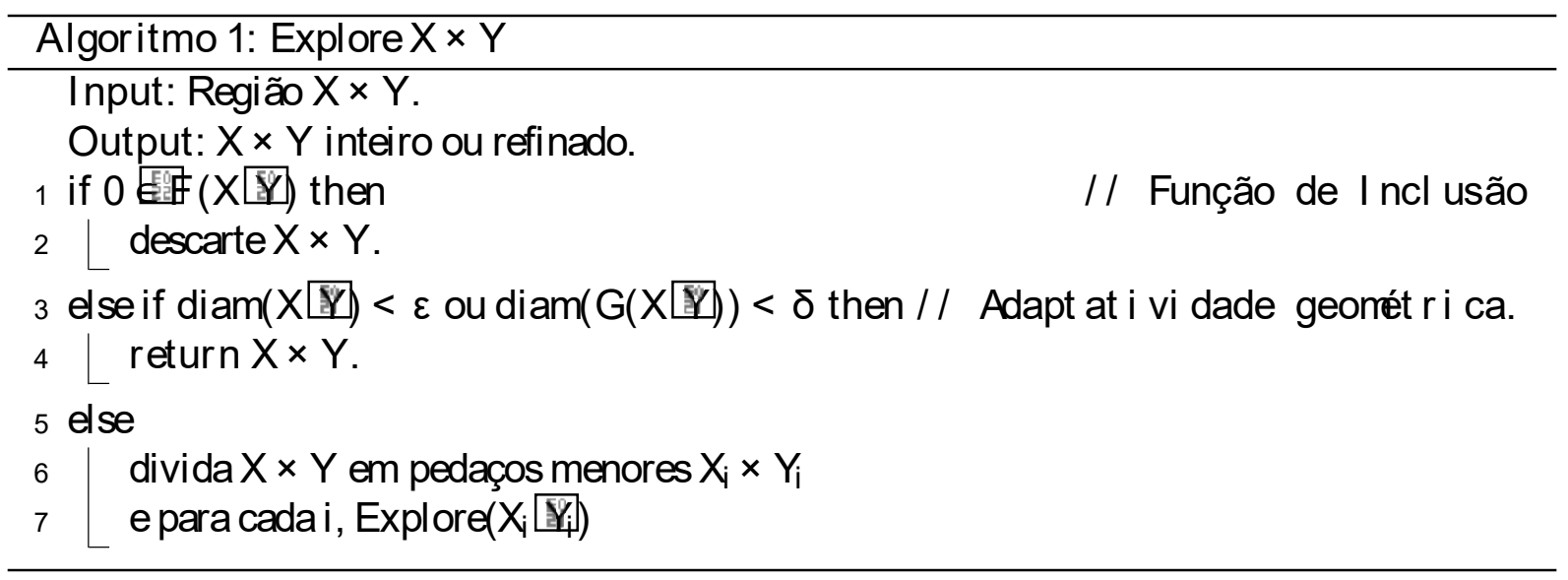

Todas as células não descartadas pelo Algoritmo 1 são células onde a curva pode ser aproximada por segmentos de reta como descrito na seção 3.1. A Figura 6 mostra um exemplo de resultado obtido através das células resul tantes da execução do Algoritmo 1 e a aproximação da curva impl ícita desenhada através dos segmentos de reta cal culados. Note como o tamanho das células diminui ao se aproximar da curva e como regiões de baixa variação de curvatura apresentam células mai ores do que célul as presentes em regiões de al ta variação de curvatura. 


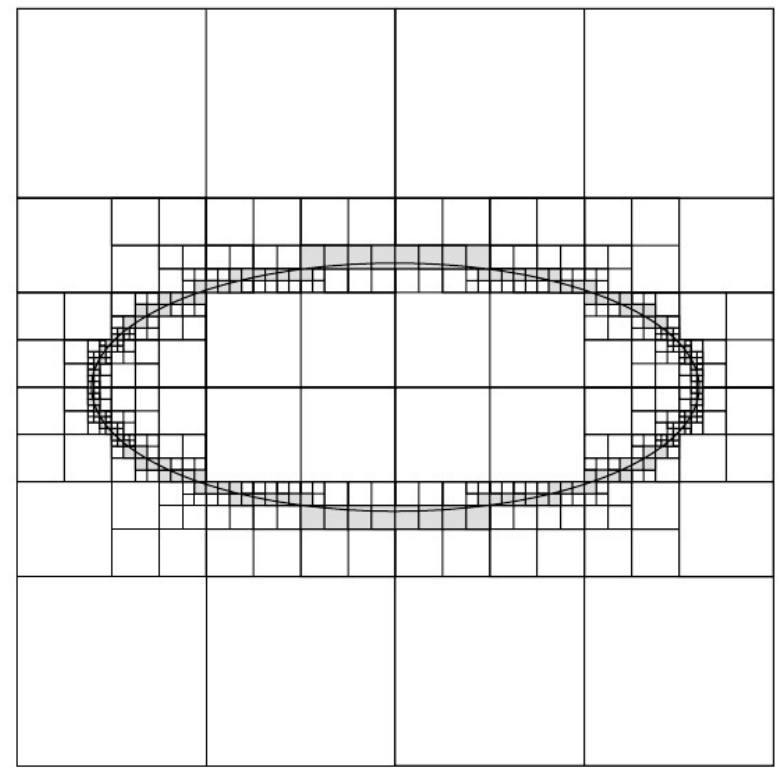

Figura 6 - Enumeração da curva dada implicitamente por $y^{2}-x^{3}+x=0$ no quadrado $\Omega=[-2[$ 2 $] \times[-2[2]$. Figura retirada de (LOPES; OLIVEIRA; FIGUEIREDO, 2002a).

\subsection{Aproximação de Curvas Implícit as com AA}

O Algoritmo 1 pode ser adaptado para o uso da AA de forma a aumentar sua eficiência. Ao invés do teste da variação de curvatura ser feito através da aproximação do gradiente normalizado da função f usando Al, é utilizada a informação geométrica (região cinza escuro na Figura 4) criada pela AA como critério de parada do al goritmo.

A cada célula a ser testada, a extensão afim da função que define $C$ é cal culada. Obtém-se com a extensão żo resul tado da função cal culada a partir das extensões afins $\hat{x}$ e ŷ, ref erentes às duas dimensões da célula. A região resul tante que define ẑ, chamada de faixa afim, é limitada por duas retas principais (pode-se pensar como a caixa limitante da faixa afim). A distância entre estas retas está relacionada à curvatura de $C$ (este processo é explicado em detal hes na subseção 3.3.1). Desta maneira, chega-se a uma variação para o Algoritmo 1, representada pelo Algoritmo 2.

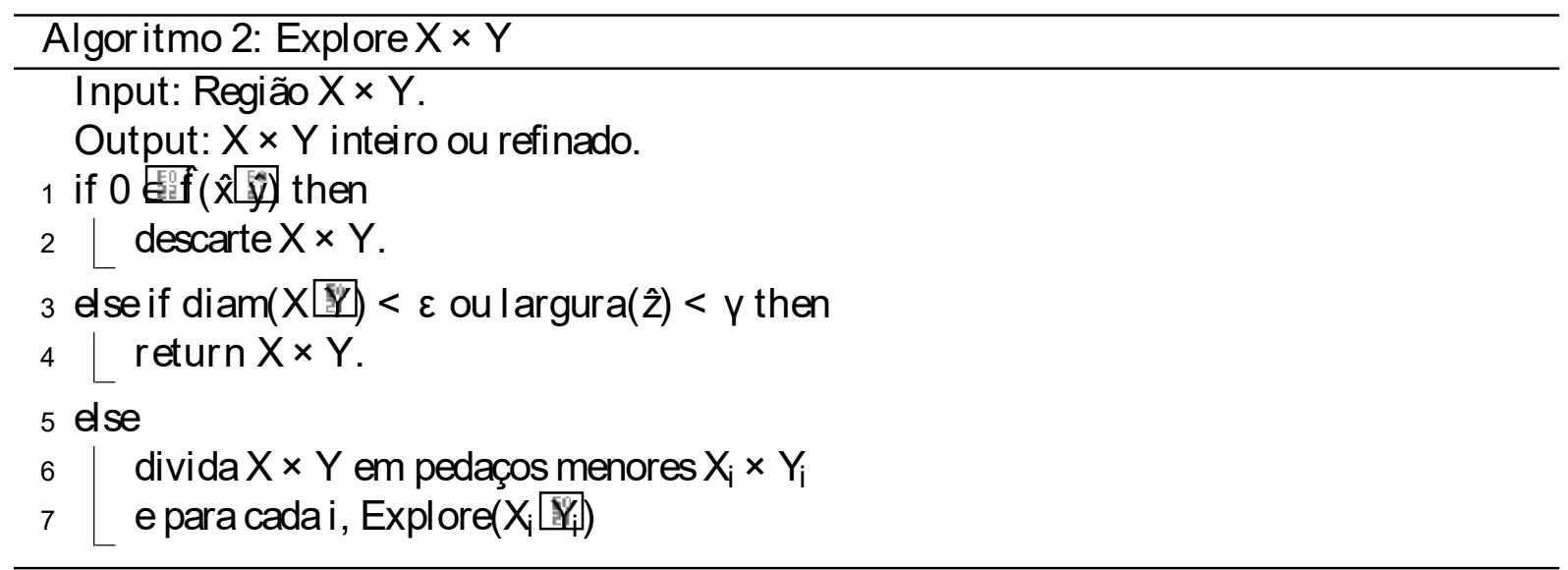


Note que, agora, não é feito mais o teste diam( $G(X \square)$. Em seu lugar, a largura da faixa

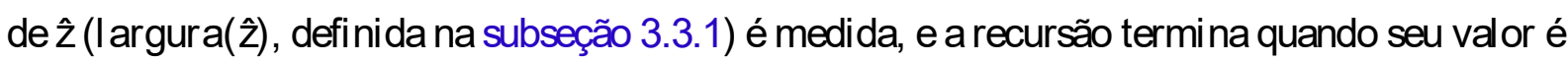
pequeno suficiente. Uma outra observação muito importante é que, com esta estratégia, não é mais preciso cal cular as derivadas da função $f$, já que AA of erece uma estimativa da curvatura tornando o processo mais rápido e simples.

\subsubsection{Estimativa de Curvatura com AA}

Os objetos que AA representa natural mente são zonotopos: politopos convexos si métricos central izados. No caso mais simples temos o domínio retangular $\Omega=\left[a_{-}-\right.$b] $\times$[c- - d] e assumimos que $f$ é dada por uma expressão matemática em $x$ ey. Para se calcular $f$ em $A A$ é preciso representar $x$ e y com as formas afins apropriadas:

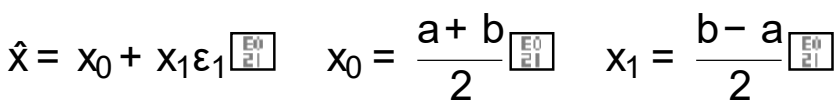

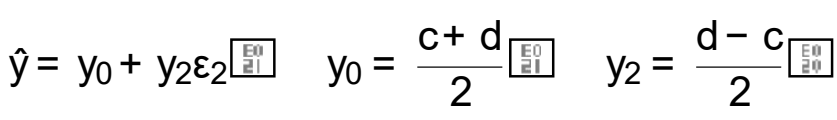

Note que x̂ e ŷ dispõem de diferentes símbolos de ruídos porque variam independentemente em $\Omega$. Cal culando $\hat{z}=\hat{f}(\hat{x}$ 国) temos:

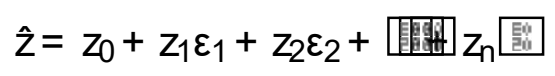

$z_{1}$ e $z_{2}$ representam os termos principais que relacionam diretamente $f(x)$ com $x$ e y. Os demais termos $z_{i}$, com $3 \leq \mathrm{i} \leq \mathrm{n}$, são termos de segunda ordem e pode ser condensados em um único termo:

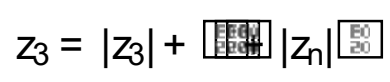

Desta maneira, a forma AA ẑ se encontra entre os dois planos paral el os

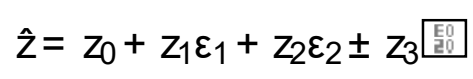

Com $\varepsilon_{1}=\frac{x-x_{0}}{x_{1}}$ e $\varepsilon_{2}=\frac{y-y_{0}}{x_{2}}$ a equação de ẑ pode ser reescrita como

$$
\hat{z}=z_{0}+\frac{z_{1}}{x_{1}}\left(x-x_{0}\right)+\frac{z_{2}}{y_{2}}\left(y-y_{0}\right) \pm z_{3} \text { 㡠 }
$$

A região onde f é zero está contida na faixa definida pelas duas retas paralelas

$$
0=z_{0}+\frac{z_{1}}{x_{1}}\left(x-x_{0}\right)+\frac{z_{2}}{y_{2}}\left(y-y_{0}\right) \pm z_{3} \text { 門 }
$$

A largura da faixa produzida por $\hat{f}$ é dada pela distância entre as retas como segue:

$$
\operatorname{largura}(\hat{z})=q \frac{2 z_{3}}{\left(\frac{z_{1}}{x_{1}}\right)^{2}+\left(\frac{z_{2}}{y_{2}}\right)^{2}}
$$


Este teste sobre a curvatura é vál ido, pois a AA tem como característica apresentar retas mais distantes diante de curvaturas mais altas. Assim, quando o valor de largura(ẑ) é pequeno, podemos garantir quea curvatura da curva é pequena, pois a curva na região da célula se encontra dentro da faixa afim (Figura 7). Portanto, comparamos com uma tol erância y para decidir se a curva dentro da região da célula pode ser aproximada por um segmento de reta. O valor de y é um limiar definido pelo usuário.

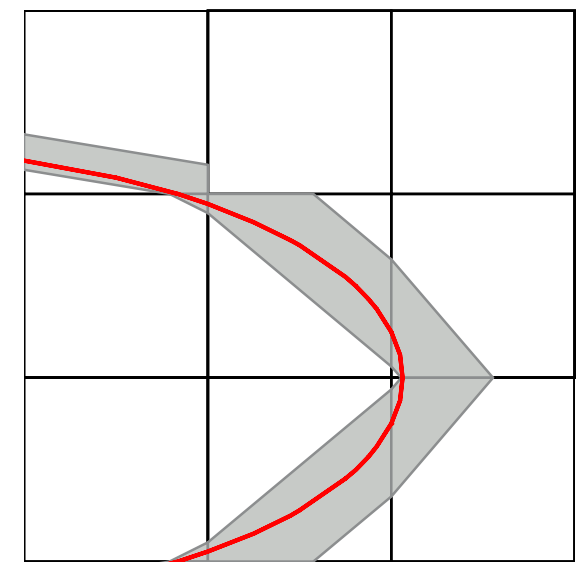

Figura 7 - Faixas afins cal culadas em cada envolvendo a curva em cada uma das células. Figura retirada de (PAIVA et al., 2012).

\subsection{Comparação entre Al e AA}

A Tabela 2 compara os resul tados obti dos nas aproximações de curvas impl ícitas utilizando Al e AA. As aproximações podem ser visualizadas nas Figuras 8 e 9 . O primeiro número de cada coluna é referente à execução do Algoritmo 1 e o segundo número é referente ao $\mathrm{Al}$ goritmo 2. O erro foi definido como o maior erro al gébrico cometido em qual quer nó fol ha do refinamento.

Note que com o mesmo erro, o Algoritmo 2 apresenta um número menor de células visitadas e nós folhas em sua arvore de recursão mostrando que mesmo que AA apresente contas mais pesadas que AI, sua precisão mai or faz com que mais células sejam descartadas e geradas. Outra vantagem, é que o Algoritmo 2 não precisa cal cular derivadas já que a AA oferece aproximações de segunda ordem. 


\begin{tabular}{|c|c|c|c|c|c|c|c|c|}
\hline Fig. & curva & erro & nível & Al & AA & \#células vis. & \#folhas & tempo (ms) \\
\hline 8a & Bicorn & $10^{-3}$ & 8 & 0.80 & 0.03 & $605 / 461$ & $124 / 98$ & $11 / 9$ \\
\hline 8b & Cubic & $10^{-2}$ & 8 & 0.35 & 0.05 & $805 / 317$ & $144 / 100$ & $7 / 5$ \\
\hline 9a & Clown smile & $10^{-2}$ & 8 & 0.50 & 0.05 & $677 / 373$ & $162 / 114$ & $15 / 12$ \\
\hline 9b & Taubin & $10^{-2}$ & 9 & 0.99 & 0.05 & $6937 / 1697$ & $341 / 221$ & $394 / 139$ \\
\hline
\end{tabular}

Tabela 2 - Performance e estatísticas entre os resultados obtidos com os Algoritmos 1 e 2, respectivamente. A coluna AI indica a tolerancia do o gradiente escol hi da para o Algoritmo 1 e a coluna AA a tol erância para a largura da faixa afim para o Algoritmo 2. As colunas restantes mostram os resul tados para AI / AA.
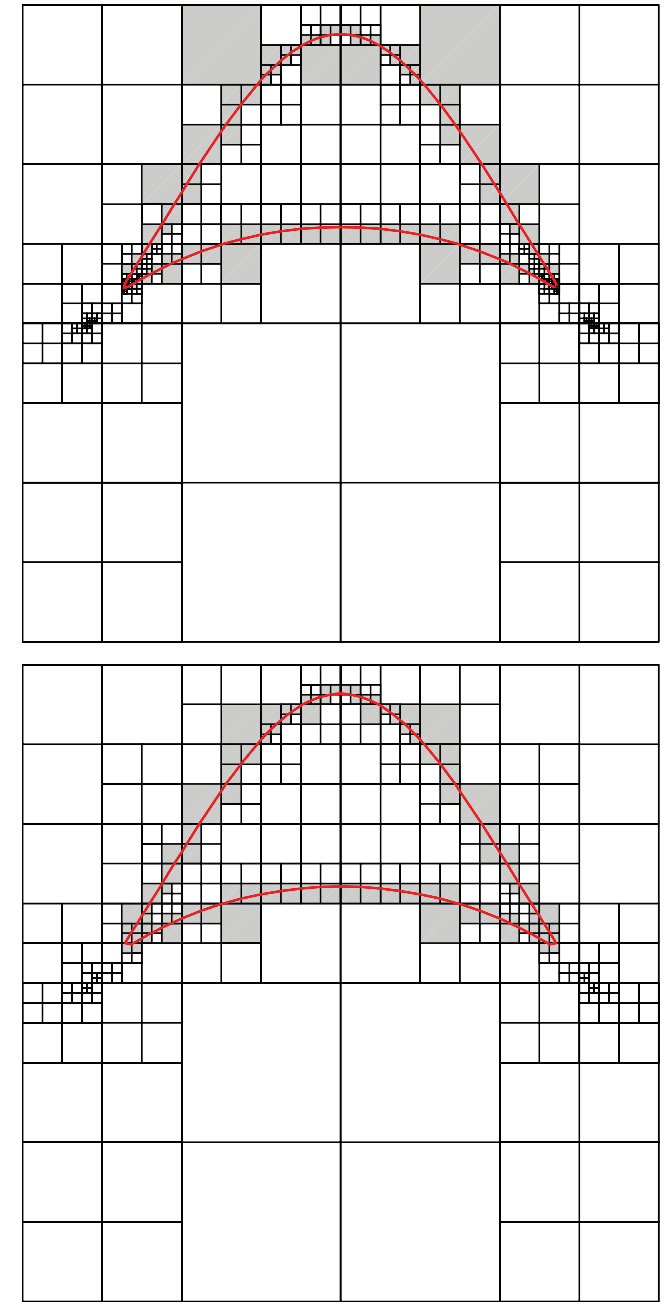

(a) Bicorn
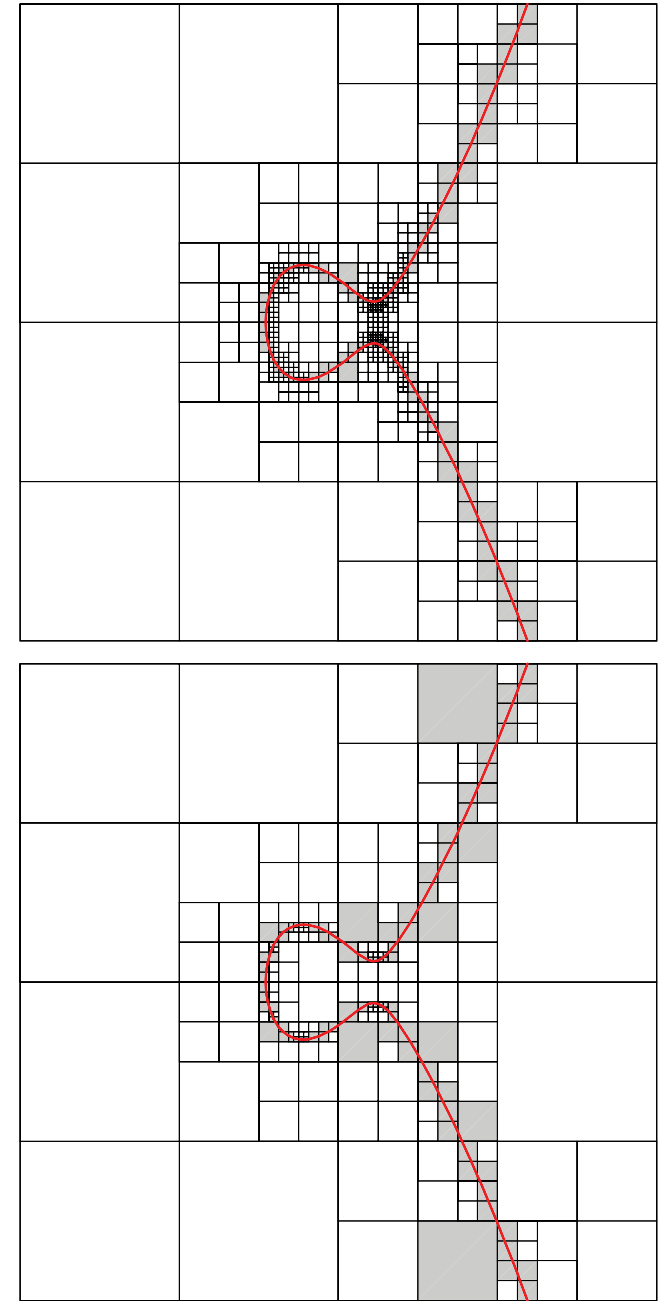

(b) Cubic

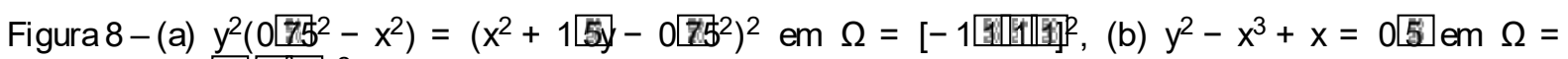
[-5[2] [5][21] $]^{2}$. As imagens de cima foram geradas com o Algoritmo 1 e as outras com o Algoritmo 2 . Figuras retiradas de (PAIVA et al., 2012). 

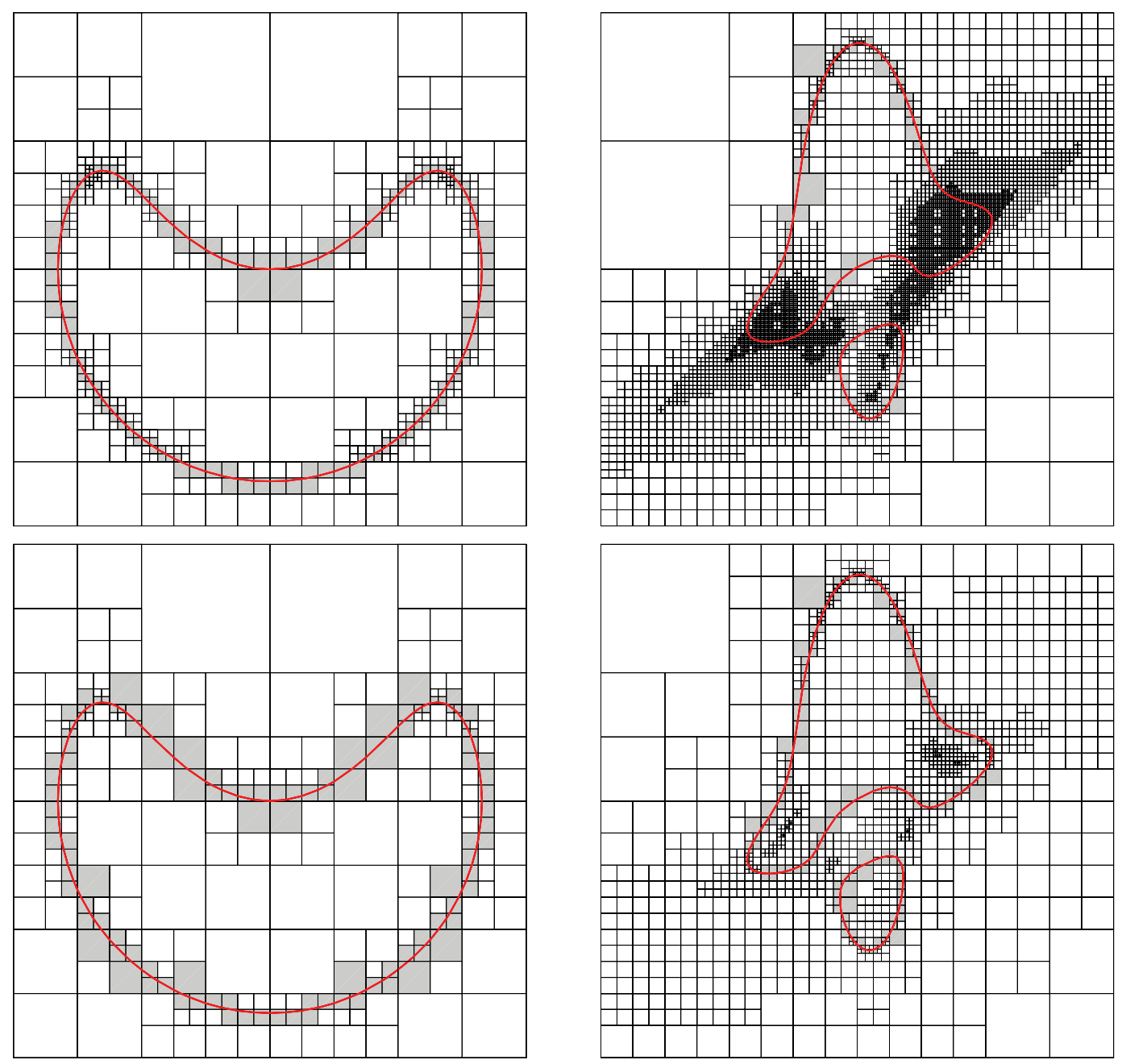

(a) Clown smile

(b) Taubin

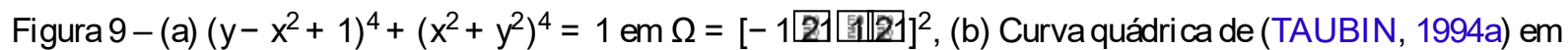

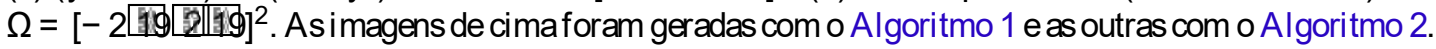
Figuras retiradas de (PAIVA et al., 2012). 
CAPÍTULO
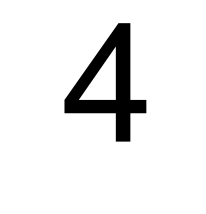

\section{CURVAS IMPLÍCITAS EM MALHAS TRIANGULARES}

Uma curva impl ícita em uma mal ha triangular é a intersecção de uma superfície impl ícita

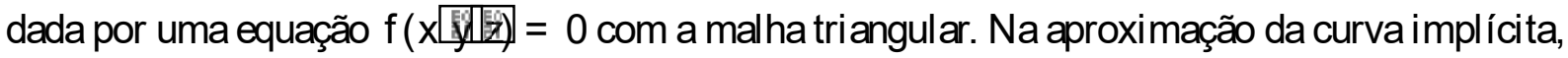
ao invés de cal cular a interseção da mal ha triangular e a aproximação poligonal da superfície implícita, pode-se adaptar a subdivisão da malha triangular a fim de concentrar o esforço computacional nos el ementos de interesse.

Como resul tado, regiões próximas à curva terão triângul os menores enquanto regiões distantes apresentarão triângulos maiores. Quando a curva intersecta o triângulo, e sua variação de curvatura é suficientemente pequena, podemos aproximála por um segmento de reta. A aproximação final de toda curva implícita será o conjunto destes segmentos de reta.

Enquanto os métodos intervalares conseguem cal cular estimativas interval ares em células retangulares, a aritmética de interval os clássica não consegue lidar com triângul os natural mente. Por esta razão, quando o domínio passa a ser uma mal ha de triângul os, o critério de subdivisão da recursão deve ser adaptado. Desta maneira, um processo similar ao Algoritmo 2 pode ser aplicado para o caso das mal has triangulares. 


\subsection{Malhas Triangulares}

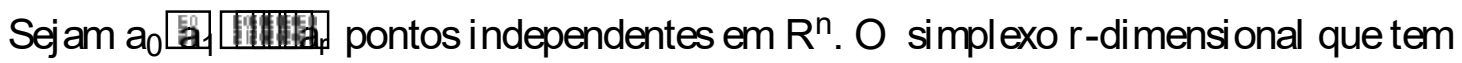

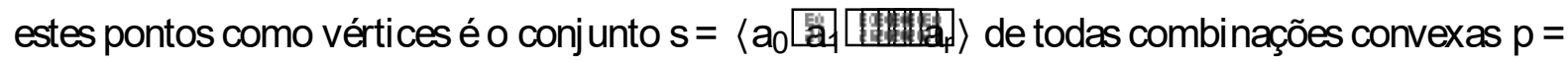

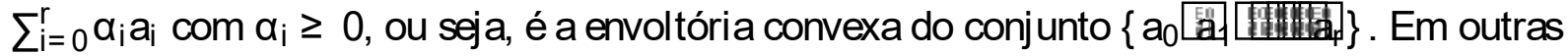
pal avras, um simplexo é o pol ígono mais simples de sua dimensão, por exemplo, o tetraedro $\left(e m R^{3}\right)$ é o pol ígono que possui o menor número vértices e arestas. A Figura 10 mostra al guns exemplos de simplexos.

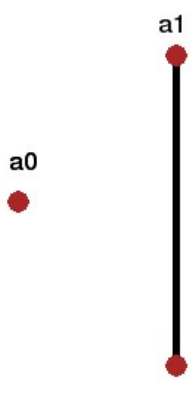

a0

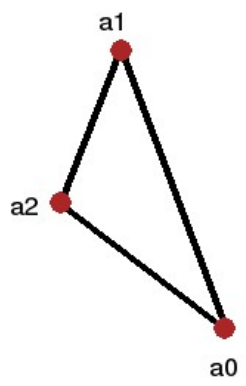

a0

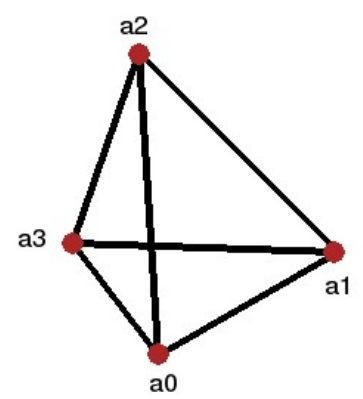

a0

Figura 10 - Simplexos de dimensões 0, 1, 2 e 3.

Uma malha triangular é um complexo simplicial. O complexo simplicial consiste basicamente de uma união de simplexos. Os simplexos estão conectados de tal maneira que cada aresta é compartilhada por no máximo dois triângulos. Neste projeto, foram escolhidas mal has triangulares de simplexos de dimensão 2 (triângulos), como pode ser no exemplo da Figura 11.

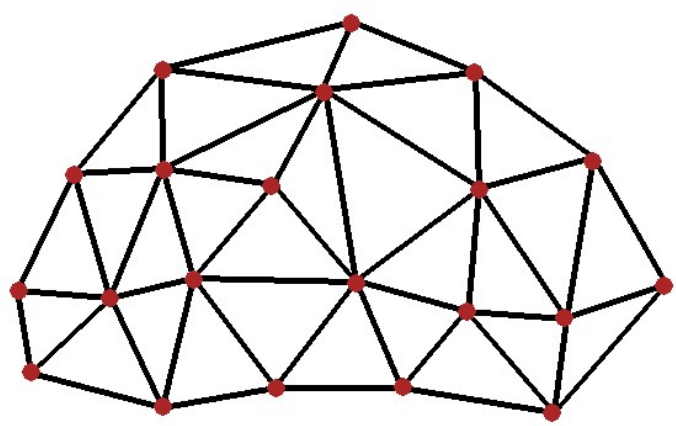

Figura 11 - Exemplo de união de simplexos de dimensão 2 constituindo um complexo simplicial .

\subsection{Aproximação em Malhas Triangulares}

O Algoritmo 2 pode ser adaptado para aproximação de curvas implícitas em mal has triangulares através de si mples modi ficações. Os elementos da mal ha são processados e refinados 
à medida que os testes acusam a presença da curva. Os triângul os que não são intersectados pela curva logo são descartados e não precisam ser processados nos próximos passos do al goritmo.

O teste sobre cada triângulo faz uso da função de inclusão e do valor das distâncias entre as retas geradas pela representação afim cal cul ada. Desta forma, triângul os que intersectam a curva são refinados até que a curva possa ser aproximada por segmentos de reta. Por fim, a mal ha se adapta à curva apresentando triângulos menores em regiões próximas a $\mathrm{C}$. Este processo pode ser representado pelo Algoritmo 3, onde

- zeroAusente(T): função de inclusão para curva em T.

- distFaixaAfim(T): função que testa o critério da curvatura.

aproxime(T): aproxima a curva por segmentos de reta dentro de $\mathrm{T}$.

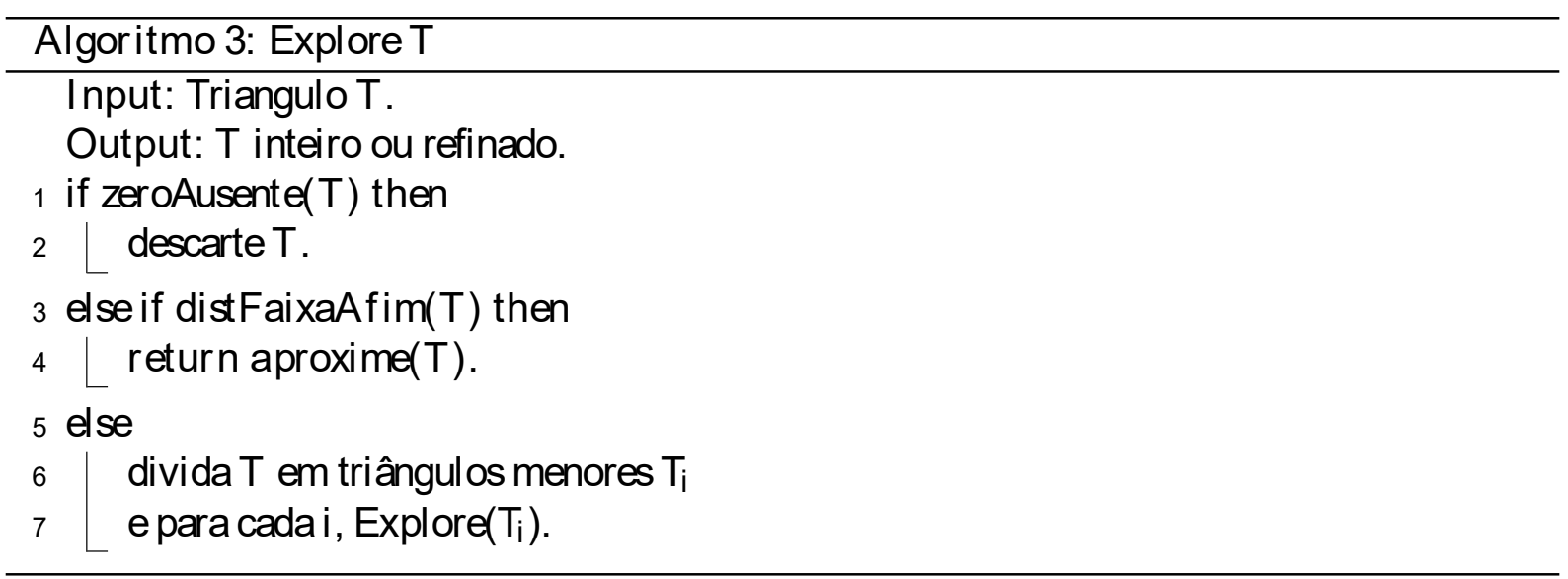

O teste AA não consegue representar diretamente triângulos, por isso é preciso trabaIhar com objetos que sejam naturais à $A A$, no caso paral elogramos, para que seja possível determinar as funções zeroAusente( $(T)$ e distFaixaAfim( $(T)$. As sol uções para zeroAusente( $T$ ), $\operatorname{distFaixaAfim(T)~e~aproxime(T)~serão~detal~hadas~na~próxima~seção.~}$

Triangulações oferecem muitos métodos de subdivisão. É importante lembrar que o método proposto neste trabal ho não depende da maneira em que a mal ha é refinada, qual quer método de refinamento pode ser utilizado. Para os resultados, foram utilizadas mal has com refinamento 4-8 (VELHO; ZORIN, 2001), que é discutido com mais detal hes na próxima seção.

\subsection{Detalhes de Implement ação}

Com respeito à implementação, além do al goritmo proposto, foi implementada uma interface gráfica para poder acompanhar os passos do al goritmo, assim como uma tela própria para visualização das faixas produzi das pela AA em cada triângulo da mal ha. 


\subsubsection{Aritmética Afim em Triângulos}

Diferente da aritmética de interval os clássica, a AA se mostra mais eficiente quando o domínio deixa de ser retangular. Com dois símbolos de ruído AA compartilhados por duas formas afins é possível definir um domínio no formato de um paral elogramo qualquer. Com as formas afins:

$$
\hat{x}=x_{0}+x_{1} \varepsilon_{1}+x_{2} \varepsilon_{2} \quad \text { e } \quad \hat{y}=y_{0}+y_{1} \varepsilon_{1}+y_{2} \varepsilon_{2}
$$

temos representado um paral elogramo central izado em $\left(x_{0} y_{0}\right)$ com lados paral el os aos vetores $v_{1}=\left(x_{1} y_{1}\right)$ e $v_{2}=\left(x_{2} y_{2}\right)$ e o dobro de suas magnitudes, respectivamente. As quantidades $x e$ y não são completamente independentes, a menos que $x_{2}=0$ e $y_{1}=0$, quando o paral el ogramo se torna um retângul o com lados paral el os aos eixos ordenados.

Triângul os não são zonotopos e por isso não podem ser representados diretamente pela AA. Sabemos representar paral elogramos em AA, logo, a solução mais simples seria incluir o triângulo em um paral elogramo. A Figura 12 mostra 3 maneiras diferentes de se fazer isto: cal culando o menor retângul o que contem o triangulo, cal culando um retângul o alinhado com al guma das arestas do triangul o ou cal culando um retângul o a partir da reflexão do triangulo com respeito a uma de suas arestas.
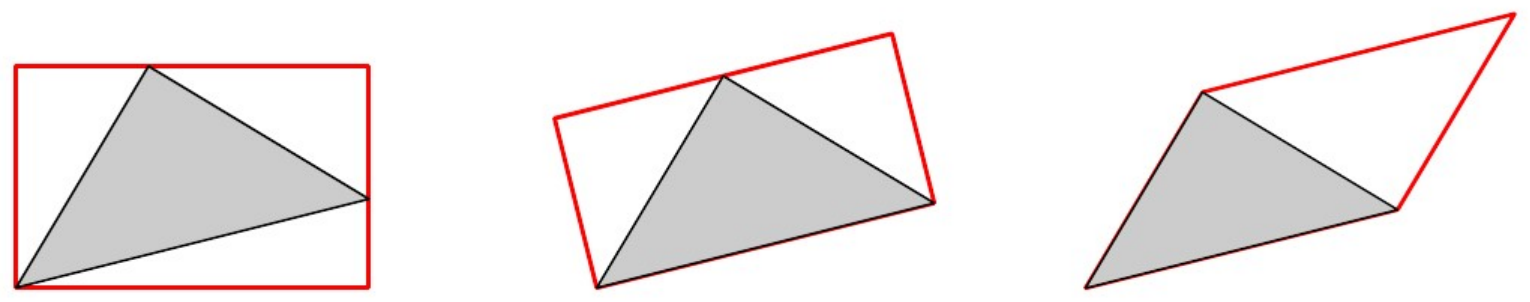

Figura 12 - Incluindo o triângulo dentro de um paral elogramo.

Outra al ternativa é decompor o triângulo em três paral elogramos sobrepostos, como mostra a Figura 13. Estes paral elogramos podem ser construídos através dos pontos médios das arestas do triângulo e f pode ser cal culada com AA para cada um. Se a curva estiver dentro de uma faixa em cada um dos paral elogramos dentro do triângul o, então a curva está em um "tubo" dentro do triângulo.
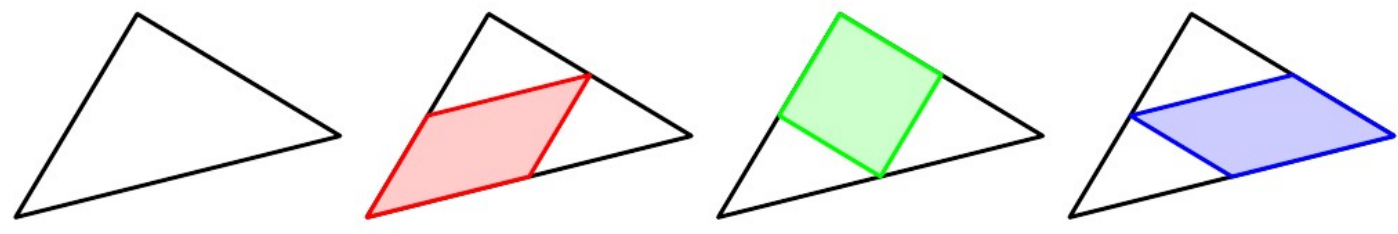

Figura 13 - Decompondo o triângulo em paral elogramos.

Embora a estratégia da decomposição do triangul o exija três verificações por triangulo, ela apresenta uma aproximação pol igonal mais precisa da curva implícita dentro do triangulo pois 
gera até 3 segmentos de reta. As outras estratégias, apesar de exigirem apenas uma verificação por triangulo, utilizam um paral el ogramo maior que o triangulo fazendo com que f sejacal culada fora do triangulo. A Tabela 3 e a Figura 14 mostram as diferentes performances entre as estratégias discutidas aci ma para a aproximação poligonal da mesma curva implícita dada pel a equação da Figura 9b. Como esperado, a estratégia da decomposição leva mais tempo para ser executada porém visita menos triângul os e gera uma aproximação poligonal melhor com mais segmentos de reta. Esta estratégia foi a escolhida para a implementação deste projeto.

\begin{tabular}{|c|c|c|c|c|c|c|}
\hline Estratégia & tempo (ms) & mal ha final & \#visitados & \#fol has & AA & seg. \\
\hline Decomposi ção & 33 & 1445 & 1805 & 250 & 4604 & 502 \\
\hline Reflexão & 25 & 2909 & 3878 & 298 & 3878 & 298 \\
\hline Menor retangulo & 28 & 3392 & 4522 & 318 & 4522 & 318 \\
\hline Retangulo Alinhado & 25 & 2882 & 3842 & 316 & 3842 & 316 \\
\hline
\end{tabular}

Tabela 3 - Diferentes performances das diferentes estratégias para o uso de paral logramos em triângulos.

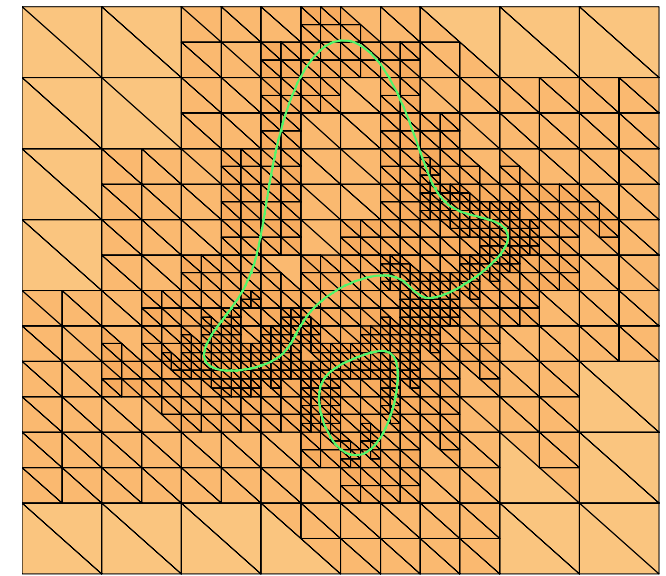

(a) Decomposição

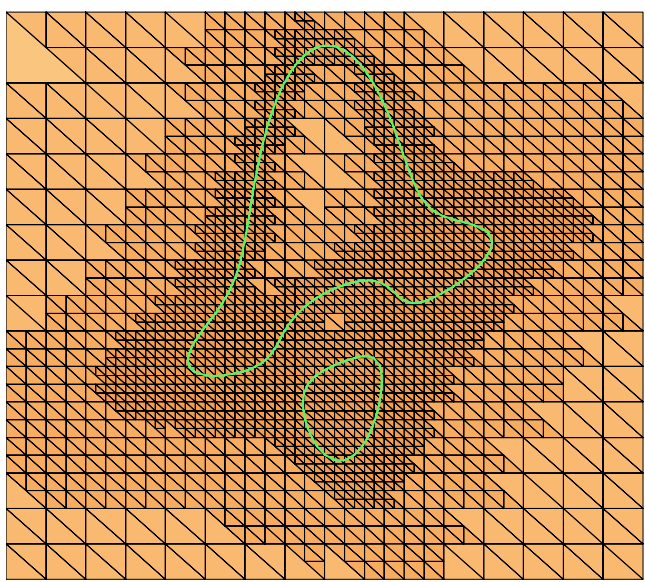

(c) Menor retângulo.

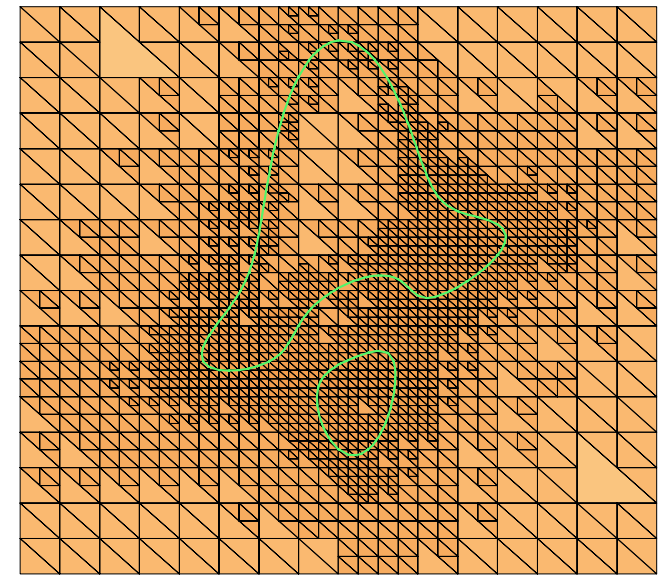

(b) Reflexão

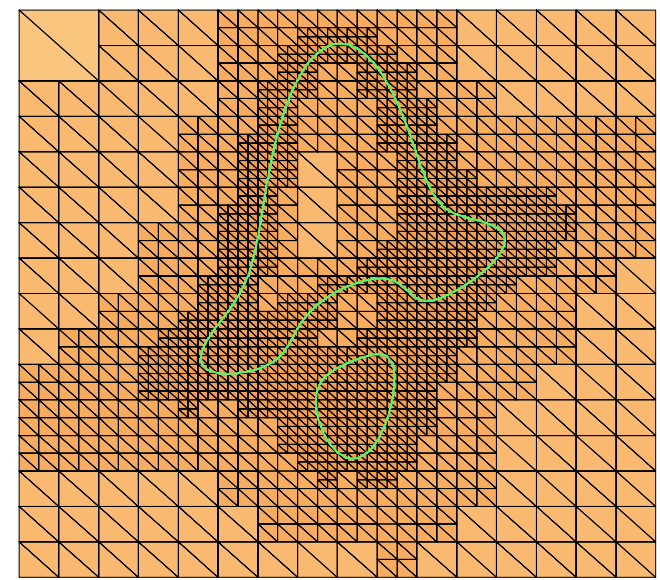

(d) Retângulo al inhado

Figura 14 - Efeitos das diferentes estratégias do uso de paral el ogramos para aproximar poligonal mente uma curva implícita em triângulos. 


\subsubsection{Função de Inclusão}

Com o paral el ogramo representado pelas duas formas afins $\hat{x}$ e ŷ em mãos, a função de incl usão deve ser verifi cada em todos paral elogramos. Se a estratégia escol hi da é a da inclusão de T em um paral elogramo então apenas uma verificação é necessária. Caso exi sta ocorrência de zero na forma afim final, passa-se ao teste da curvatura.

A pesar de exigir apenas uma verificação por triangulo, a forma afim que representa o paralelogramo que envol ve o triangulo cobre um domínio maior que o triangulo. Isto significa que f estará sendo processada fora do domínio levando a um resultado menos preciso da função de inclusão. Na prática, o al goritmo subdividi rá e processará mais triângul os que o necessário.

Se a estratégia da decomposição do triangulo é escolhida, então f̂ deve ser cal culada para cada um dos três paral el ogramos. Neste caso, T será descartado por este teste se e somente se a $\hat{f}$ cal culada de todos paral elogramos não conter o zero.

É importante observar que a possível presença do zero dentro de $T$ não quer dizer que $C$ intersecta suas arestas. $\mathrm{O}$ teste $\mathrm{AA}$ detectará componentes de $\mathrm{C}$ que se encontram dentro dos limites de T. Este fato garante a robustez do algoritmo, no sentido de que todas as partes da curva que intersectam a mal ha serão encontradas.

\subsubsection{Estimativa da Curvatura}

O teste distFaixaAfim( $T$ ) representa o teste da curvatura. Triângul os em que a variação da curvatura da curva que se encontra em seu interior é al ta devem ser refinados. A curva será aproximada por um segmento de reta quando a variação de sua curvatura é suficientemente pequena. Para primeira estratégia (triângulo incluído em um paral logramo), basta cal cular $\hat{f}$ e verificar a distância entre as faixas.

Para a estratégia da decomposição do triangulo, existirá uma di stância entre as faixas cal culada para cada um dos paral el ogramos. A curva será aproximada para o segmento de reta apenas quando a distância é suficientemente pequena em todos os paral elogramos de $T$.

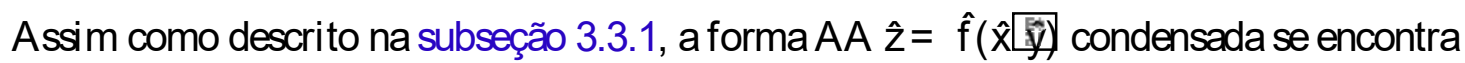
entre os dois planos paralelos

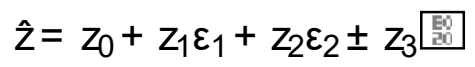

Escrevendo as equações das formas afins que definem o paralelogramo em forma matricial temos:

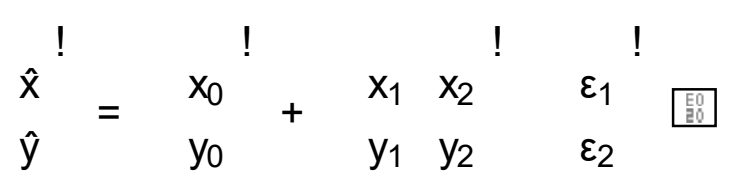

Separando $\varepsilon_{\mathrm{i}}$,

$$
\begin{aligned}
& \varepsilon_{1}=\mathrm{B} \\
& \varepsilon_{2} \begin{array}{l}
\hat{\mathrm{x}} \\
\hat{\mathrm{y}}
\end{array}
\end{aligned}
$$


onde

$$
B=\begin{array}{lll}
x_{1} & x_{2}^{!-1} \\
y_{1} & y_{2}
\end{array}=\begin{array}{lll}
b_{11} & b_{12} \\
b_{21} & b_{22}
\end{array}
$$

podemos reescrever ẑ da seguinte forma:

$$
\hat{z}=a \hat{x}+b \hat{y}+c \pm z_{3} \text { 티리 }
$$

com $a=z_{1} b_{11}+z_{2} b_{21}$ (b e c calculados de maneira análoga). Observe que a intersecção dos planos paral elos no plano $x \times$ y resul ta em duas retas,

$$
\begin{aligned}
& r: a \hat{x}+b \hat{y}+c+z_{3}=0, e \\
& s: a \hat{x}+b \hat{y}+c-z_{3}=0
\end{aligned}
$$

A largura da fai xa produzida por $\hat{f}$ é dada pela distância entre as retas $r$ e s como segue:

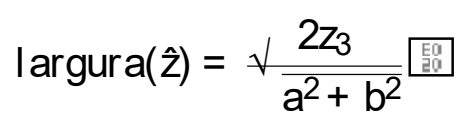

Quando o valor de largura(ẑ) é pequeno, podemos garantir que a curvatura da curva é pequena, pois a curva na região do paral elogramo se encontra entre as retas $r$ e s. Portanto, comparamos com uma tolerância y para decidir que a curva dentro da região do paral el ogramo possa ser aproximada por um segmento de reta. $O$ val or de y é um limiar definido pelo usuário.

Na Figura 15 estão representadas as regiões (em cinza) entre as retas r e s em cada paral elogramo, deste modo pode-se ter uma visão mel hor sobre este teste. Note que a curva se encontra dentro da porção da faixa que intersecta o paral el ogramo. A curva será aproximada por um segmento de reta quando as faixas forem suficientemente estreitas.

Para paral elogramos degenerados não é possível calcular a matriz inversa B. Porém, testes com triângulos extremamente finos foram feitos a fim de reproduzir esta limitação e o al goritmo não apresentou problemas. Na prática, as mal has difícilmente possuem triângulos de tão baixa qualidade.
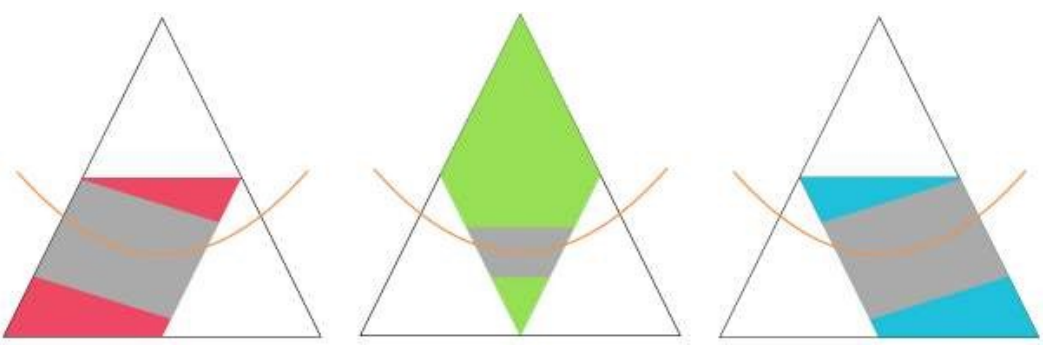

Figura 15 - Exemplo de faixas afins (em cinza) cal culadas para cada um dos paral elogramos que compõem o triângulo. 


\subsubsection{Estimativa de Curvatura em Triângulos 3D}

A subseção 4.3.3 define a estimativa de curvatura em triângul os definidos em $R^{2}$, mas não pode ser aplicada para triângulos em $\mathrm{R}^{3}$. Para isto, a estimativa de curvatura deve sofrer

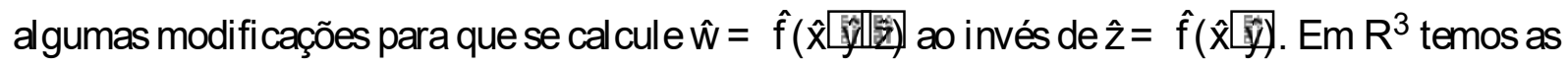
seguintes formas afins:

$$
\hat{x}=\mathrm{x}_{0}+\mathrm{x}_{1} \varepsilon_{1}+\mathrm{x}_{2} \varepsilon_{2} \quad \hat{\mathrm{y}}=\mathrm{y}_{0}+\mathrm{y}_{1} \varepsilon_{1}+\mathrm{y}_{2} \varepsilon_{2} \quad \hat{z}=\mathrm{z}_{0}+\mathrm{z}_{1} \varepsilon_{1}+\mathrm{z}_{2} \varepsilon_{2}
$$

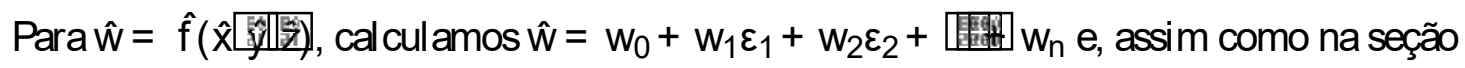
anterior, condensamos os termos de segunda ordem:

$$
w_{3}=\left|w_{3}\right|+\left[w_{n} \mid\right.
$$

Desta maneira, a forma AA ŵ se encontra entre os dois planos paral elos

$$
\hat{w}=w_{0}+w_{1} \varepsilon_{1}+w_{2} \varepsilon_{2} \pm w_{3} \text { 厬 }
$$

Escrevendo as equações em forma matricial encontramos:

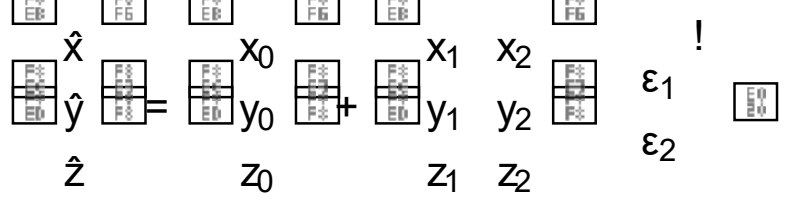

Separando $\varepsilon_{\mathrm{i}}$

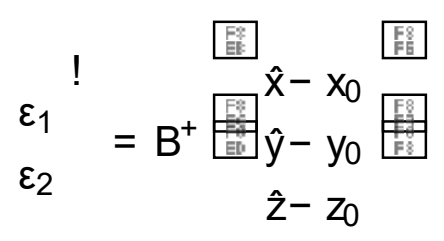

onde

$$
B^{+}=\left(B^{\top} B\right)^{-1} B^{\top}=\begin{array}{llll}
b_{11} & b_{12} & b_{13} \\
b_{21} & b_{22} & b_{23}
\end{array} \quad \text { 卧 } \quad B=\begin{array}{lll}
x_{1} & x_{2} \\
y_{1} & y_{2} \\
z_{1} & z_{2}
\end{array}
$$

podemos reescrever da seguinte forma:

$$
\hat{w}=a \hat{x}+b \hat{y}+c \hat{z}+d \pm w_{3} \text { 韧 }
$$

com $a=w_{1} b_{11}+w_{2} b_{21}$, e b, c e d cal culados de maneira análoga. $A$ matriz $B^{+}$é chamada pseudo-inversa de B. Portanto, os planos paral el os pel os quais a curva está limi tada são:

$$
\begin{aligned}
& p: a \hat{x}+b \hat{y}+c \hat{z}+d+w_{3}=0, e \\
& \cdot q: a \hat{x}+b \hat{y}+c \hat{z}+d-w_{3}=0
\end{aligned}
$$

A largura da faixa produzida por $\hat{f}$ no caso de triângulos em $R^{3}$ é então:

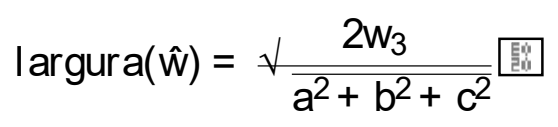

O teste com largura( $\hat{w})$ é utilizado da mesma maneira que largura(ẑ) na subseção 4.3.3, e possui as mesmas propriedades de largura(ẑ) necessárias para o al goritmo. 


\subsubsection{Subdivisão da Malha Triangular}

Uma regra de refinamento é um algoritmo que produz uma mal ha mais fina a partir da mal ha de entrada. A regra utiliza a informação de conectividade da mal ha e não utiliza a informação geométrica (ex: posição dos vértices). Normalmente os métodos de refinamento estão relacionados a ladrilhos regulares, ou seja, divisões do plano compostas por polígonos idênticos regulares de $n$ lados.

Existem três tipos de ladrilhamento regulares no plano: o polígono deve ser um quadrado, um triângulo equilátero ou um hexágono regular. Porém, quando se consi dera uma classe mai or de ladrilhamento é possível obter novas classes de regras de refinamento.

A subdivisão 4-8 é uma técnica introduzida por Luiz Velho e Denis Zorin (VELHO; ZORIN, 2001) que utiliza ladrilhamento 4-8. Seus vértices al ternam a valência entre 4 e 8. A estrutura básica neste ladrilhamento é o par de triângul os que formam um bloco quadrado dividido por uma de suas diagonais, como mostra a Figura 16a.

Uma mal ha 4-8 regular tem a mesma estrutura de bl ocos do ladrilhamento 4-8, e suas arestas podem ser classificadas como interiores ou exteriores a cada bloco. Cada triângulo tem uma única aresta interior e duas exteriores. Isto permite o uso da bisseção como operação de refinamento primitiva: para cada triângulo, a única aresta interior é bisseccionada e os vértices opostos ao ponto de divisão são conectados. Um exemplo do refinamento por bisseção é visto na Figura 16b. Para o uso do refinamento 4-8 na implementação do trabal ho, foi utilizada a biblioteca (VELHO, 2004).

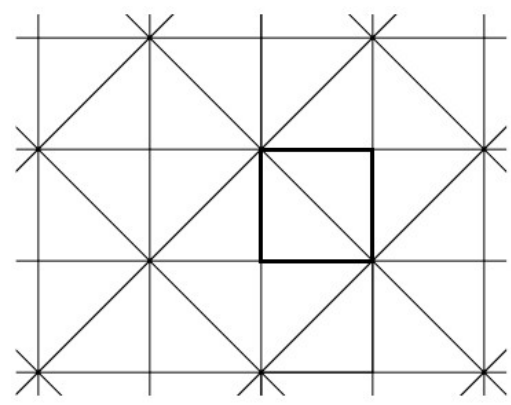

(a) Ladrilhamento 4-8
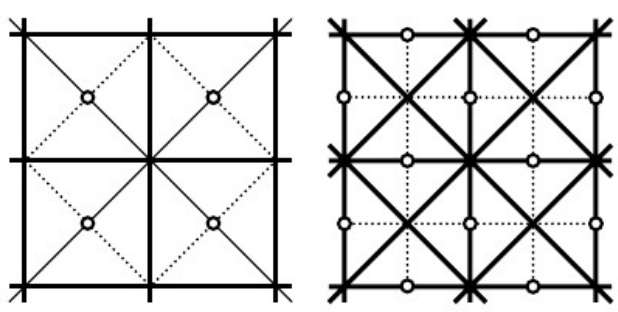

(b) Refinamento por bisseção em ação.

Figura 16 - Mal ha 4-8. Imagem retirada de (VELHO; ZORIN, 2001).

Outra técnica de refinamento de triângul os utilizada na implementação é a subdivisão Mid-Point (MP). A subdivisão MP é obtida conectando-se os pontos médi os das arestas a fim de formar 4 triângul os menores (Figura 17a). Desta forma, obtém-se um novo triangulo com as novas arestas e mais 3 triângul os com o restante das sub-arestas (Figura 17b). A subdivisão MP não gera mal has conformes (Figura 17c). Mal has conformes são mal has onde a intersecção entre dois el ementos é um vértice ou uma aresta. No caso da subdivi são MP, vértices são criados em cima de arestas e uma aresta pode ser formada por arestas dos triângul os vizinhos. Esta 
subdivisão não consi dera triângul os vizinhos, por isto a mal ha pode ser representada por uma sopa de triângulos.

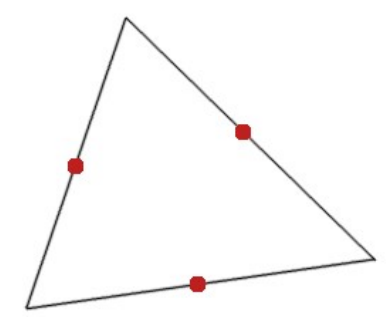

(a) Pontos médios das arestas do triangulo.

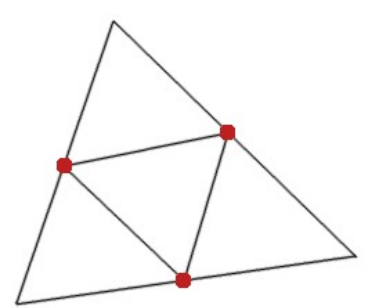

(b) Triangulo após a subdivisão MP.

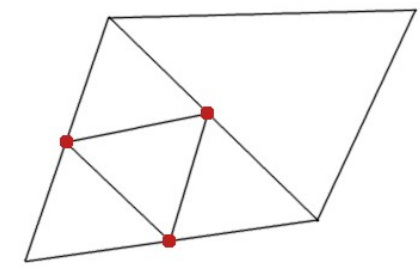

(c) Mal ha não conforme.

Figura 17 - Subdivisão MP. Triangulo é dividido em 4 novos triângul os através da conexão dos pontos médios de suas arestas.

\subsection{Visualização dos Resultados}

Para visual ização dos resultados foi utilizada a biblioteca gráfica @penG. Para facilitar, uma interface gráfi ca utilizando a biblioteca Gu foi desenvol vida. Desta maneira, é possível escol her facilmente as mal has, curvas e ajustar os parâmetros. A interface é composta de duas tel as principais, como pode ser visto na Figura 18. A primeira tela é onde a mal ha e a curva são mostradas de fato, nesta tela o usuário tem al guns control es sobre a imagem.

A tela de control es é responsável por todas as ações sobre o experimento a ser executado. Neste painel, a curva e a mal ha são escol hi das, assim como a tolerância y para o teste de curvatura afim y. Cada passo do algoritmo é comandado por esta tela, pelo botão Refine. É neste painel também que o usuário pode gerar a curva, através do botão Compute Curve.

Existe uma tela extra para auxiliar na visual ização da faixa afim em cada paral elogramo do triângulo. Desta forma o usuário pode selecionar um triângulo na mal ha e observar como a AA se comporta. Esta tela pode ser vista na Figura 19. A faixa afim aparece em verde claro, eé referente ao paral el ogramo selecionado (arestas coloridas). Na Figura 19b encontra-se um ponto de singularidade, note como a faixa afim é mais grossa.

\subsection{Resultados}

Para se gerar o conjuntos de segmentos de reta (aproxima(T)), que representam a aproximação da curva a seguinte estratégia é utilizada: quando um triângulo passou por todos os testes e podemos afirmar que a curva pode ser bem aproximada em seu interior, o segmento é cal culado a partir das intersecções da curva com suas arestas. Porém, afim de se produzir mais um nível de refinamento na precisão, o triângulo é dividido em quatro triângul os menores via MP e cada um tem seu segmento cal culado. Esta estratégia está representada na Figura 20. 


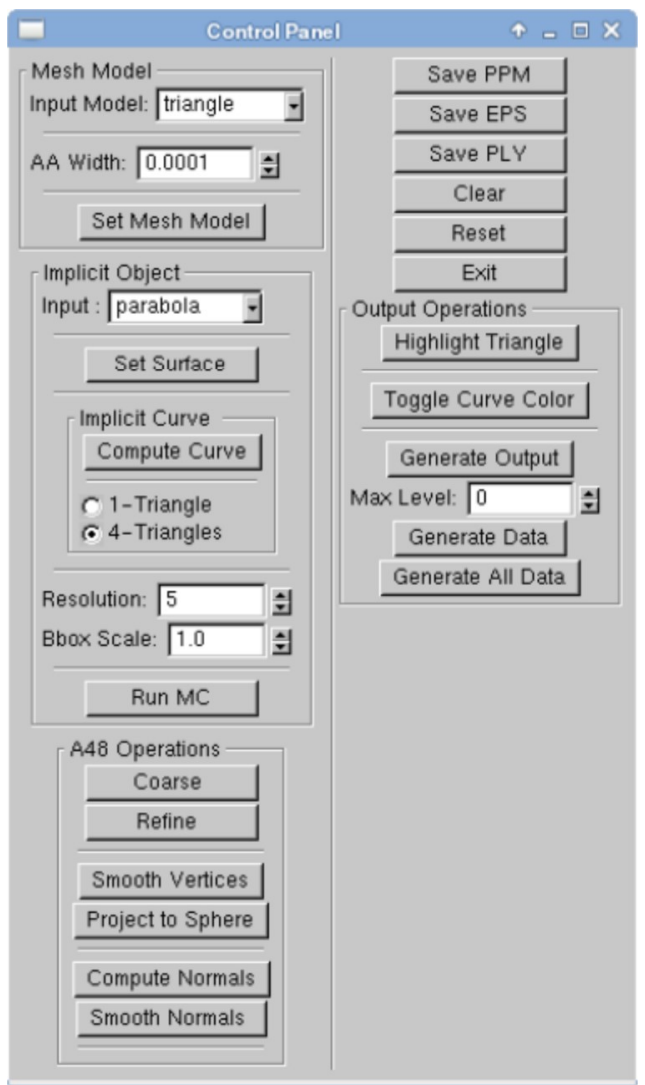

(a) Tela de controle.

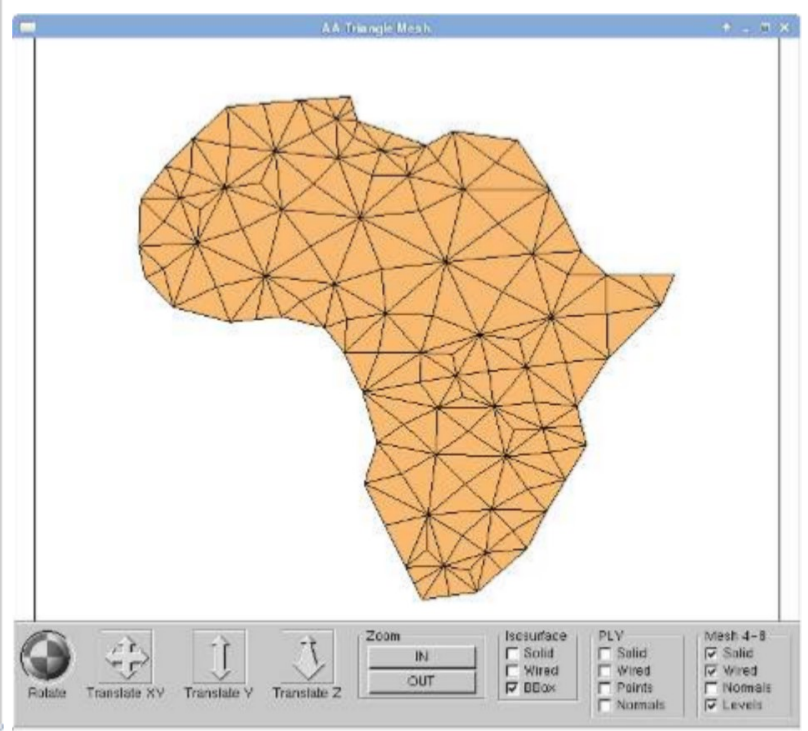

(b) Tela de visual ização.

Figura 18 - Janelas principais.

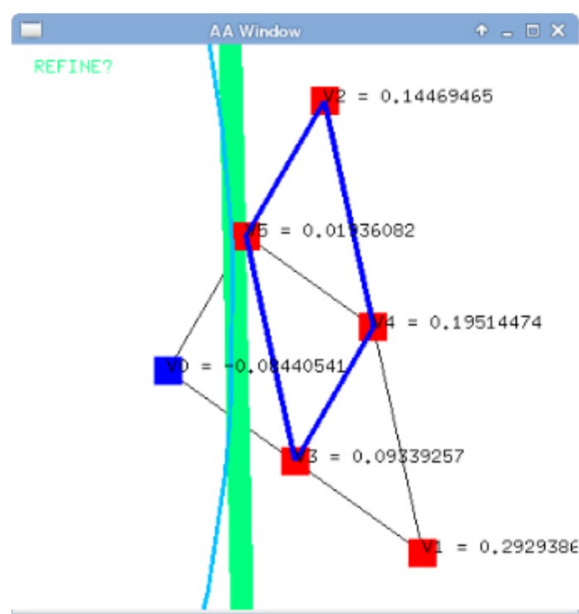

(a) Faixa afim do paralelogramo selecionado.

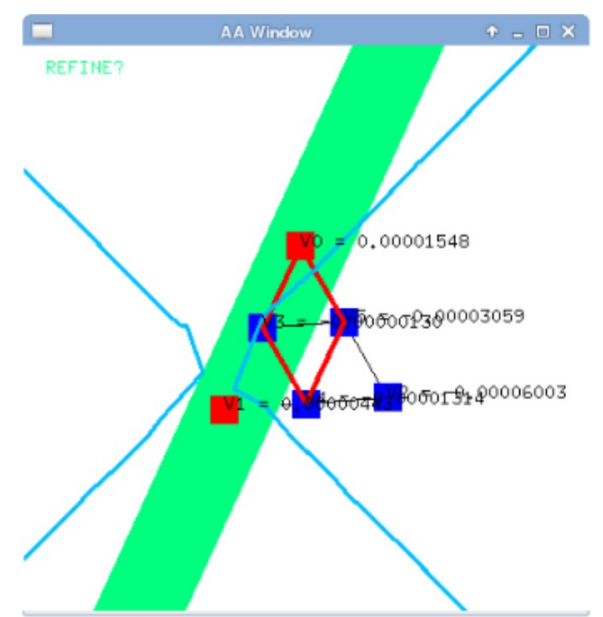

(b) Faixa afim próxima ao ponto de singularidade.

Figura 19 - Janela AA.

A Tabela 4 lista as estatísticas de vários exemplos de aproximações de diferentes curvas em diferentes malhas. Nesta tabela é possível verificar para cada par de curva e malha, qual prof undi dade de recursão o al goritmo al cançou, qual o val or de $\gamma$, a quantidade de triângul os na mal ha inicial e final e por fim o tempo(ms) que todo processo de refinamento levou. Os resultados 

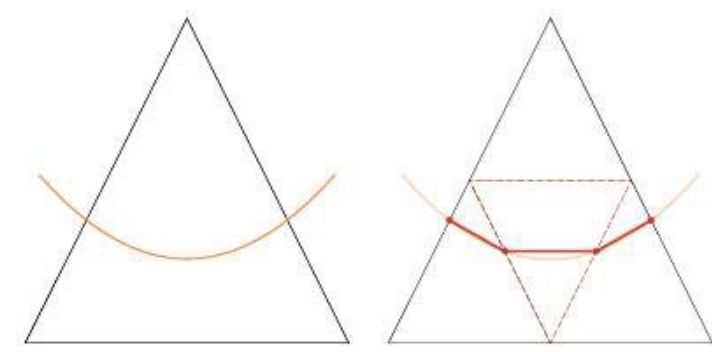

Figura 20 - Aproximação da curva por segmentos de reta em um triângulo.

foram gerados em uma máquina $1.83 \mathrm{GHz}$ Intel Core 2 Duo com 3GB de RAM. Através das figuras com os resultados é possível notar que o método permite aproximar curvas tanto em mal has convexas como não-convexas. A Figura 28b mostra que o al goritmo também aproxima curvas não-algébricas.

\begin{tabular}{|c|c|c|c|c|c|c|c|}
\hline Fig. & Curva & Malha & Prof. & Y & $\triangle$ iniciais & $\triangle$ finais & tempo \\
\hline $21 a$ & Taubin & Square & 5 & $1 \times 10^{0}$ & 8 & 389 & 109 \\
\hline $21 b$ & Taubin & Square & 6 & $1 \times 10^{-1}$ & 8 & 1466 & 401 \\
\hline $21 c$ & Taubin & Square & 6 & $1 \times 10^{-2}$ & 8 & 2736 & 537 \\
\hline $22 b$ & Circle & Africa & 3 & $1 \times 10^{-3}$ & 193 & 922 & 33 \\
\hline $22 c$ & Circle & Africa & 5 & $1 \times 10^{-3}$ & 193 & 1106 & 42 \\
\hline $23 b$ & Bicorn & Octagon & 5 & $5 \times 10^{-3}$ & 126 & 1168 & 54 \\
\hline $24 b$ & ClownSmile & K7 & 4 & $5 \times 10^{-3}$ & 1006 & 2134 & 214 \\
\hline $25 b$ & Cubic & Aircraft & 3 & $5 \times 10^{-3}$ & 3530 & 4142 & 244 \\
\hline $26 b$ & Heart & Gear & 3 & $3 \times 10^{-3}$ & 1424 & 3289 & 189 \\
\hline $27 \mathrm{~b}$ & Pear & Beetle & 4 & $1 \times 10^{-2}$ & 940 & 1771 & 115 \\
\hline $28 b$ & Irrational & Eight & 4 & $1 \times 10^{-3}$ & 1032 & 3897 & 247 \\
\hline $30 c$ & Pisces & Circle & 6 & $5 \times 10^{-3}$ & 101 & 2382 & 641 \\
\hline $29 b$ & Capricorn & Tree & 22 & $1 \times 10^{-3}$ & 1015 & 11678 & 4324 \\
\hline
\end{tabular}

O método se adapta à topologia da curva, como pode ser visto na Figura 30c, onde a mal ha inicial apresenta poucos triângulos. Este nível de adaptação não é adquirido com o al goritmo de marching triangles (Figura 30a), a não ser que seja utilizado após um grande refinamento da mal ha (Figura 30b).

As Figuras 23b, 25b, 27b e 29b apresentam restultados em malhas mais simples, enquanto as Figuras 24b, 26b e 28b mostram que o método também funciona para mal has mais complexas (com buracos).

A Figura 21 ilustra o efeito do critério sobre a curvatura no método em cima da curva implícita Taubin dada por um polinômio de $4^{\circ}$ grau (retirada de (TAUBIN, 1994b)). A tolerância y é o úni co parâmetro fornecido pelo usuário, note como a mal ha apresenta uma concentração mai or de triângulos em regiões de alta curvatura a medi da que o parâmetro é variado. 


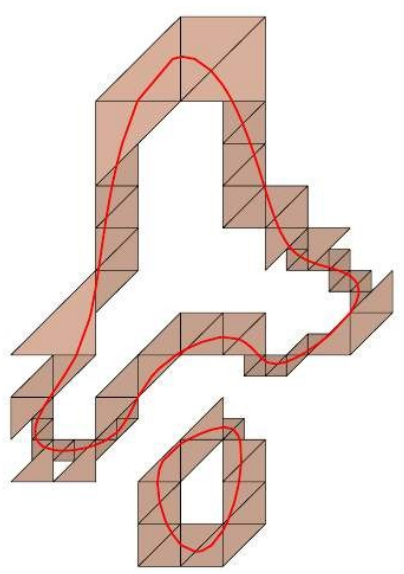

(a) $Y=1$

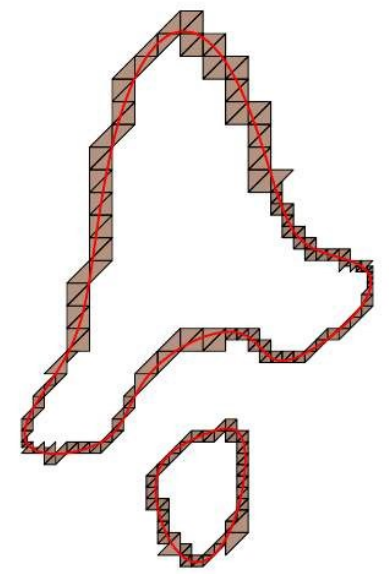

(b) $\mathrm{Y}=0$ 國

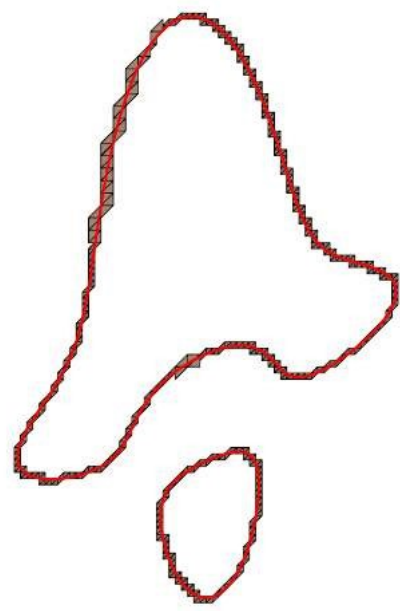

(c) $\mathrm{Y}=0001$.

Figura 21 - Curva implícita Taubin. Regiões de mai or curvatura apresentam maior número de triângul os.

O resultado apresentado na Figura 22 mostra que o método é capaz de aproximar uma curva impl ícita em uma col eção desordenada de triângul os (chamada sopa de triângulos) assim como em uma mal ha de triângul os com informação topológica. Para o primeiro exemplo (Figura 22b) foi utilizado refinamento por ponto médio, e no segundo refinamento mal ha 4-8 (Figura 22c).

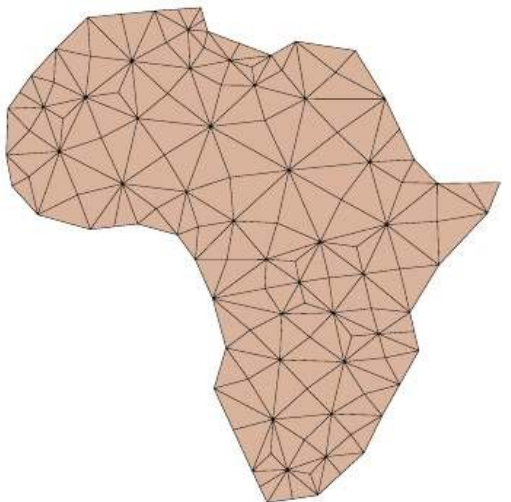

(a)

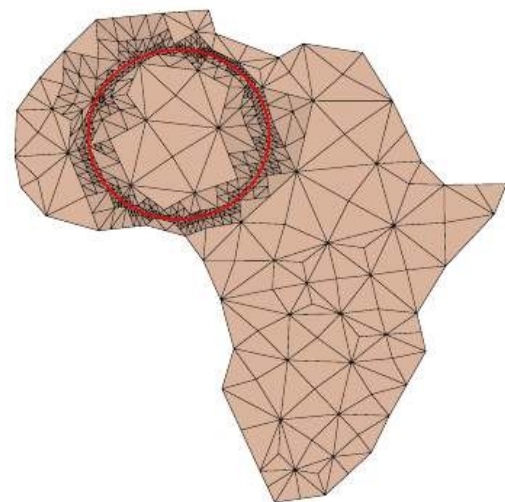

(b)

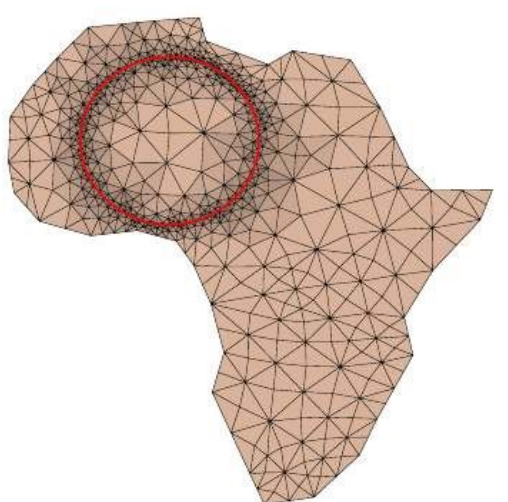

(c)

Figura 22 - Método aplicado em uma (b)sopa de triângul os, e em uma (c)mal ha. 


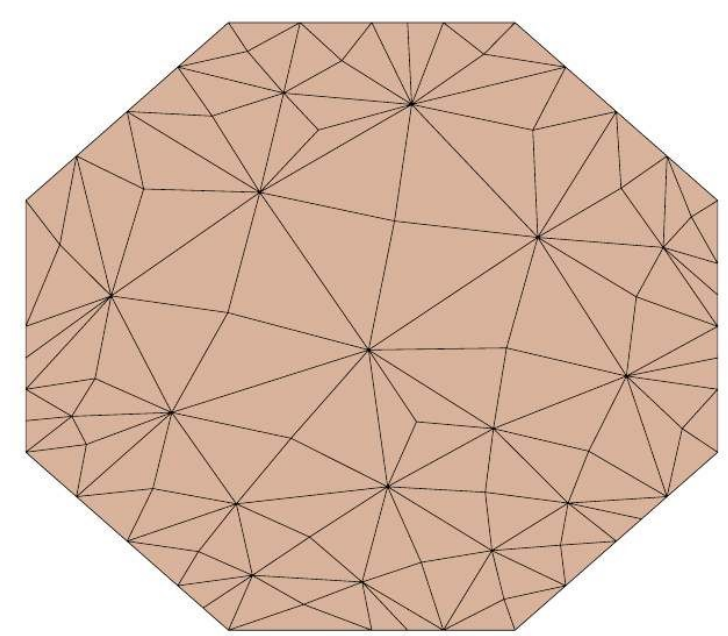

(a) Mal ha I nicial (Octagon).

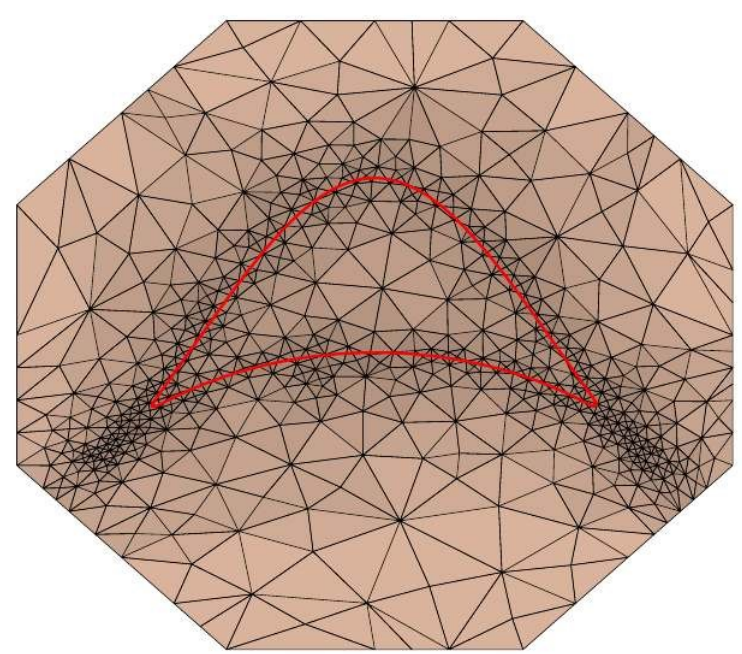

(b) Malha refinada com a curva.

Figura 23 - Curva implícita dada por $y^{2}\left(a^{2}-x^{2}\right)-\left(x^{2}+2 a y-a\right)^{2}=0$ com $a=08$.

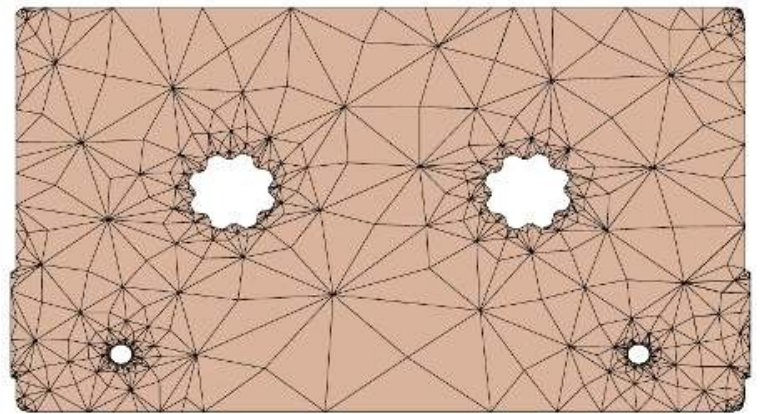

(a) Malha Inicial (K7).

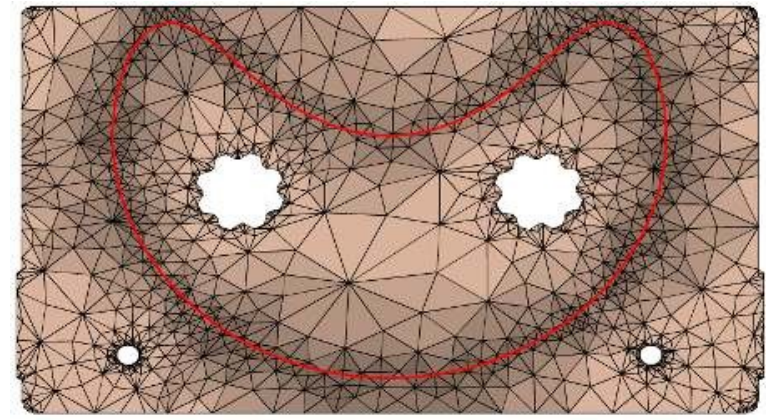

(b) Malha refinada com a curva.

Figura 24 - Curva implícita dada por $\left(y-x^{2}+1\right)^{4}+\left(x^{2}+y^{2}\right)^{4}-1=0$.

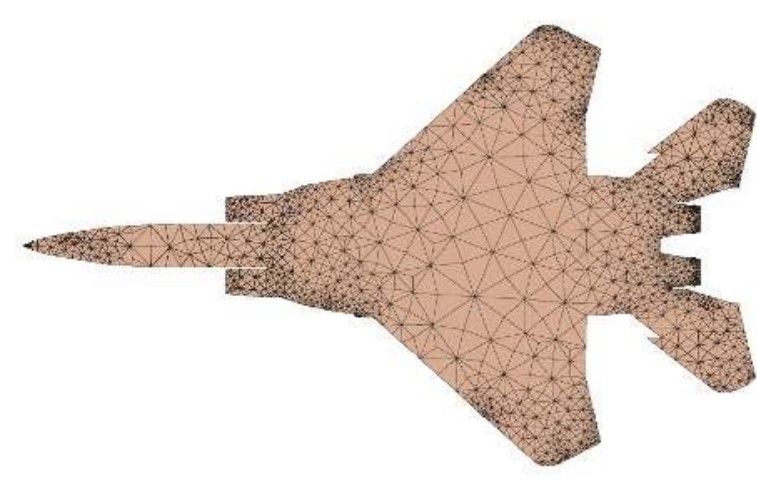

(a) Mal ha Inicial (Aircraft).

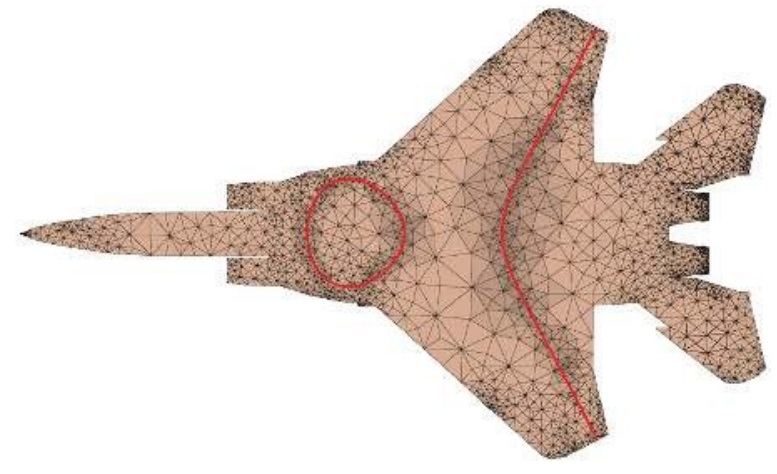

(b) Mal ha refinada com a curva.

Figura 25-Curva implícita dada por $\mathrm{y}^{2}-\mathrm{x}^{3}+\mathrm{x}-0$ 5: $=0$. 


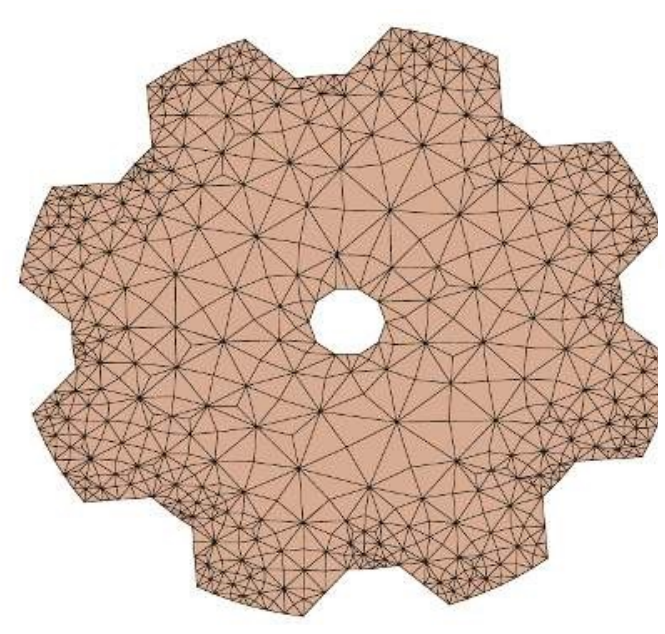

(a) Malha Inicial (Gear).

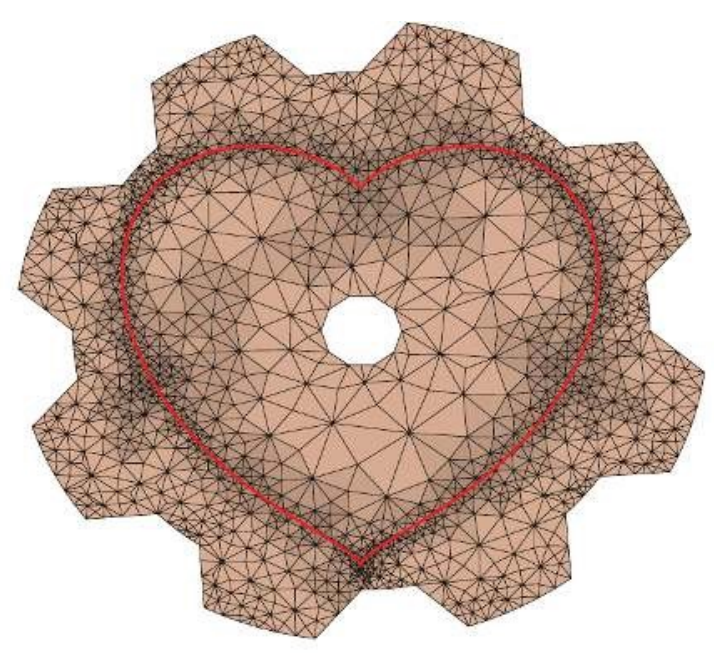

(b) Malha refinada com a curva.

Figura 26 - Curva implícita dada por $x^{2} y^{2}-\left(x^{2}+y^{2}-1\right)^{3}=0$.

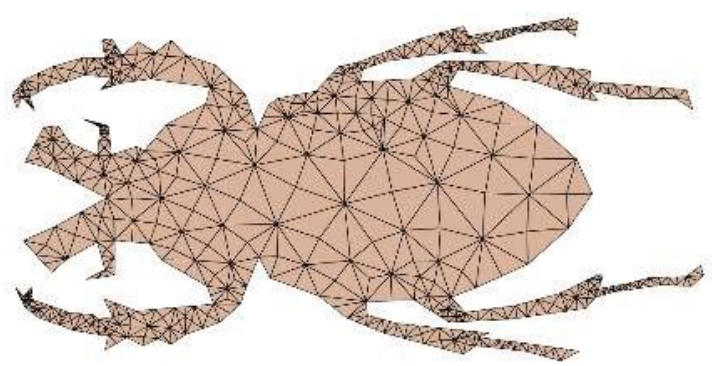

(a) Mal ha I nicial (Beetle).

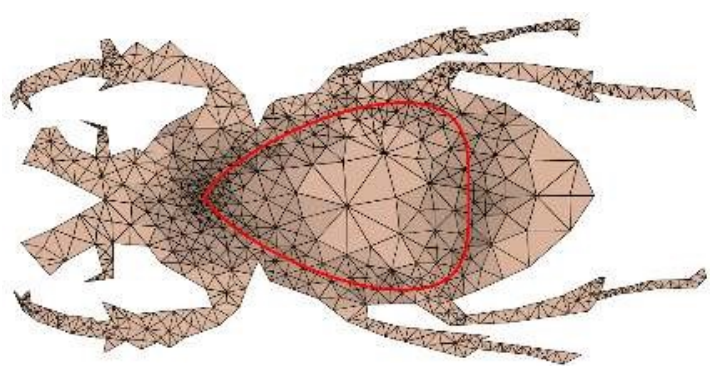

(b) Mal ha refinada com a curva.

Figura 27 - Curva implícita dada por $4 y^{2}-(x+1)^{3}(1-x)=0$.

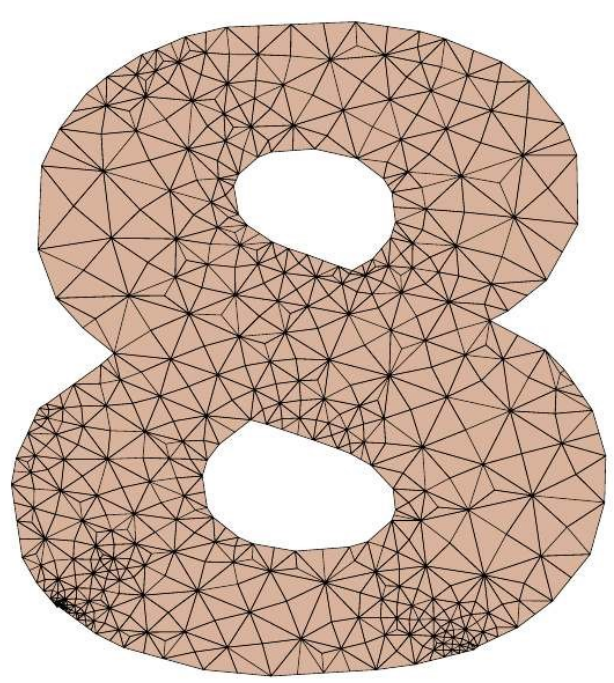

(a) Mal ha Inicial (Eight).

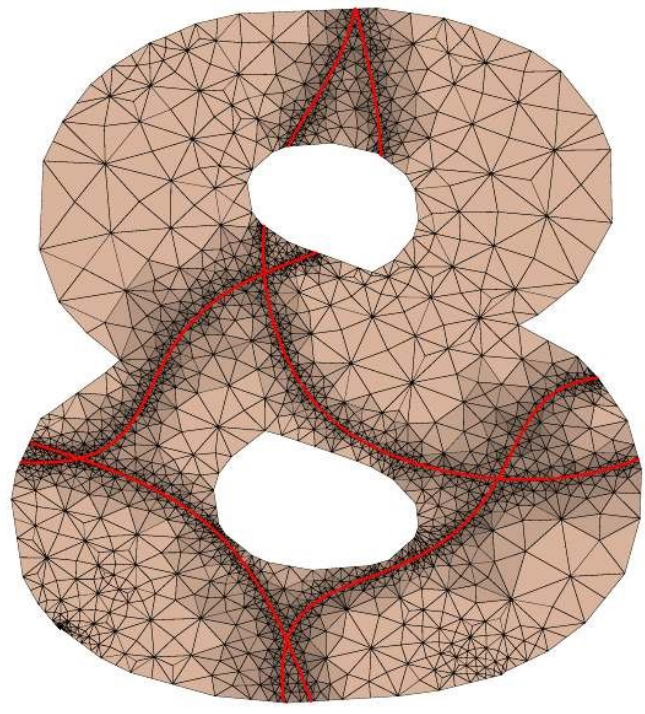

(b) Malha refinada com a curva.

Figura $28-$ Curvaimplícita dada por $(x y+\cos (x+y))(x y+\sin (x+y))=0$. 


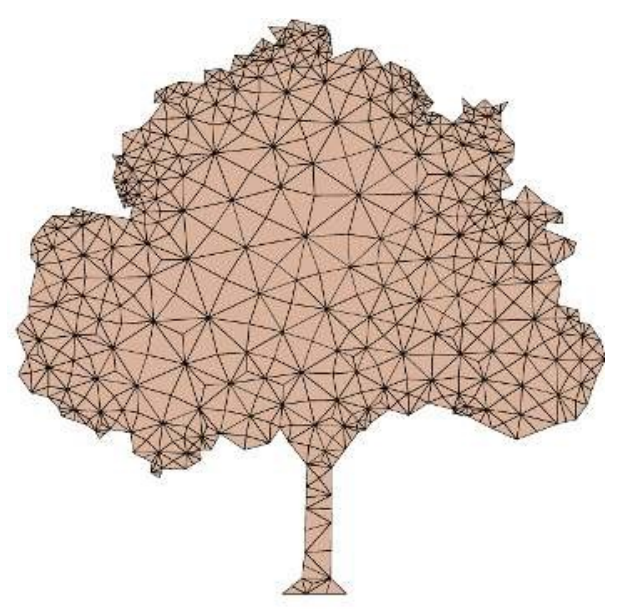

(a) Malha Inicial (Eight).

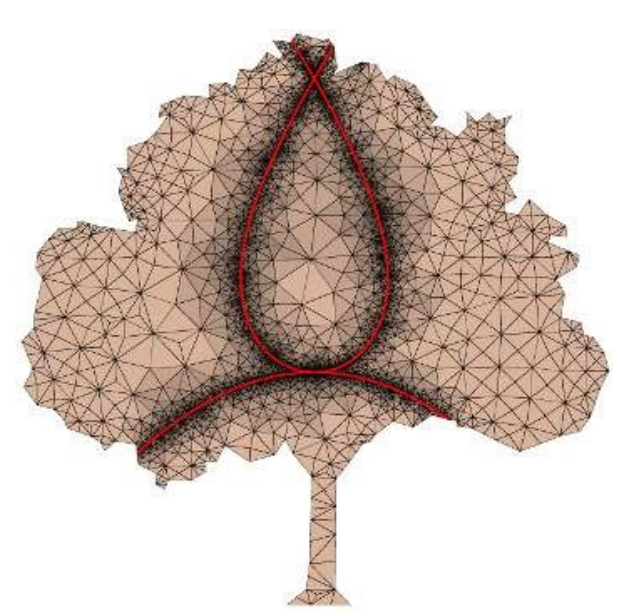

(b) Mal ha refinada com a curva.

Figura $29-$ Curva implícita dada por $(x y+\cos (x+y))(x y+\sin (x+y))=0$.

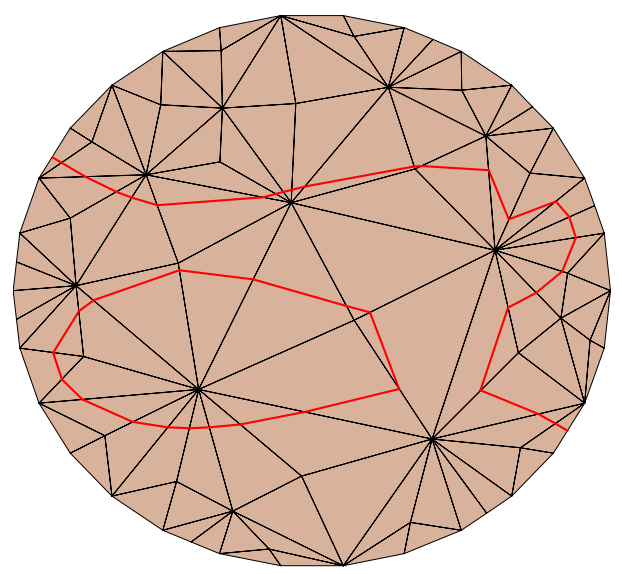

(a)

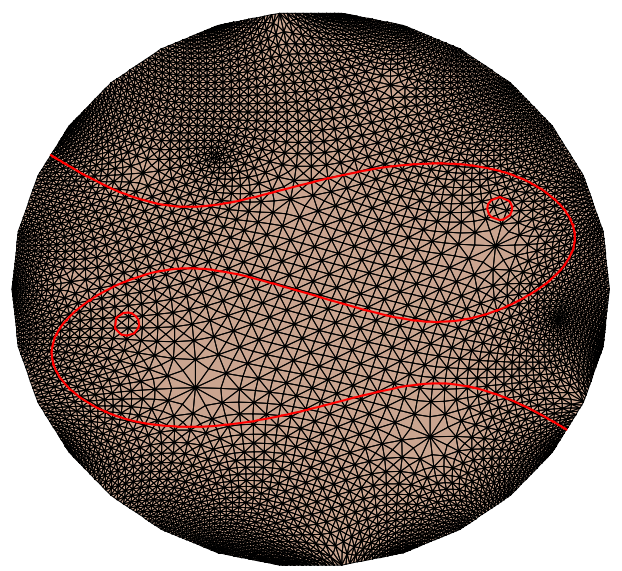

(b)

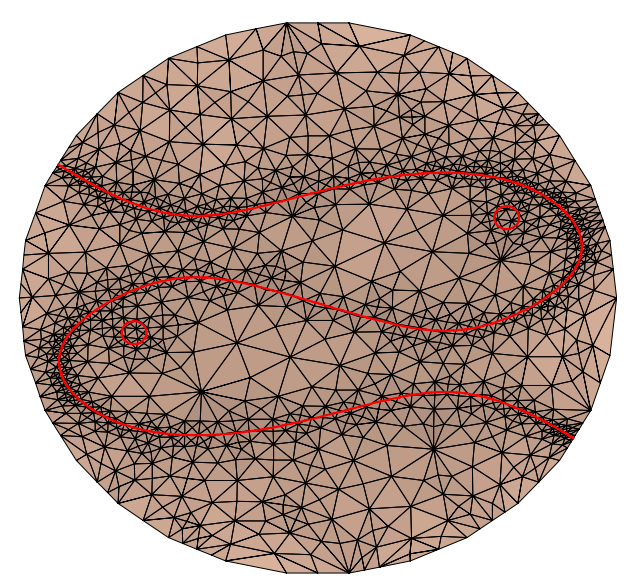

(c)

Figura 30 - Logotipo Pisces (http://www.geom.umn.edu/ fjw/pisces/). (a) O algoritmo de marching cubes gera uma curva com topologia errada na mal ha de 101 triangul os e (b) só produz um resultado satisfatório com a mal ha de 12928 triangul os. (c) utilizando adaptatividade obtem-se um bom resultado com 2382 triangulos. 


\subsection{Resultados em Malhas Triangulares 3D}

A Tabela 5 lista as estatísticas de vários exemplos de aproximações de diferentes curvas em diferentes mal has 3D. Esta tabel a apresenta a mesma configuração da Tabel a 5. Os resultados foram gerados em uma máquina Intel Core i7 2.4 GHz com 8GB de RAM.

\begin{tabular}{|c|c|c|c|c|c|c|c|}
\hline Fig. & Curva & Malha & Prof. & $\mathrm{Y}$ & $\triangle$ iniciais & $\triangle$ finais & tempo \\
\hline \hline 31b & Sin & Dinosaur & 4 & $1 \times 10^{-4}$ & 1852 & 21073 & 315 \\
32b & Knot Curve & Lauranna & 4 & $1 \times 10^{-4}$ & 7817 & 12604 & 250 \\
33b & Curve1 & Teapot & 3 & $1 \times 10^{-4}$ & 1962 & 10902 & 112 \\
34b & TwoCircles & Gorilla & 5 & $1 \times 10^{-4}$ & 8474 & 12898 & 487 \\
35b & Harmonic 0 & Sphere & 4 & $1 \times 10^{-4}$ & 1536 & 7382 & 237 \\
35c & Harmonic 1 & Sphere & 4 & $1 \times 10^{-4}$ & 1536 & 8586 & 215 \\
35d & Harmonic 2 & Sphere & 6 & $1 \times 10^{-4}$ & 1536 & 19612 & 574 \\
35e & Harmonic 3 & Sphere & 6 & $1 \times 10^{-4}$ & 1536 & 18718 & 523 \\
35f & Harmonic 4 & Sphere & 7 & $1 \times 10^{-4}$ & 1536 & 26808 & 924 \\
36c & Sphere & Bitorus & 3 & $1 \times 10^{-4}$ & 3386 & 5974 & 125 \\
37b & Cylinder 0 & Sphere & 5 & $1 \times 10^{-4}$ & 1536 & 3300 & 91 \\
37d & Cylinder 1 & Sphere & 9 & $1 \times 10^{-4}$ & 1536 & 11856 & 418 \\
37f & Cylinder 2 & Sphere & 5 & $1 \times 10^{-4}$ & 1536 & 4984 & 116 \\
38a & Hiperboloide & Klein Bottle & 3 & $1 \times 10^{-4}$ & 800 & 4463 & 29 \\
38b & Hiperboloide & Klein Bottle & 10 & $1 \times 10^{-4}$ & 8 & 4890 & 37 \\
\hline
\end{tabular}

Tabela 5 - Resultados produzidos pelo Algoritmo 2 para Mal has Triangulares 3D.

As Figuras 31, 32 e 33 são exemplos produzi dos através do refinamento MP enquanto no restante utilizou-se refinamento 4-8. Nos exemplos de intersecções com superfícies 3D, a superfície pode ser vista na cor azul e foi aproximada com o algoritmo Marching Cubes (LORENSEN; CLINE, 1987) (Figuras 36 e 37 ).

Harmônicos esféricos são a porção angular de um conjunto de soluções da equação de Laplace $(\Delta \phi=0)$. Representados em coordenadas esférias, os harmônicos esféricos de Laplace $Y_{1}^{m}$ são um conjunto específico de harmônicos esféricos que formam um sistema ortogonal (os elementos deste conjunto também são chamados de auto-funcões). As curvas da Figura 35 são resul tados de intersecções de uma esfera com os harmôni cos esféricos reai s:

- Harmonic $0: Y_{4}^{0}=\frac{3}{16} \frac{\overline{1}}{\pi} \frac{\left(35 z^{4}-30 z^{2} r^{2}+3 r^{4}\right)}{r^{4}}$ (Figura 35b)

- Harmonic 1:i $\frac{\mathrm{q}}{\frac{1}{2}}\left(Y_{4}^{-1}+Y_{4}^{1}\right)=\frac{3}{4} \frac{\mathrm{q}}{\frac{5}{2 \pi}} \frac{\left(y z\left(7 z^{2}-3 r^{2}\right)\right.}{r^{4}}$ (Figura 35c)

- Harmonic 2: $\frac{\mathrm{q}}{\frac{1}{2}}\left(Y_{4}^{-2}+Y_{4}^{2}\right)=\frac{3}{8} \frac{\overline{5}}{\frac{5}{\pi}} \frac{\left(\left(x^{2}-y^{2}\right)\left(7 z^{2}-r^{2}\right)\right)}{r^{4}}$ (Figura 35d)

- Harmonic 3:i $\frac{1}{2}\left(Y_{4}^{-3}+Y_{4}^{3}\right)=\frac{3}{4} \frac{q}{\frac{35}{2 \pi}} \frac{\left(y z\left(3 x^{2}-y^{2}\right)\right.}{r^{4}}$ (Figura 35e)

- Harmonic 4: ${ }^{q} \frac{1}{2}\left(Y_{4}^{-4}+Y_{4}^{4}\right)=\frac{3}{16} \frac{q}{\frac{35}{\pi}} \frac{\left(x^{2}\left(x^{2}-3 y^{2}\right)-y^{2}\left(3 x^{2}-y^{2}\right)\right)}{r^{4}}$ (Figura 35f) 
A Figura 38 mostra a intersecção de uma superfície implícita com um uma superfície definida no domínio paramétrico. Para fins de comparação, uma mal ha triangular representando a superfície paramétrica foi gerada para que a intersecção fosse cal culada tanto sob a malha quanto no domínio paramétrico.
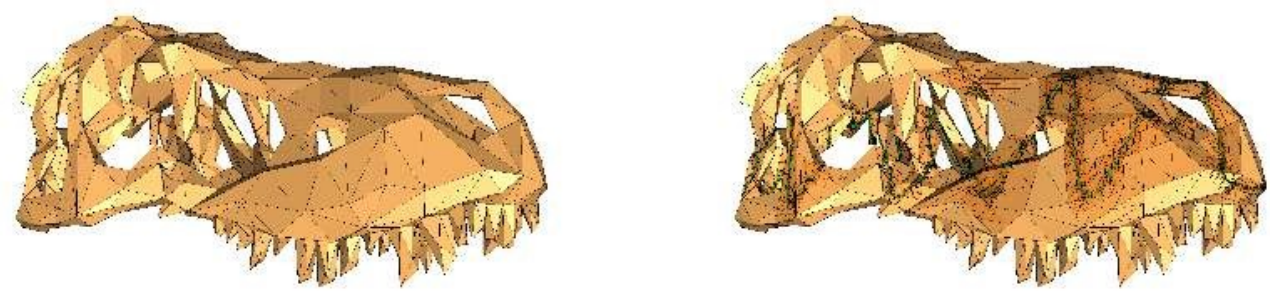

(a) Malha Inicial (Dinosaur).

(b) Mal ha refinada com a curva.

Figura $31-$ Curva implícita dada por $y-3 \operatorname{sen} x=0$.

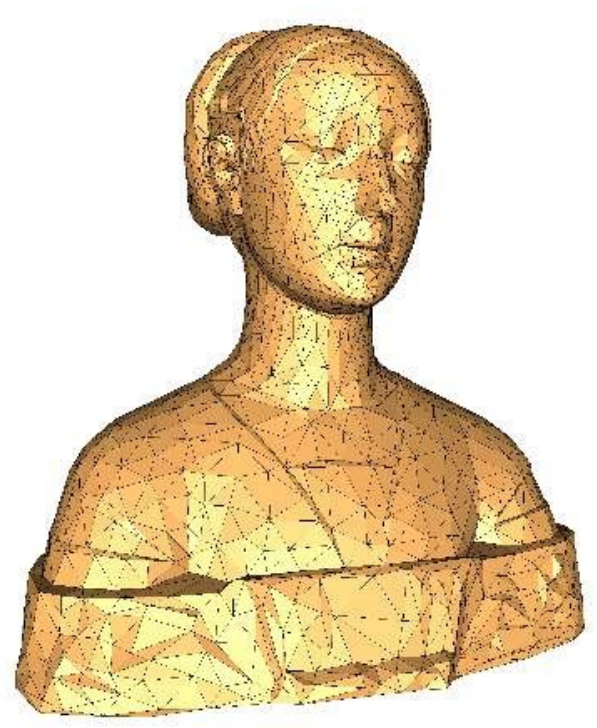

(a) Mal ha Inicial (Lauranna).

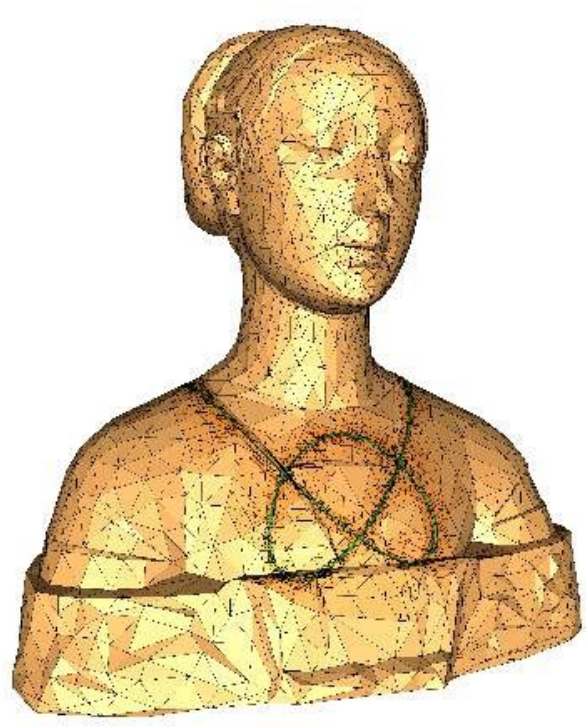

(b) Mal ha refinada com a curva.

Figura $32-$ Curva implícita dada por $\mathrm{y}^{2}(3+2 \mathrm{y})-\left(\mathrm{x}^{2}-1\right)^{2}=0$. 

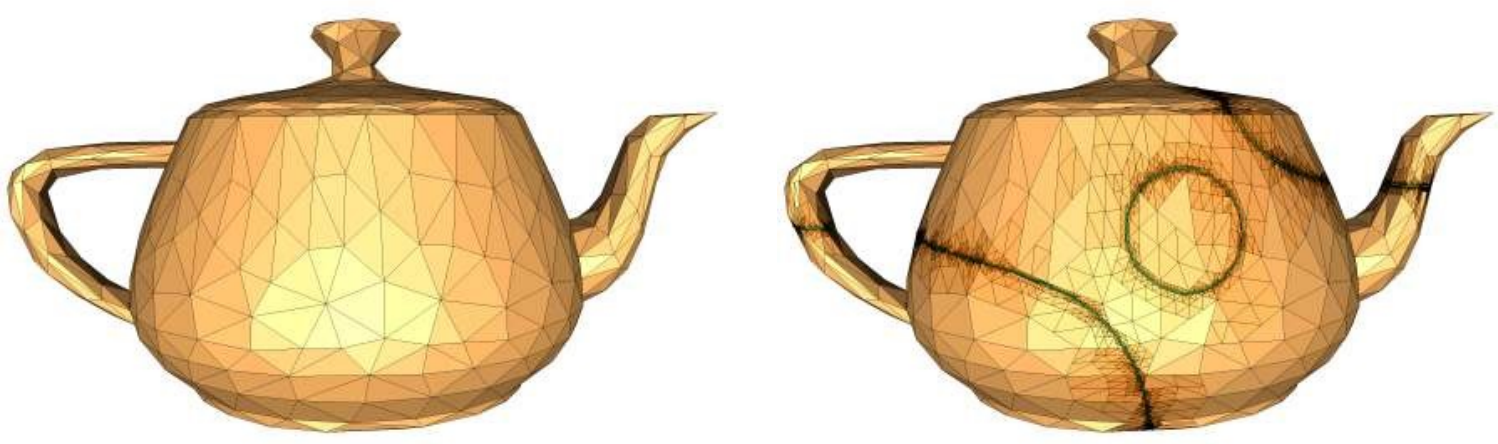

(a) Malha Inicial (Teapot).

(b) Mal ha refinada com a curva.

Figura $33-$ Curva implícita dada por $(x y-2)\left(x^{2}+y^{2}-1\right)=0$.

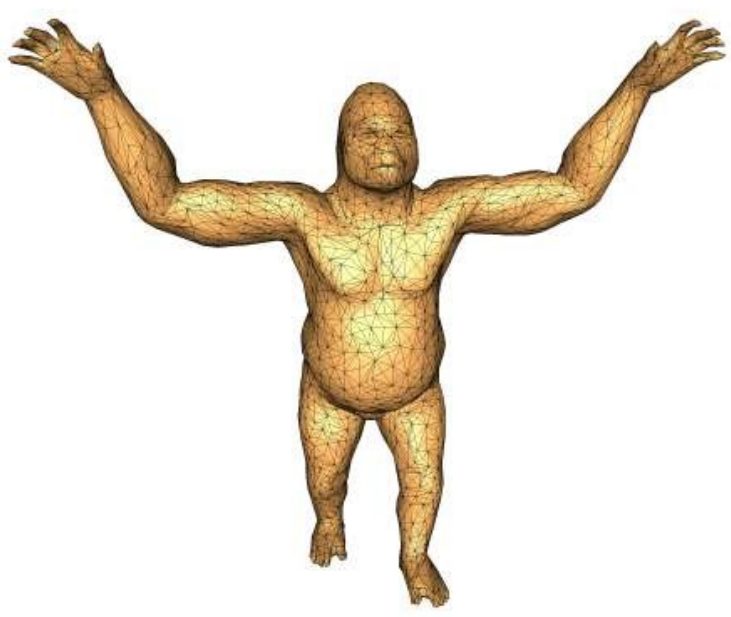

(a) Mal ha Inicial (Gorilla).

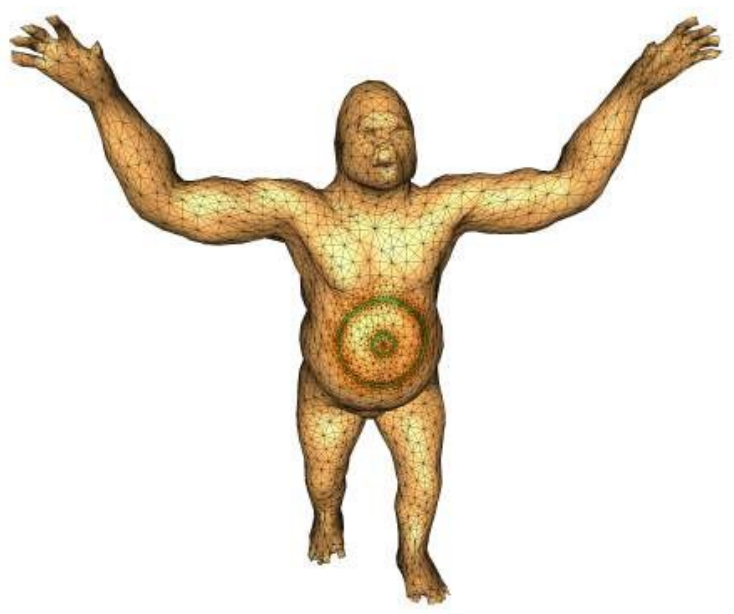

(b) Mal ha refinada com a curva.

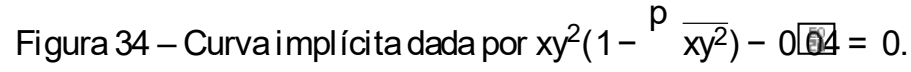

\subsection{Considerações Finais}

Existem al gumas limitações para a técnica proposta. Tal vez a mais crucial seja quando a curva a ser aproximada apresenta pontos de singularidade. Nestes pontos, a distâncias das retas geradas pel as fai xas afim é grande. Desta forma, dependendo do val or de y escol hido, a recursão em cima do ponto de singularidade continuará e será limi tada pela precisão computacional. Por conta di sto, como é utilizado o método da bisseção para o cál culo dos segmentos de reta, o val or da função nos vértices dos triângul os é mui to pequena e a ligação entre os segmentos já não é mais garantida (são limitações que surgem por conta do marching triangles). 

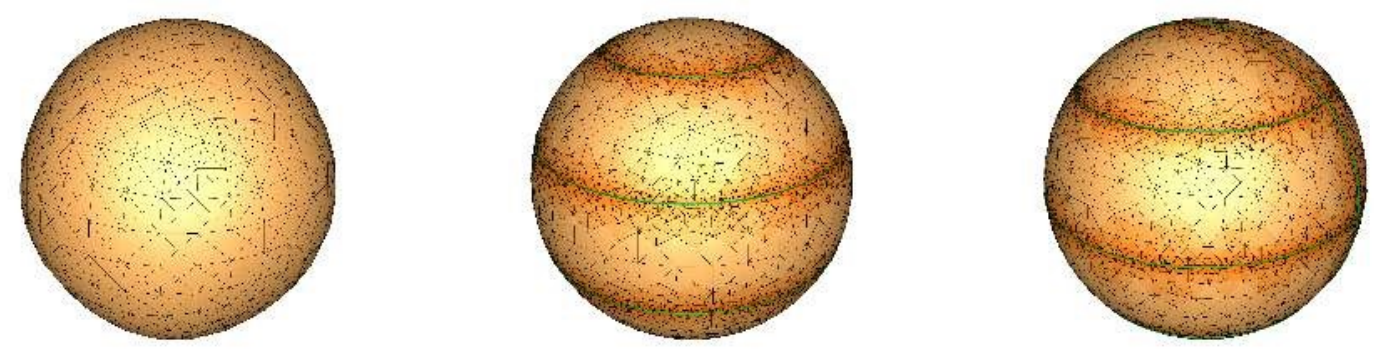

(a) Malha Inicial (Sphere).

(b) Harmônico 0.

(c) Harmônico 1.
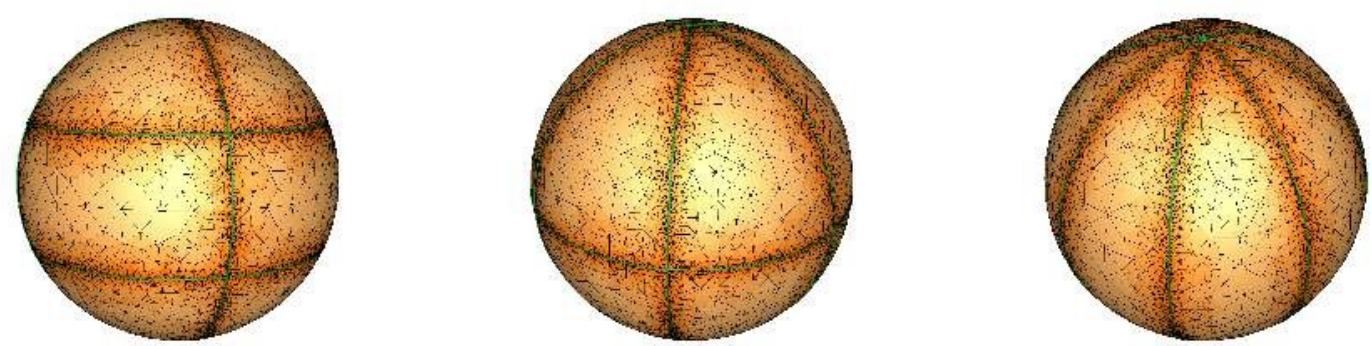

(d) Harmônico 2.

(e) Harmônico 3.

(f) Harmônico 4.

Figura 35 - Intersecção da esfera com harmônicos esféricos reais.

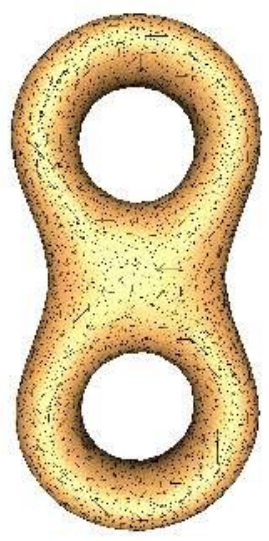

(a) Malha Inicial (Bitorus).

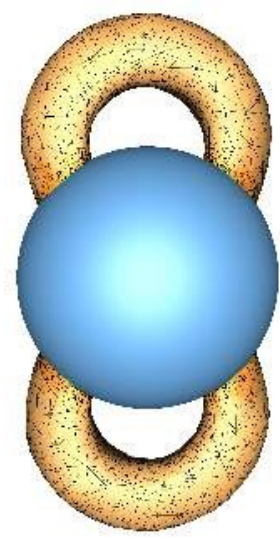

(b) Superfície impl ícita.

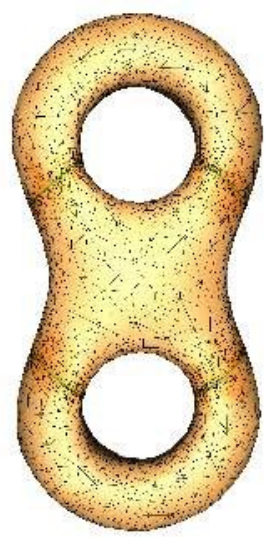

(c) Malha refinada com a curva.

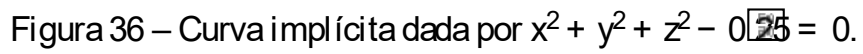




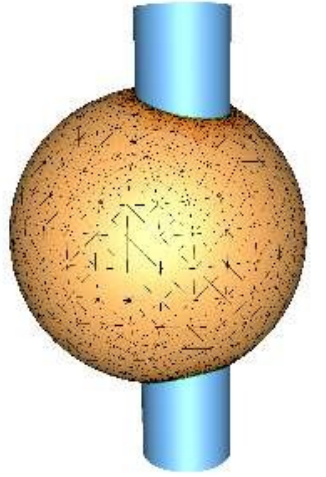

(a) Superfície impl ícita para $a=0$

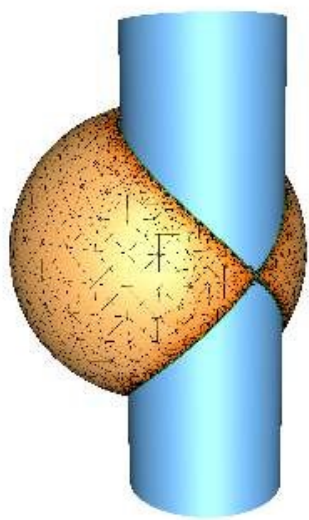

(c) Superfície impl ícita para $a=10$

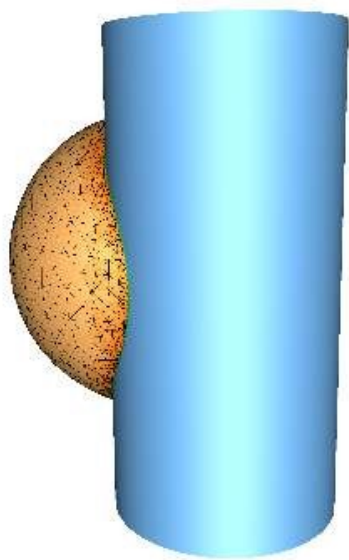

(e) Superfície impl ícita para $=15$

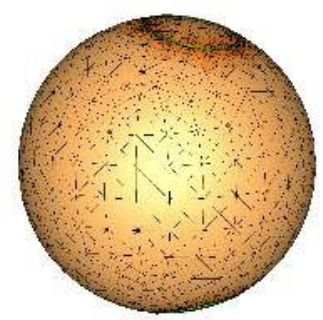

(b) Mal ha refinada com a curva.

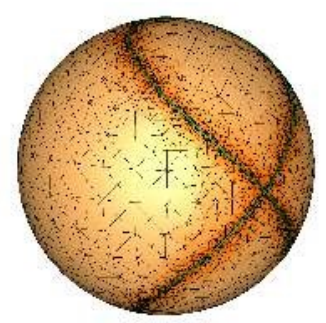

(d) Mal ha refinada com a curva.

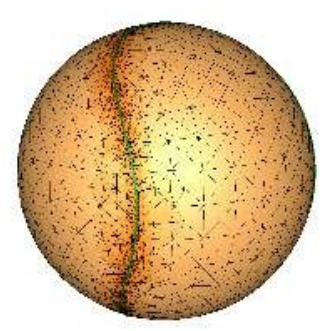

Figura 37 - Curvas implícitas dadas pela Esfera e $(x-a)^{2}+y^{2}-a^{2}=0$ com diferentes val ores de a. 

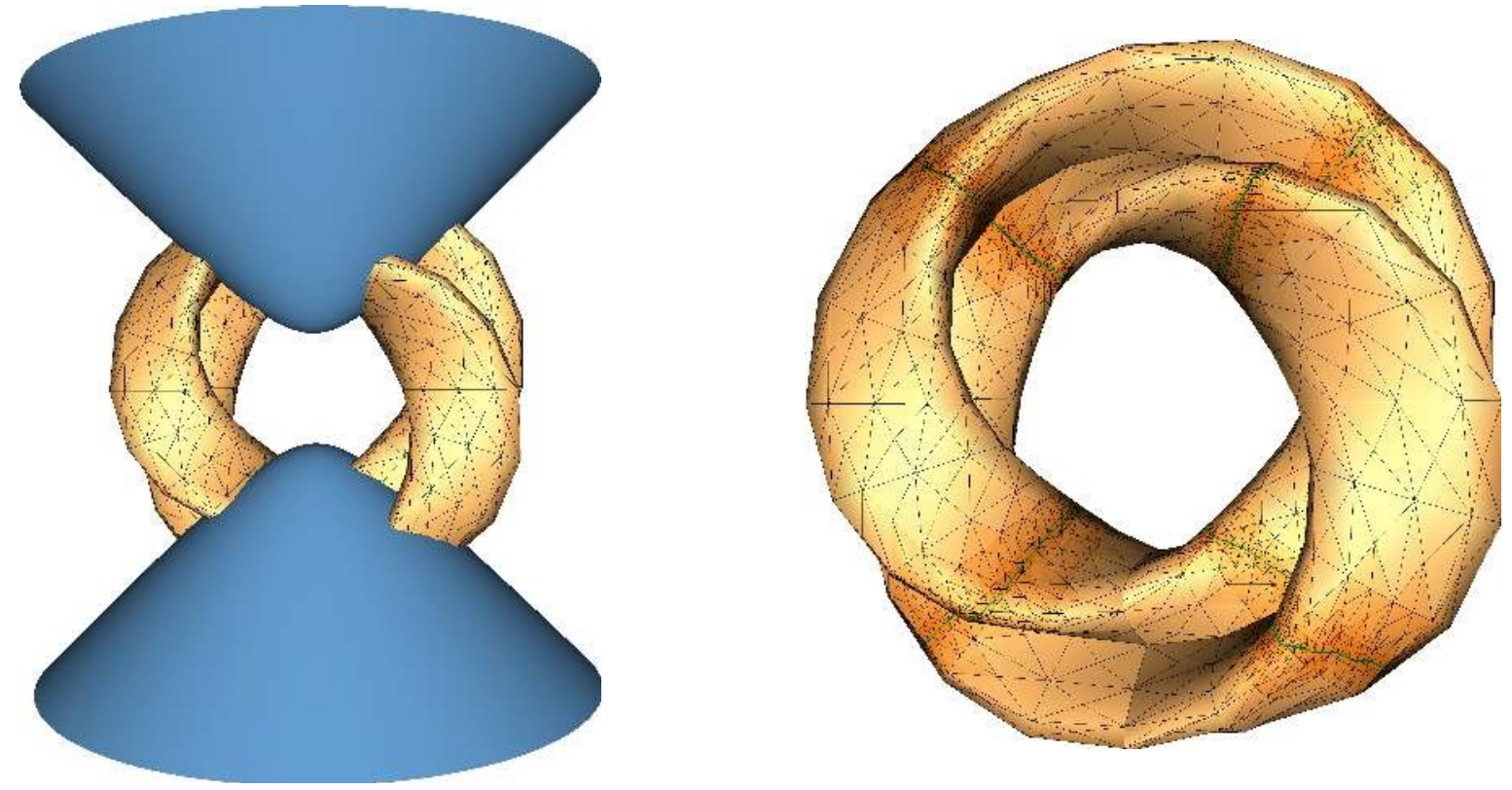

(a) Curva cal culada na mal ha triangular.
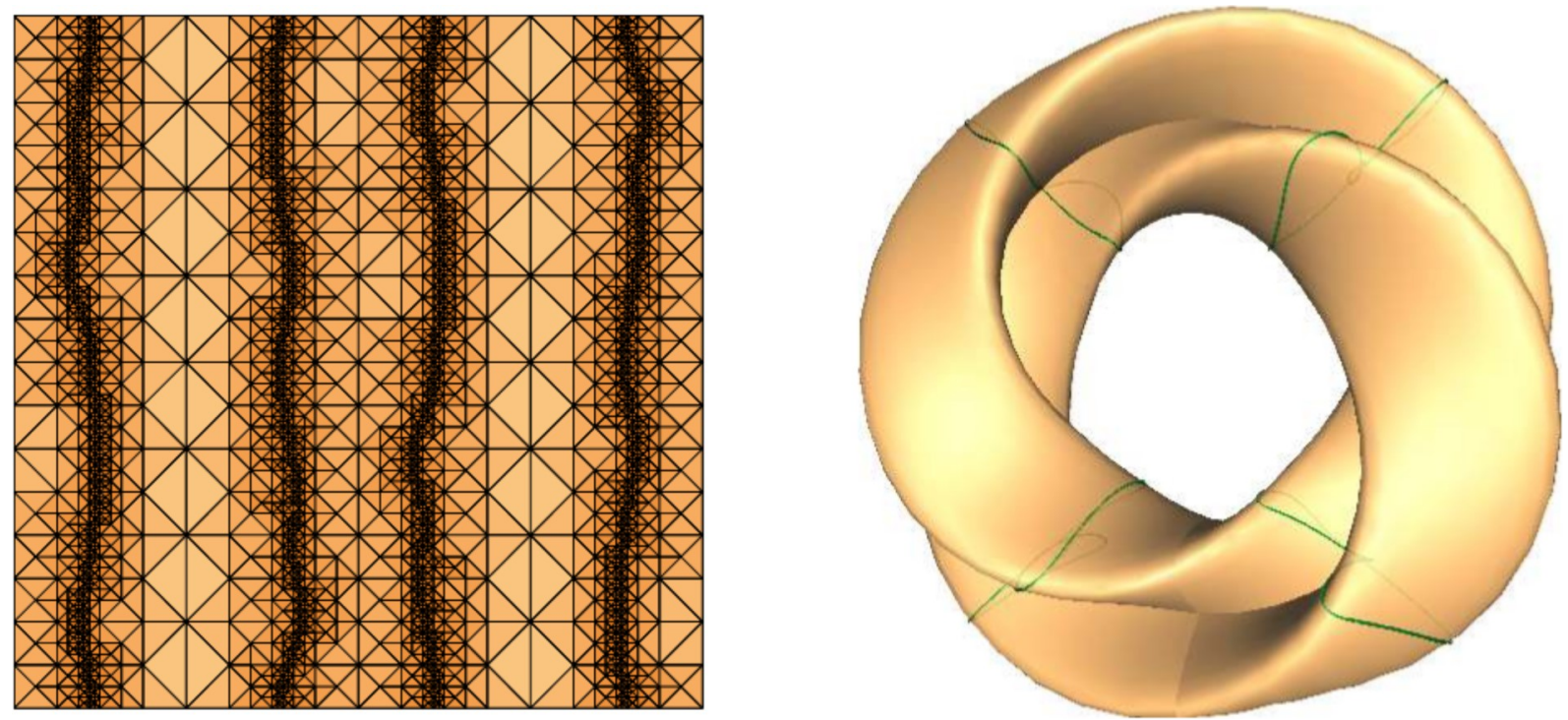

(b) Curva cal cul ada di retamente no domínio paramétrico.

Figura 38 - Intersecção entre o hiperboloide dado pela equação $x^{2}-y^{2}-z^{2}=1$ e a superfície paramé trica definida por $x(u$ 间 $)=(a+\cos (u) \sin (v)-\sin (u) \sin (2 v)) \cos (u), y(u$ 间 $)=(a+\cos (u) \sin (v)-$ $\sin (u) \sin (2 v)) \sin (u), z\left(u[v)=\sin (u) \sin (v)+\cos (u) \sin (2 v)\right.$, onde $a=27 \mathrm{7t}\left(u\left[V_{v}\right] \in[0[2 \pi) \times[0[2 \pi)\right.$.

A Figura 39 ilustra um ponto de singularidade, onde os segmentos da curva de cor vermel ha representam locais que devem ser refinados ainda. Note que pelo método a região deverá ser refinada continuamente, porém serálimitada pela precisão do hardware. Desta forma, o código permite que o usuário opte pela bi-coloração da curva, a fim de visual mente identificar porções da curva que o método exige refinamento, e por fim identificar possíveis pontos de singularidade.

Existe um estudo feito sobre a largura da faixa afim gerada pela AA de acordo com os ângul os formados pelas arestas dos triangulo. $\mathrm{Na}$ Figura $40 \mathrm{a}$, triângul os com o ângul os do vértice 


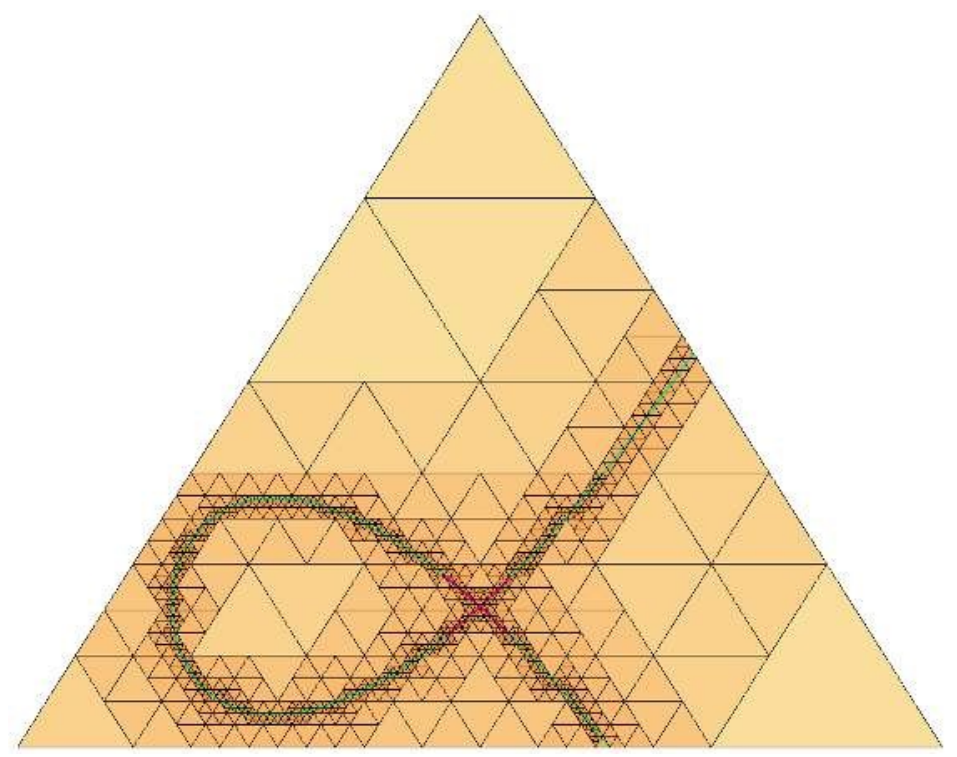

Figura 39 - Ponto de singularidade.

superior iguais a $15^{\circ}, 45^{\circ}$ e $60^{\circ}$ são intersectados com uma parábola. É possível notar a variação do comprimento da fai xa afim a medi da que o angul o aumenta. Já na Figura 40b, o mesmo é feito com a função cosseno, porém neste caso a largura da faixa não se al tera entre os 3 triângul os. 

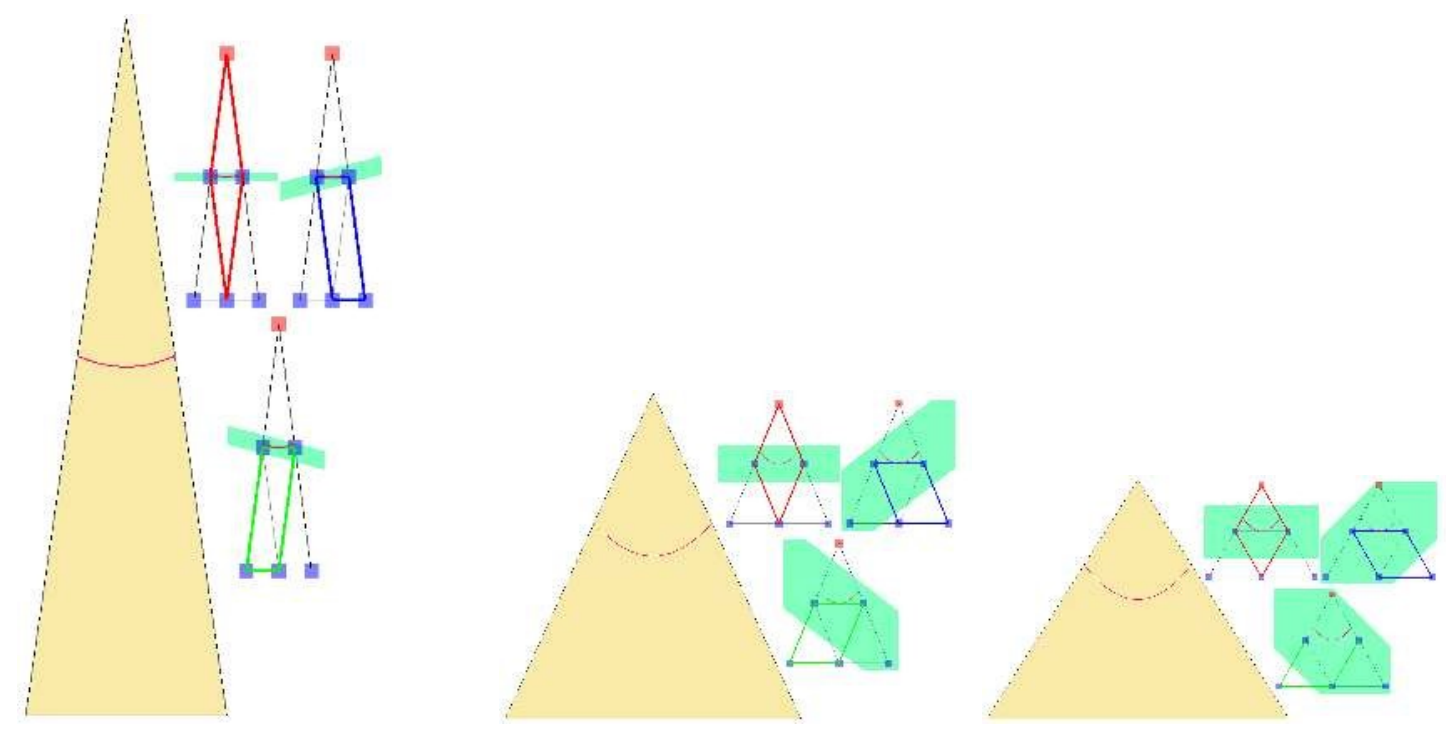

(a) Função $y=04 x^{2}$.
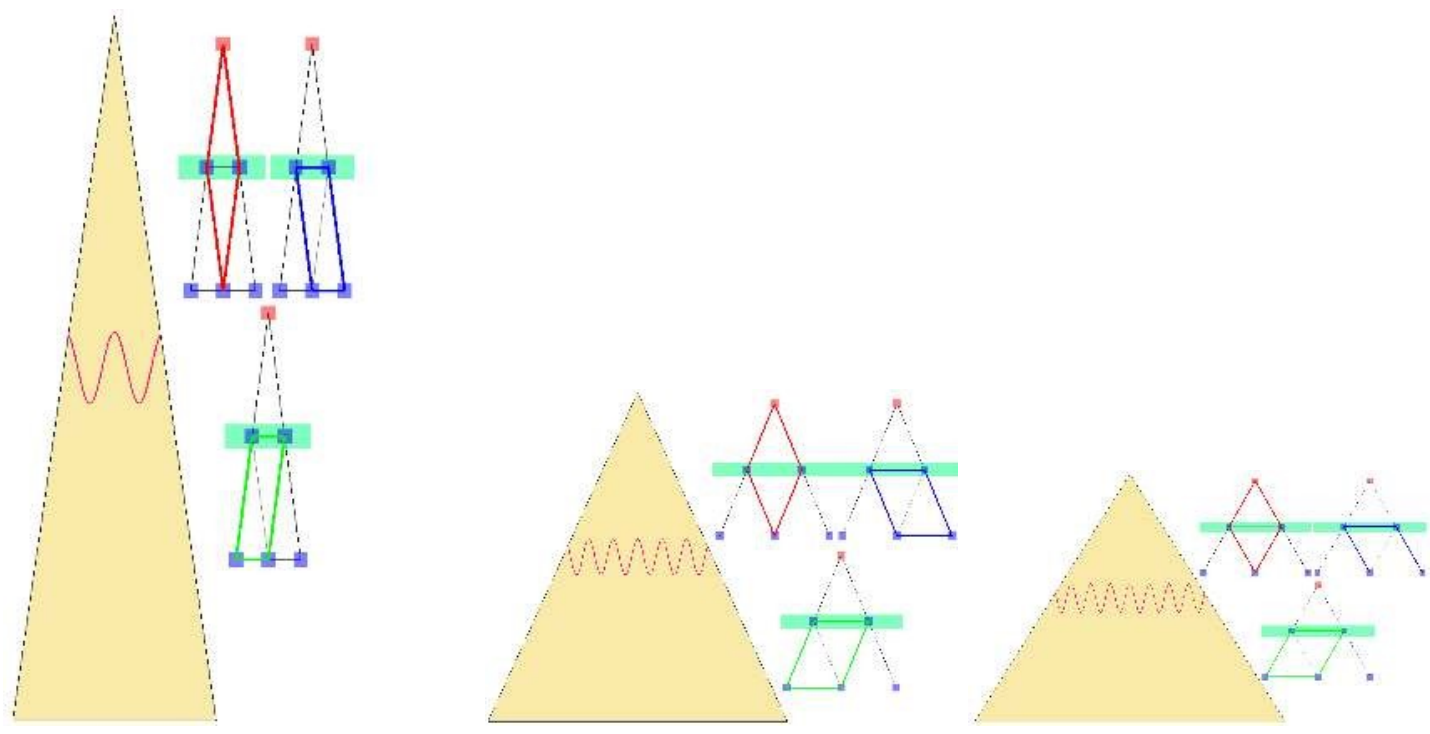

(b) Função $y=0$ 5icos $(10 x)$.

Figura 40 - Variação do comprimento da faixa afim para diferentes ângul os do vértice superior e diferentes funções para cada um dos paral el ogramos que dividem o triângulo. 


\section{TRABALHOS COM PLEMENTARES}

\subsection{Imagens ConAáveis de Curvas Implícitas}

Os métodos descritos nos capítul os anteriores buscam efi ciência na aproximação poligonal de curvas implícitas através da enumeração adaptativa. Os al goritmos propostos utilizam apenas informações locais ao processar cada célula - a aproximação da curva impl ícita dentro de uma cél ula não necessi ta de informações de outras célul as da decomposição para ser feita. Esta característica possi bilita uma execução em paral el o do al goritmo.

Hoje em dia, uma placa de processamento gráfico (GPU - Graphics Processing Unit) di spõe de centenas de processadores permitindo a execução paral el a de al goritmos, o que permite o uso de um número mai or de células na decomposição do domínio. O número de célul as pode ser escol hido de tal maneira que se produza uma imagem da curva implícita com resolução a nível de pixel.

Uma imagem de uma região retangular de um domínio $\Omega$ pode ser obtida pelo método de enumeração através da decomposição da região por uma mal ha regular da qual cada célula corresponde a pixel s e a cada pixel é atribuída uma cor. Normal mente, a cor do pixel é atribuída de acordo com o valor da função impl ícita em seu centro. Porém, para que uma imagem seja confiável, a cor do pixel deve ser baseada no val or da função implícita em toda a região do pixel. Por exemplo, se branco significa que o val or da função é positivo, então um pixel branco deve garantir que toda região que cobre tem valor positivo como resultado da função. A melhor imagem é, então, a imagem cuja resolução é igual à resol ução da decomposição do domínio, onde cada cél ul a corresponde a apenas um pixel.

O uso de métodos intervalares como a Al permite a atribuição robusta de cores para pixels em imagens construídas a partir da decomposição regular do domínio. Podem-se definir 3 cores para a imagem: preto, onde a função tem val or negativo, branco para regiões positivas e vermelho para regiões que contém o zero. Mais precisamente, a cor vermelha representará regiões 
onde a curva impl ícita se encontra e por sua vez serão os pixels que defini rão a aproximação da curva implícita.

O uso da GPU permite definir uma função de inclusão (descrita na seção 3.2) para cada pixel de uma imagem a fim de produzir uma imagem confiável de uma curva implícita. As dimensões de cada pixel são cal culadas de acordo com o domínio escol hido e utilizadas, em conjunto com a posição do pixel, para definir os interval os em cada pixel. A função implícita é então cal culada com Al em cada pixel e através da análise do intervalo resul tante, a cor do pixel é definida. Se o intervalo inteiro é negativo, o pixel é pintado de preto. Se o interval o é inteiramente positivo, o pixel é pintado de branco. Caso contrário o pixel é pintado de vermelho representando a presença do zero.

Este al goritmo pode ser executado através da aplicação desenvolvida para o projeto que se encontra no website <ht t p: / / f i l i pecn. gi t hub. i o/ VebG- Tool s/ 2DOur ves. ht mh > (NASCIMENTO, 2015). A aplicação permite que o usuário digi te uma expressão al gébrica da curva implícita qual quer, defina as propriedades do domínio e visualize a imagem gerada em tempo real. A Figura 41 mostra um exempl o de uso da apl icação.
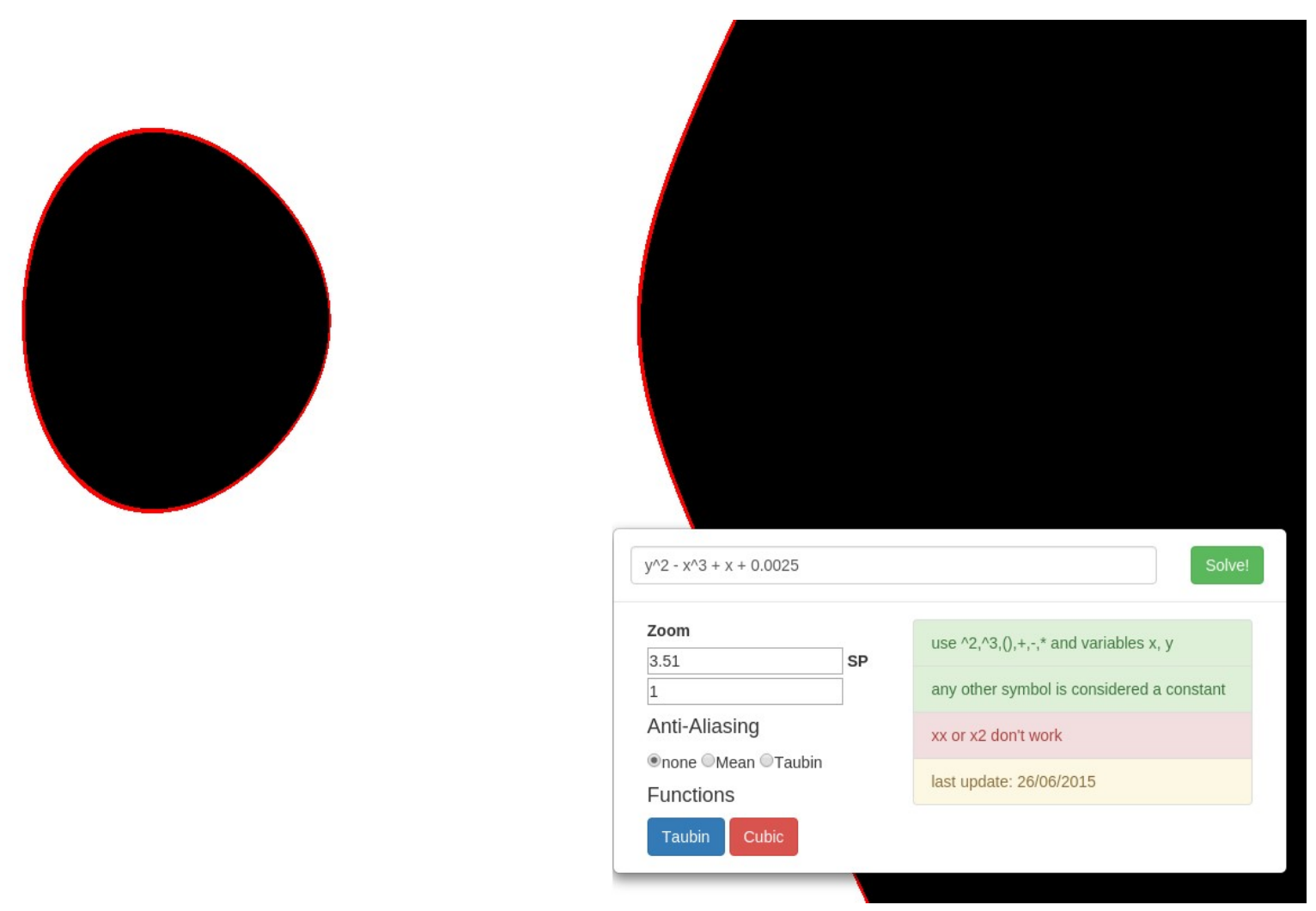

Figura 41 - Exemplo de geração de imagem confiável de uma curva implícita fornecida pelo usuário.

\subsection{Superfícies Implícitas de Conjuntos de Pontos}

Dado um conjunto de pontos $S=\left\{s_{i}\right\}_{i=1}^{N}$ que representa os $N$ pontos contidos numa superfície, uma função implícita deve ser definida de tal maneira que a superfície implícita 
represente a superfície original .

Normal mente, esta função é uma função impl ícita $f \operatorname{com}|f(p)|=d(p)$, onde d é uma função de distância. A função de distância $d(p)$ é definida como

$$
d(p)=\min _{i}\left(\left\|p-s_{i}\right\|\right) \text { 鼠 }
$$

implicando que $d(p)=0$ na frontei ra onde $p \in S$. Geometricamente, d pode ser construída como se segue. Se $p \in S$, então $d(p)=0$. Caso contrário, para um dado ponto $p$, encontre o ponto $\hat{p} \in S$ mais próximo de $p$. Então $d(p)=\|p-\hat{p}\|$.

A função $f$ é definida com $f<0$ no interior da região definida por $f=0$ e $f>0$ fora desta região. Então, $f(p)=d(p)=0$ para todo $p \in S, f(p)=-d(p)$ para todo $p$ dentro $e$ $f(p)=d(p)$ para todo $p$ fora. Dadas estas propriedades de $f$ e $\|\nabla f\|=1$, f é definida como a Função de Distância com Sinal (FDS). Uma descrição da FDS pode ser encontrada em (FEDKIW; OSHER, 2003). Um simples exemplo da FDS é baseado no Moving Least Squares (MLS) (KOLLURI, 2008). A FDS de um ponto $p$ é definida como a média ponderada envolvendo os pontos de S da seguinte maneira:

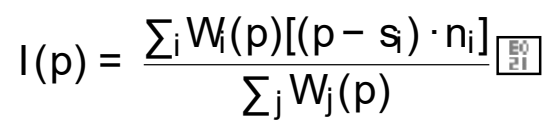

com $n_{i}$ sendo a normal da superfície em $s_{i} e W_{i}(p)=\exp \left(-\left\|p-s_{i}\right\|^{2}\left[E^{2}\right) A_{i}\right.$, onde $A_{i}$ é o número de pontos dentro de uma bola de raio $\varepsilon$ centrada em $s$, incluindo $s$.

O principal desafio ao construir funções impl ícitas para conjuntos de pontos é conseguir superfícies suaves enquanto preservando volume. Existem várias técnicas que utilizam funções implícitas mais sofisticadas baseadas em FDS que tentam atingir estes objetivos (GOMES et al ., 2009). Duas destas técni cas são:

- Técnicas baseadas em Funções de Base Radial (RBFs) (CARR et al ., 2001), que produzem um interpolador único que aproxima todos os pontos do conjunto.

- Técnicas que utilizam funções locais e são unidas por meios de partição de unidade. A partição de unidade é um conjunto de pesos locais (ou funções de peso) que somam 1 em todo o domínio. A técnica apresentada em (OHTAKE et al., 2005) utiliza o Mul tilevel Partition of Unity (MPU) em conjunto com 3 tipos de quádricas locais para reconstrução de superfícies implícitas de conjuntos grandes de pontos.

\subsubsection{Implementação}

A primeira função FDS escol hida para os experimentos foi a Equação 5.2, utilizando uma Gaussiana com função de peso:

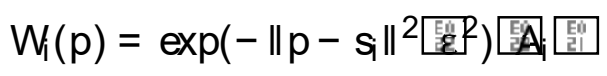


onde $A_{i}$ é o numero de pontos dentro da bola de raio $\varepsilon$ centrada no ponto $s$, incluindo $s_{i}$.

Foi implementada uma adaptação do Algoritmo 2 utilizando as Equações 5.2 e 5.3. Como conjuntos de pontos iniciais, foram utilizados pontos de curvas de contorno extraídas de imagens bi nárias (Figura 42) ou pontos gerados por equações paramétricas. A Figura 43 mostra o processo de extração de imagens binarias. Todos exemplos, Circle Test, Hand Test e Arrow Test mostrados nas Figuras 44, 45 e 46, respectivamente. A curva aproximada é composta por segmentos pintados em vermel ho e o conjunto de pontos é representado por pequenos pontos e suas normais.

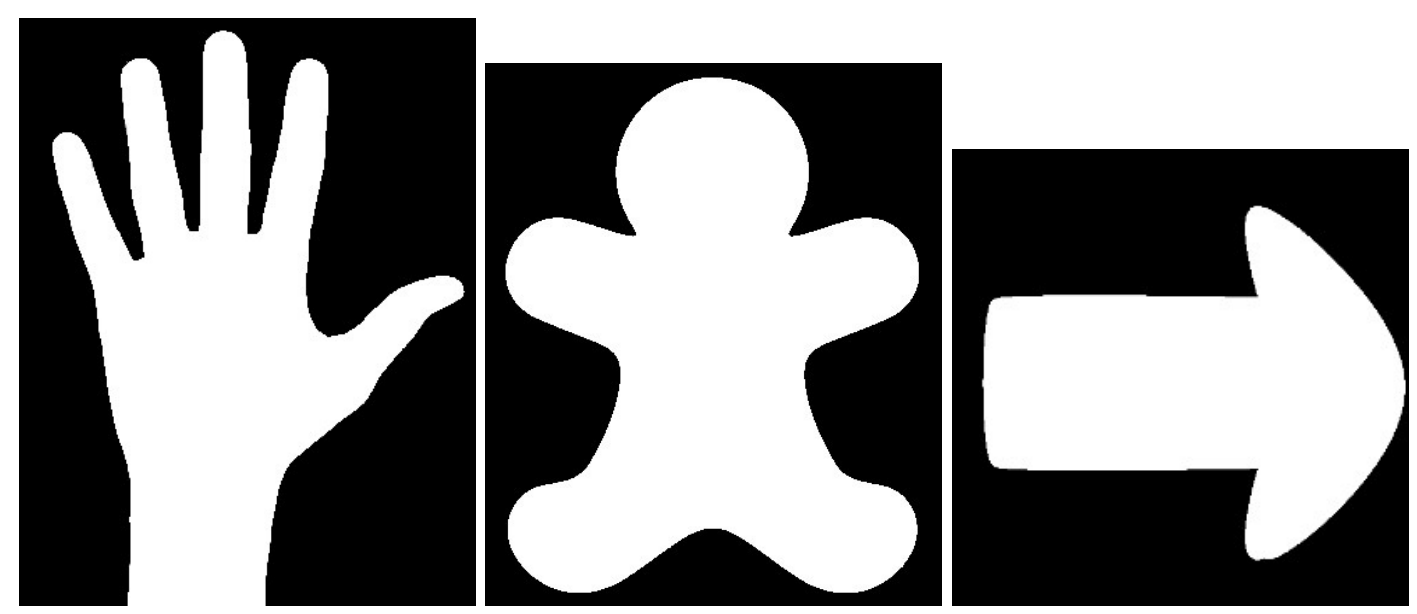

Figura 42 - Exemplos de imagens binárias usadas para construção de conjuntos de pontos.

Original: 1828 verts

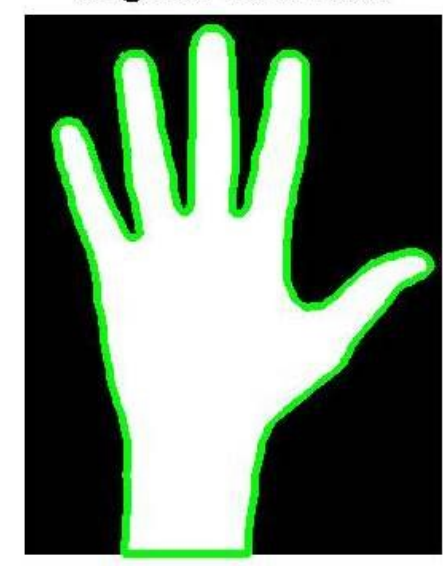

Decimated by $\times 10: 91$ verts

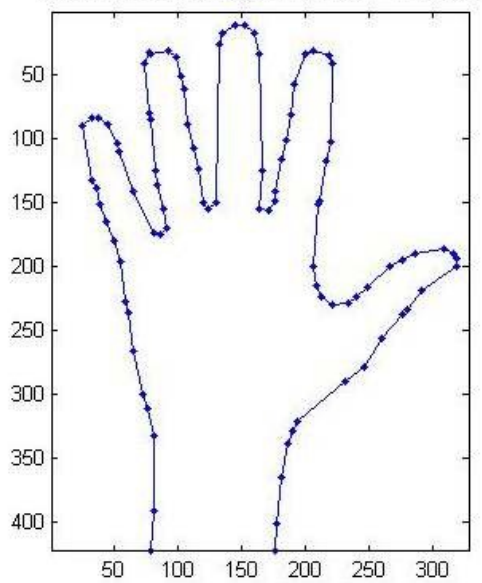

Decimated by $\times 20: 46$ verts

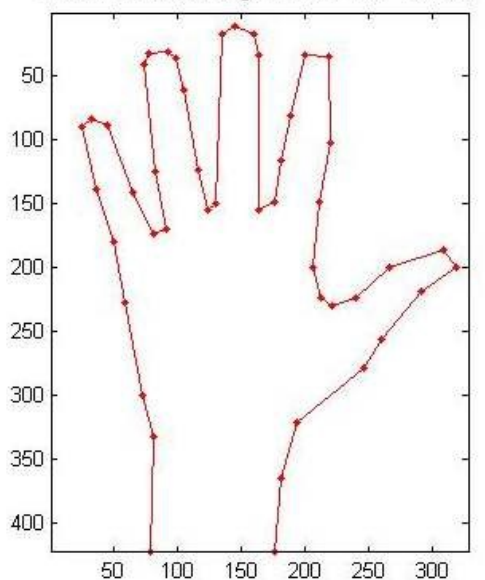

Figura 43 - O processo de construção de conjuntos de pontos a partir de imagens binarias: Primeiro, o contorno da curva é extraído pixel a pixel, onde cada pixel representa um vértice da curva e depois a curva pode ser simplificada diminuindo o número de vértices. Foi utilizado o código Deci mat e Pol ygon fornecido por (SEMECHKO, 2012).

Inicial mente os testes deram bons resul tados, o Circle Test mostrou boa adaptatividade espacial do algoritmo. O Arrow Test mostrou sinais de boa adaptatividade geométrica, mas não tão boa quanto era esperado. O Hand Test foi mais problemático, nem a adaptatividade geométrica ou espacial funcionaram. A mai or parte do domínio foi igual mente refinada, com muitas partes 


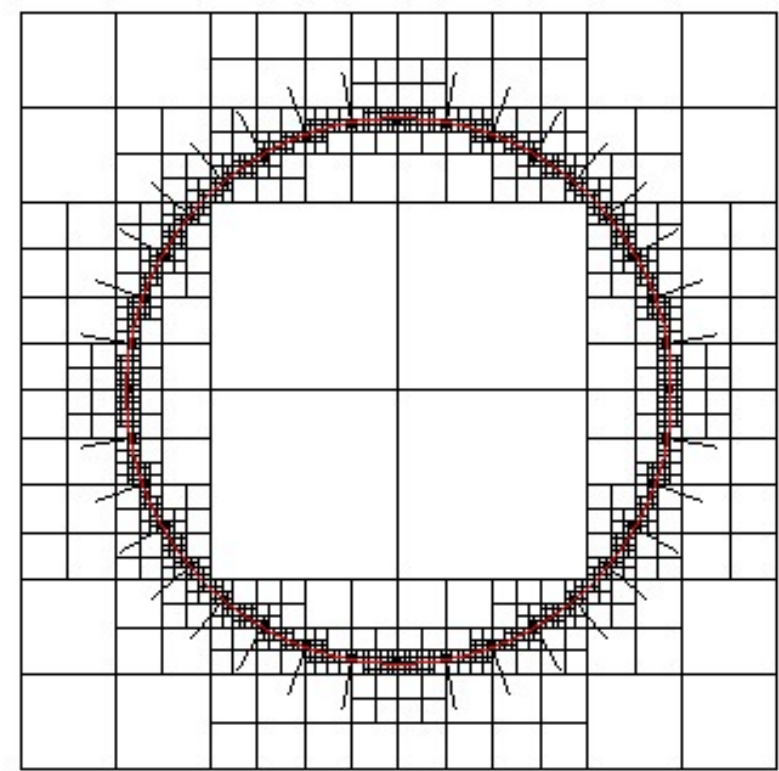

Figura 44 - Circle Test: Teste utilizando pontos gerados pela equação paramétrica do circulo.

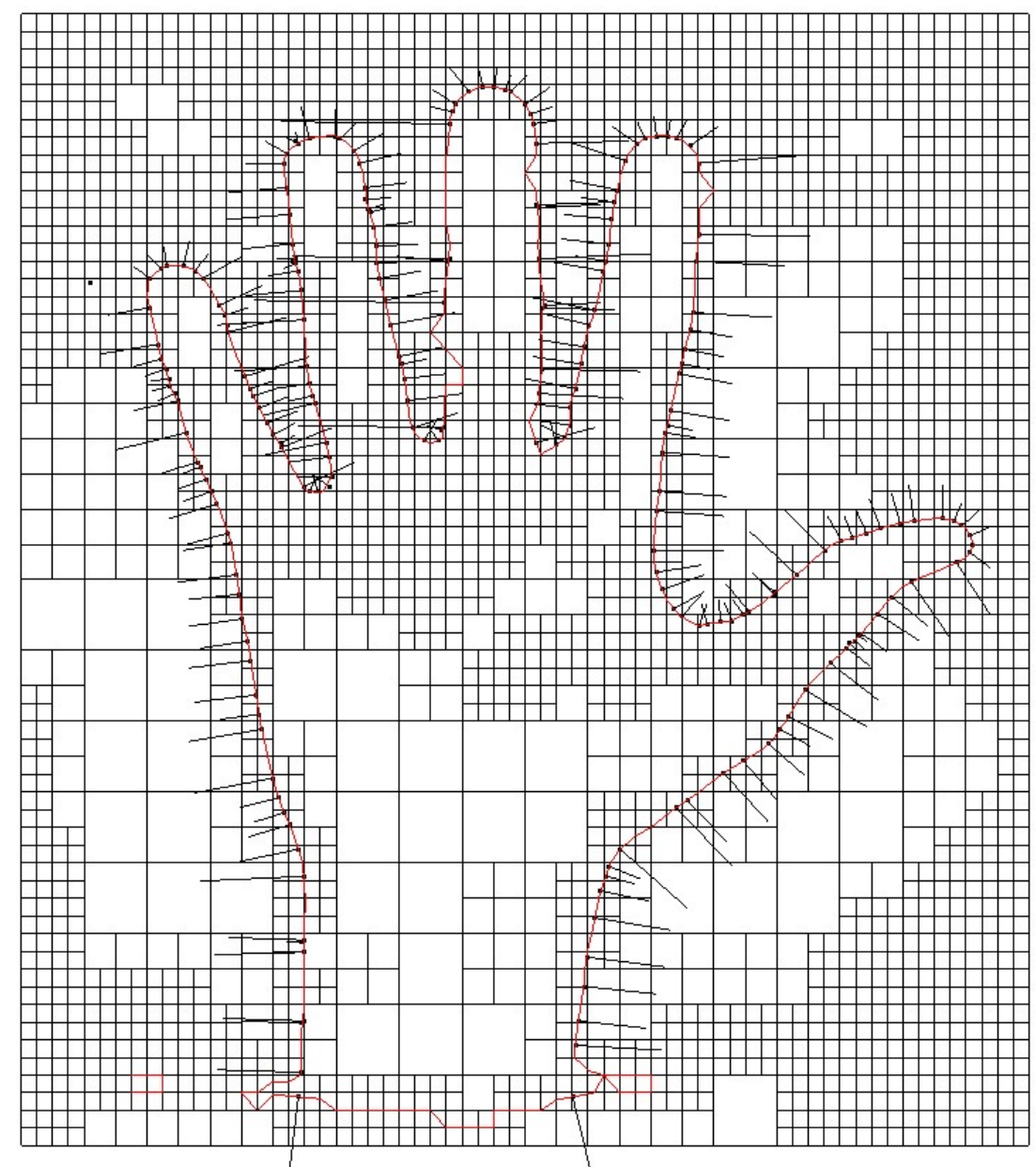

Figura 45 - Hand Test: Teste usando os pontos extraídos da imagem binaria de uma mão.

refinadas longe da curva (má adaptatividade espacial) e mesmo nas pontas dos dedos, onde existe maior variação de curvatura, o domínio não foi mais refinado (má adaptatividade geométrica). 


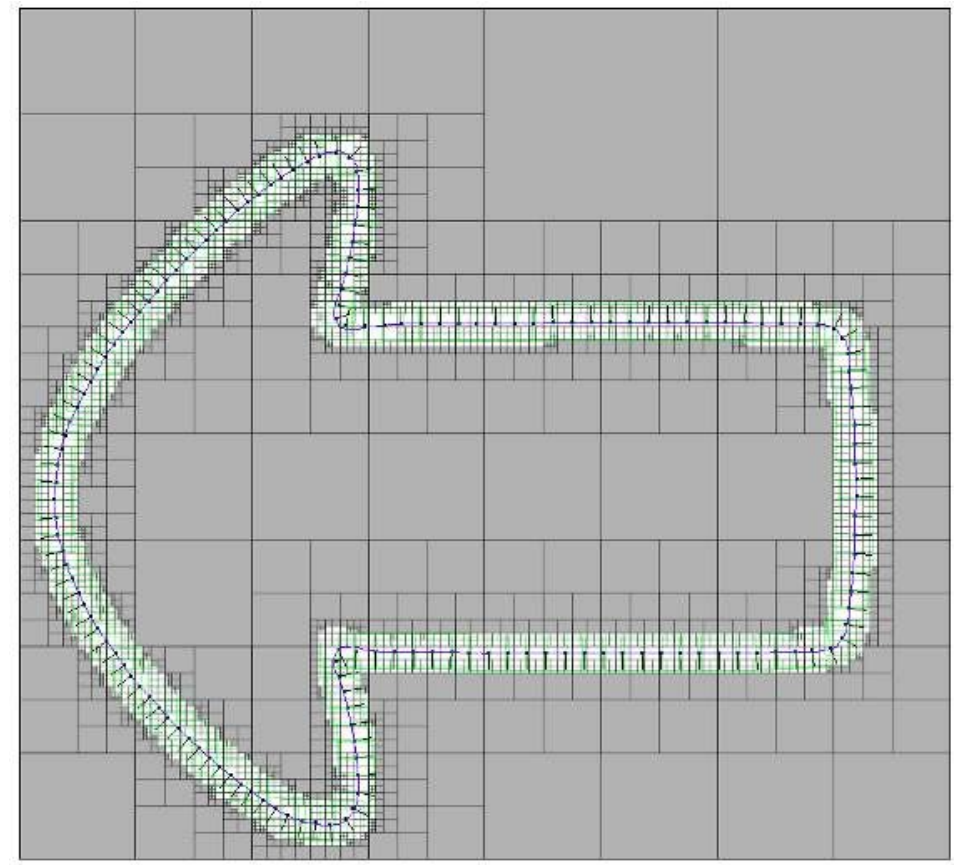

Figura 46 - Arrow Test: Teste usando os pontos extraídos da imagem binaria de uma mão. Células descartadas pela ausência da curva estão pintadas de cinza.

Mais pesquisa teve de ser feita para tentar solucionar os problemas, mas dois fatos impediram de continuar:

A função de peso (Equação 5.3) utiliza operação de raiz, por conta do cal culo da distancia Euclidiana. Como AA trabal ha com regiões de incerteza, estas regiões podem estar total ou parcial mente composta de números negativos, levando a resul tados errados para Equação 5.2. A Tabelas 6 e 7 mostram os resul tados inconsi stentes quando executando a operação de raiz em duas bibliotecas AA diferentes.

\begin{tabular}{|c|c|}
\hline func |lib & LIBAFFA \\
\hline $\mathrm{X}^{2}$ & $165+-8 e 1+05 e 2$ \\
\hline$x^{3}$ & $- 6 6 + 4 8 \sqrt { 5 e } 1 + 0 \mathrm { e } 2 + - 2 \mathrm { e } 3 + 8 \longdiv { 5 e 4 }$ \\
\hline $\bar{X}$ & - nan + - nane1 + - nane2 \\
\hline $\operatorname{expX}$ & 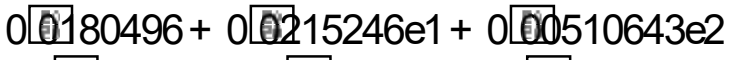 \\
\hline $\sin X$ & 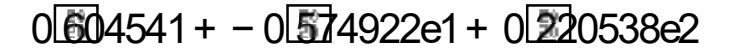 \\
\hline
\end{tabular}

Tabela 6 - Resultados com a região parcial mente negativa utilizando (GAY; COEURJOLLY; HURSTAND, 2006).

Poderia se evitar cál cul os envol vendo raiz de números negativos substituindo a Equação 5.3 por outras equações. Entretanto isto não resolve o problema. É preciso pesquisar mais a respeito para saber como tratar corretamente estes casos.

- Uma característica da AA é de gerar símbolos de ruido para toda quantidade independente (seção 2.2). Isto funciona muito bem para cal cul os que envolvem poucas quanti dades. 


\begin{tabular}{|c|c|}
\hline func|lib & AAFLIB \\
\hline $\mathrm{X}^{2}$ & $165-8 e 1-05 \mathrm{~s} 2$ \\
\hline$x^{3}$ & $- 6 9 \longdiv { 9 8 9 6 + 4 9 e 1 + 6 e 2 }$ \\
\hline $\bar{x}$ & error \\
\hline $\exp X$ & 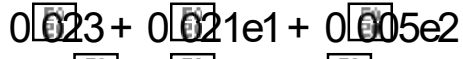 \\
\hline $\sin x$ & $06-05 \mathrm{se} 1+05 \mathrm{ee}$ \\
\hline
\end{tabular}

Tabela 7 - Resul tados com a região parcial mente negativa utilizando (IMS, 2010).

Neste caso, para cada ponto é considerada uma quantidade independente, então novos símbolos de ruido são criados. A Equação 5.2 é cal culada para cada ponto, e toda vez que isto ocorre, todo termo nesta soma gera novos símbolos. Quanto maior o conjunto de pontos, mai or o numero de símbolos necessários. Como AA armazena os símbolos global mente (mesmo para pares de pontos que não estão rel acionados di retamente ou nem mesmo fazem parte do mesmo passo da recursão), o programa encontra limitações de memoria rapidamente.

A pesquisa continuou para se obter um mel hor entendimento de AA na resolução destes problemas. Outras pessoas estão tentando resolver questões similares. Um exemplo é o trabalho de (KASHIWAGI, 2012), que propõe um modo de comprimir os símbol os de ruido, mantendo um numero fixo de símbolos, podendo ser uma solução para um dos obstáculos do projeto. Outra alternativa, é investigar o trabal ho de (CHATTOPADHYAY; PLANTINGA; VEGTER, 2012), onde propõe um novo método para cal cular FDS utilizando métodos interval ares.

Enquanto isso, tentou-se adaptar este projeto para cal cular curvas de intersecção entre conjuntos de pontos e mal has triangulares (Figura 47), uma operação importante em si tuações onde se tem diferentes tipos de elementos. Para este teste foi utilizada mal ha com refinamento 4-8. 

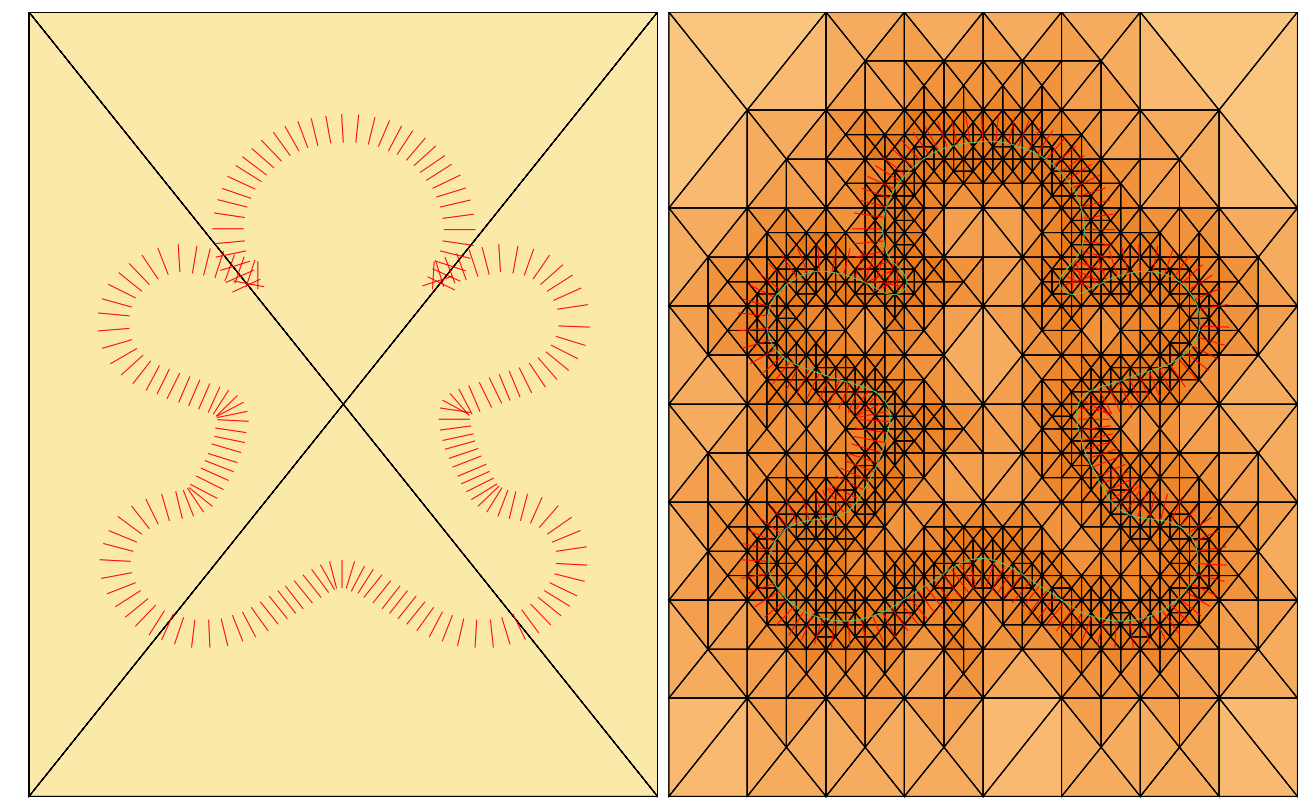

Figura 47 - Intersecção de um conjunto de pontos e uma mal ha triangular. Mal ha inicial (esquerda). Mal ha após 11 chamadas recursivas (direita). As normais dos pontos estao pintadas de vermel ho e a curva aproximada de verde. 
CAPÍTULO

6

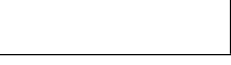

CONCLUSÕES

O projeto trata da aproximação poligonal de curvas impl ícitas em diferentes domínios. A característicaadaptativa do al goritmo permite mai or eficiência comparada às técni cas tradicionais de enumeração. O uso da ferramenta numérica AA fornece estimativas de curvatura sem exigir o cál culo de derivadas da função implícita e permite a detecção de pontos de singularidade. A AA também garante robustez ao método, característica importante em aplicações de visual ização de objetos implícitos.

O método de aproximação poligonal de curvas implícitas em mal has triangulares não depende de regras de refinamento ou estrutura da mal ha. Isto signi fica que o método pode ser aplicado a qual quer tipo de mal ha triangular independente do tipo de refinamento. Uma limitação porém, é que os resul tados podem depender da qual idade dos triângul os da decomposição inicial, a menos que o esquema de refinamento escol hido evite triângul os de má qual idade.

A maior limitação deste trabal ho está no fato de que a curva impl ícita deve ser fornecida ao método apenas em sua forma al gébrica, deixando de fora aplicações importantes como a aproximação de superfícies implícitas a partir de conjuntos de pontos. Um trabal ho foi iniciado neste sentido mas ainda sem resul tados, os experimentos ini ciais foram discutidos no seção 5.2. A solução para este problema faz parte do conjunto de trabal hos futuros do proj eto.

O trabal ho apresentado em (PAIVA et al., 2006) propõe um algoritmo robusto para aproximação de superfícies implícitas utilizando AI. Diante dos resul tados obti dos com AA para aproximação de curvas implícitas, estender este trabal ho para o uso da AA se torna uma ideia natural.

Métodos Intervalares como a AA podem ser aplicados em diversos outros tipos de problema, um exemplo é o cál culo de complexos Morse-Smale, cujo um método baseado em Al é proposto por (CHATTOPADHYAY; VEGTER; YAP, 2015). Como trabal ho futuro relacionado a este projeto de mestrado, este tema pode ser um forte candidato ao desenvol vimento de métodos baseados em AA. 
Por fim, enquanto a Al cobre apenas regiões retangulares do domínio, a AA permite a formação de paral el ogramos e outros tipos de zonotopos. Um trabal ho interessante é o estudo destas formas a fim de aplicar a AA em outros tipos de decomposição do domínio, não só no 2D como também no 3D. A cobertura de diferentes tipos de decomposição de domínio, juntamente com a possível aplicação de AA a outros tipos de objetos (ex, curvas e superfícies paramétricas), pode possibilitar o desenvolvimento de ferramentas capazes de mani pular os diferentes tipos de dados. 
CARR, J. C.; BEATSON, R. K.; CHERRIE, J. B.; MITCHELL, T. J.; FRIGHT, W. R.; MCCALLUM, B. C.; EVANS, T. R. Reconstruction and representation of 3d objects with radial basis functions. In: ACM. Proceedings of the 28th annual conference on Computer graphics and inter active techniques. [S.I.], 2001. p. 67-76. Citado na página 71.

CHATTOPADHYAY, A.; PLANTINGA, S.; VEGTER, G. Certified meshing of radial basis function based isosurfaces. The Visual Computer, Springer, v. 28, n. 5, p. 445-462, 2012. Citado na página 75.

CHATTOPADHYAY, A.; VEGTER, G.; YAP, C. Certified computation of planar morse-smale compl exes. CoRR, abs/1506.06265, 2015. Disponível em: <http://arxiv.org/abs/1506.06265>. Citado na página 77.

COMBA, J. L. D.; STOLFI, J. Affine arithmetic and its applications to computer graphics. In: Proceedings of SI BGRAPI'93. [S.I.: s.n.], 1993. p. 9-18. Citado na página 29.

DOBKIN, D. P.; LEVY, S. V. F.; THURSTON, W. P.; WILKS, A. R. Contour tracing by piecewise linear approximations. ACM Transactions on Graphics, v. 9, n. 4, p. 389-423, 1990. Citado 2 vezes nas páginas 27 e 29 .

FEDKIW, R.; OSHER, S. Level set methods and dynamic implicit surfaces. Springer, 2003. Citado na página 71.

FIGUEIREDO, L. H. de; STOLFI, J. Adaptive enumeration of implicit surfaces with affine arithmetic. Computer Graphics For um, v. 15, n. 5, p. 287-296, 1996. Citado na página 29.

. Self-Validated Numerical Methods and Applications. [S.I.]: IMPA, 1997. Citado 4 vezes nas páginas $28,31,32$ e 33 . 28 e 34.

An Introduction to Affine Arithmetic. [S.I.: s.n.], 2003. Citado 3 vezes nas páginas 13,

GAY, O.; COEURJOLLY, D.; HURSTAND, N. Libaffa, C++ Affine Arithmetic Library. 2006. <http://www.nongnu.org/libaffa/>. Citado 3 vezes nas páginas 19, 35 e 74.

GOMES, A.; VOICULESCU, I.; JORGE, J.; WYVILL, B.; GALBRAITH, C. I mplicit Curves and Surfaces: Mathematics, Data Structures and Algorithms: Mathematics, Data Structures and Algor ithms. [S.I.]: Springer, 2009. Citado na página 71.

GUÉZIEC, A.; HUMMEL, R. Exploiting triangulated surface extraction using tetrahedral decomposition. Visualization and Computer Graphics, IEEE Transactions on, IEEE, v. 1, n. 4, p. 328-342, 1995. Citado na página 28.

IMS. aaflib - An Affine Arithmetic C++ Library, Institute of Microelectronic Systems- url: http://aaflib.sour ceforge.net/. 2010. Disponível em: <http://aaflib.sourceforge.net/>. Citado 2 vezes nas páginas 19 e 75 . 
JR., A. de C.; FIGUEIREDO, L. H. de; GATTASS, M. Interval methods for ray casting implicit surfaces with affine arithmetic. In: Proceedings of SI BGRAPI' 99. [S.I.]: IEEE Press, 1999. p. 65-71. Citado na página 29.

KASHIWAGI, M. An al gorithm to reduce the number of dummy variables in affine arithmetic. In: SCAN confer ence, Novosibir sk. [S.I.: s.n.], 2012. Citado na página 75.

KOLLURI, R. Provably good moving least squares. ACM Transactions on Algorithms (TALG), ACM, v. 4, n. 2, p. 18, 2008. Citado na página 71.

LOPES, H.; OLIVEIRA, J. B.; FIGUEIREDO, L. H. de. Robust adaptive polygonal approximation of implicit curves. Computers \& Graphics, v. 26, n. 6, p. 841-852, 2002. ISSN 0097-8493. Disponível em: <http://www.sciencedirect.com/science/article/pii/S0097849302001735>. Citado 4 vezes nas páginas 13, 27, 38 e 40.

. Computers \& Graphics, v. 26, n. 6, p. 841-852, 2002. Citado na página 29.

LORENSEN, W. E.; CLINE, H. E. Marching cubes: A high resolution 3d surface construction al gorithm. SI GGRAPH Comput. Graph., ACM, New York, NY, USA, v. 21, n. 4, p. 163-169, ago. 1987. ISSN 0097-8930. Disponível em: <http://doi.acm.org/10.1145/37402.37422>. Citado 2 vezes nas páginas 28 e 61 .

MARTIN, R.; SHOU, H.; VOICULESCU, I.; BOWYER, A.; WANG, G. Comparison of interval methods for plotting al gebraic curves. Computer Aided Geometric Design, Elsevier Science Publishers B. V., v. 19, n. 7, p. 553-587, 2002. ISSN 0167-8396. Citado na página 29.

MITCHELL, D. P. Three applications of interval analysis in computer graphics. In: Frontiers in Render ing cour se notes. [S.I.]: SIGGRAPH' 91, 1991. p. 14-1-14-13. Citado na página 29.

MOCHIZUKI, K. Robust and adaptive polygonization of implicit curves and surfaces. Dissertação (Mestrado) - University of Aizu, Aizu-Wakamatsu, Japan, 2004. Citado na página 34.

NASCIMENTO, F. de C. 2015. Disponível em: <http://filipecn.github.io/WebGL-Tools/ 2DCurves.html>. Acesso em: 02/12/2015. Citado 2 vezes nas páginas 30 e 70.

NASCIMENTO, F. de C.; PAIVA, A.; FIGUEIREDO, L. H. D.; STOLFI, J. Approximating implicit curves on plane and surface triangulations with affine arithmetic. Computers \& Graphics, Elsevier, v. 40, p. 36-48, 2014. Citado na página 30.

OHTAKE, Y.; BELYAEV, A.; ALEXA, M.; TURK, G.; SEIDEL, H.-P. Multi-level partition of unity implicits. In: ACM. ACM SIGGRAPH 2005 Cour ses. [S.I.], 2005. p. 173. Citado na página 71.

PAIVA, A.; LOPES, H.; LEWINER, T.; FIGUEIREDO, L. H. de. Robust adaptive meshes for implicit surfaces. In: Sibgrapi 2006 (XIX Brazilian Symposium on Computer Graphics and I mage Processing). Manaus, AM: IEEE, 2006. p. 205-212. Citado 5 vezes nas páginas 13, 25, 28,29 e 77.

PAIVA, A.; NASCIMENTO, F. d. C.; FIGUEIREDO, L. H. d.; STOLFI, J. Approximating implicit curves on triangulations with affine arithmetic. In: FREITAS, C. M. D. S.; SARKAR, S.; SCOPIGNO, R.; SILVA, L. (Ed.). Proceedings... Los Alamitos: IEEE Computer Society Conference Publishing Services, 2012. Disponível em: <http://urlib.net/sid.inpe.br/sibgrapi/ 
2012/07.04.00.56>. Acesso em: 2012, Nov. 07. Citado 6 vezes nas páginas 13, 30, 38, 42, 43 e 44.

PERSIANO, R. C. M.; COMBA, J. L. D.; BARBALHO, V. An adaptive triangulation refinement scheme and construction. In: Proceedings of SIBGRAPI'93. [S.I.: s.n.], 1993. p. 259-266. Citado na página 29.

SEMECHKO, A. Source code of Decimate Poly: library LosTopos and sample applications - url: http://www.mathworks.com/matlabcentral/fileexchange/34639-decimatepolygon. 2012. Disponível em: <http://www.mathworks.com/matlabcentral/fileexchange/ 34639-decimate-polygon>. Citado 2 vezes nas páginas 15 e 72.

SNYDER, J. M. Generative Modeling for Computer Graphics and CAD. [S.I.]: Academic Press, 1992. xxii+311 p. Citado na página 29.

. Interval analysis for computer graphics. Computer Graphics, v. 26, n. 2, p. 121-130, 1992. (SIGGRAPH' 92 Proceedings). Citado na página 29.

SUFFERN, K. G. Quadtre al gorithms for contouring functions of two variables. Comput. J., Oxford University Press, Oxford, UK, v. 33, n. 5, p. 402-407, out. 1990. ISSN 0010-4620. Disponível em: <http://dx.doi.org/10.1093/comjnl/33.5.402>. Citado na página 27.

SUFFERN, K. G.; FACKERELL, E. D. Interval methods in computer graphics. Computers \& Graphics, v. 15, n. 3, p. 331-340, 1991. Citado na página 29.

TAUBIN, G. Rasterizing algebraic curves and surfaces. IEEE Computer Graphics and Applications, v. 14, n. 2, p. 14-23, 1994. ISSN 0272-1716. Citado 2 vezes nas páginas 13 e 44 .

. IEEE Computer Graphics and Applications, IEEE Computer Society, Los Alamitos, CA, USA, v. 14, p. 14-23, 1994. ISSN 0272-1716. Citado na página 56.

VELHO, L. A dynamic adaptive mesh library based on stellar operators. Journal of Graphics Tools, v. 9, n. 2, p. 1-29, 2004. Citado na página 53.

VELHO, L.; ZORIN, D. 4-8 subdivision. Computer Aided Geometric Design, v. 18, n. 5, p. 397-427, 2001. Citado 3 vezes nas páginas 14, 47 e 53. 